\title{
Switched on
}

How do we get the best out of automation and $\mathrm{AI}$ in health care?

Tom Hardie, Tim Horton, Matt Willis, Will Warburton

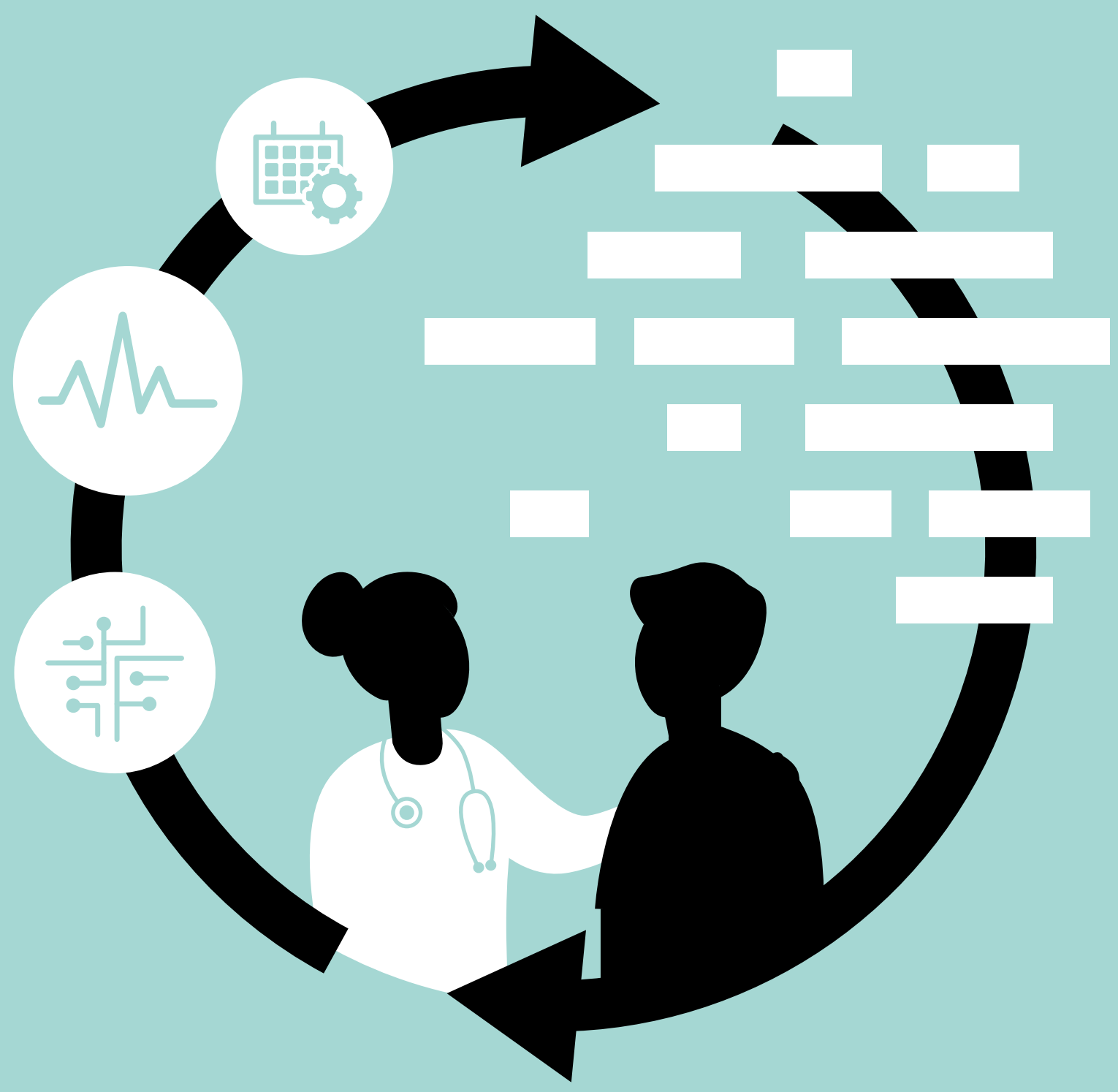

The

Health

Foundation 
The authors would like to thank a number of people who have provided helpful comments and insights during the production of this report. These include Amanda Begley, Ben Bray, Alan Davies, Jennifer Dixon, Mary Dixon Woods, Ruth Glassborow, Trish Greenhalgh, Nik Haliasos, Hugh Harvey, Kassandra Karpathakis, Josh Keith, Xiaoxuan Liu, Michael MacDonnell, Erik Mayer, Breid O'Brien, Sarah Jane Reed, Paul Sullivan, Richard Turnbull and Wenjuan Wang.

The views expressed in this report are those of the authors alone.

When referencing this publication please use the following URL: https://doi.org/10.37829/HF-2021-I03 


\section{Contents}

$\begin{array}{lr}\text { Key points } & 2\end{array}$

$\begin{array}{ll}\text { Introduction } & 4\end{array}$

1. A brief introduction to automation and AI $\quad 8$

1.1. What are automation and AI? $\quad 8$

1.2. Policy approaches to support automation and AI in health care $\quad 12$

1.3. Public, patient and professional attitudes to automation and AI $\quad 15$

2. The potential for automation and AI in health care $\quad 20$

2.1. Types of task amenable to automation 20

2.2. Application to administrative tasks in health care 24

2.3. Application in clinical services $\quad 26$

3. Challenges for applying automation and AI in health care 33

$\begin{array}{ll}\text { 3.1. The human dimension } & 34\end{array}$

3.2. The complexity of work in health care $\quad 37$

3.3. Challenges for implementing automation and $\mathrm{AI}$ in health care $\quad 43$

4. Implications for automation and AI in health care $\quad 51$

4.1. How automation will affect work in health care $\quad 51$

4.2. Perceptions of the benefits and risks of automation and AI in health care $\quad 56$

4.3. Considerations for policymakers, organisation and system leaders, and $\begin{array}{ll}\text { practitioners } & 60\end{array}$

$\begin{array}{ll}\text { 4.4. Conclusion } & 67\end{array}$

$\begin{array}{lc}\text { References } & 68\end{array}$ 


\section{Key points}

- As the NHS emerges from the latest wave of the COVID-19 pandemic, there are hopes that technologies such as automation and artificial intelligence (AI) will be able to help it recover, as well as meet the very significant future demand challenges it was already facing (and which have since grown worse). Drawing on learning from the Health Foundation's research and programmes, along with YouGov surveys of over 4,000 UK adults and 1,000 NHS staff, this report explores the opportunities for automation and $\mathrm{AI}$ in health care and the challenges of deploying them in practice. We find that while these technologies hold huge potential for improving care and supporting the NHS to increase its productivity, in developing and deploying them we must be careful not to squeeze out the human dimension of health care, and must support the health and care workforce to adapt to and shape technological change.

- The nature of health care constrains the use of automation and AI technologies in important ways. Health care is a service that is fundamentally co-produced between patients and clinicians, making the human, relational dimension critically important to the quality of care. The prospect of health care becoming more impersonal with less human contact was ranked the biggest risk of automation in both our public and NHS staff surveys. Furthermore, many health care tasks require skills and traits that computers cannot yet replicate, while the complexity of many tasks and work environments in health care also poses challenges for automation. Much of what is known about the use of automation is taken from product manufacturing, meaning caution is required in assessing how well ideas and strategies from the wider literature might translate into health care.

- Given the nature of work in health care is different to many other industries, the impact of these technologies on work will also tend to be different. In many cases, automation and AI technologies will be deployed to support rather than replace workers, potentially improving the quality of work rather than threatening it. Particular opportunities exist for the automation of administrative tasks, freeing up NHS staff to focus on activities where humans add most value - which is especially important at a time when the NHS is struggling with significant demand pressures and longstanding workforce shortages. In other cases, automation and AI can significantly enhance human abilities, such as with information analysis to support decision making, with the dividends accruing through combining human and machine input.

- Government and NHS leaders have an important role to play in working with and supporting health care workers to respond to the rise of automation and AI, especially those parts of the workforce that may be more heavily impacted. The NHS staff we surveyed were on balance slightly optimistic about the future impact of 
automation, with more thinking the main impact would be to improve the quality of work rather than to threaten jobs and professional status. Nevertheless, there were occupational differences in these views, highlighting that these technologies may have an uneven impact across the workforce.

- The benefits of a new technology clearly don't come from how it performs in isolation, but from fitting it successfully into a live health care setting and redesigning roles and ways of working to derive the benefits of the new functionalities it offers. And the journey from having a viable technology product to successful use in practice is often significant. Teams and organisations will need to consider the 'human infrastructure' and processes that need to accompany the technology, and policymakers, organisational leaders and system leaders will need to fund 'the change' not just 'the tech'.

- Government, working with health care professions and industry, needs to engage proactively with the automation agenda to shape outcomes for the benefit of patients, health care workers and society as a whole. In particular, government and NHS leaders have an important role to play in identifying and articulating NHS needs and priorities, working proactively with researchers and industry to ensure that technologies are developed to meet important health care problems, and supporting the development and adoption of technologies in practice.

- While new, cutting-edge medical applications of automation and AI often steal the headlines, there are also important quality and efficiency gains to be made through applying these technologies to more routine, everyday tasks such as dealing with letters or appointment scheduling. There is also scope to get more out of existing applications of these technologies. So it is important for the NHS to have strategies in place for doing this, as well as supporting the development of new technologies.

- $\quad$ Our surveys found public and NHS staff opinion divided on whether automation and $\mathrm{AI}$ in health care are a good thing or a bad thing. Majorities said the benefits and risks were finely balanced, and some groups tended to be less positive than others. So government and NHS leaders must engage with the public and NHS workforce to raise awareness and build confidence about technology-enabled care as well as to better understand views about how these technologies should and should not be applied in health care, how we can ensure they serve the needs of all groups, and how important risks should be mitigated. Notably, our surveys also found that those who had already heard about these technologies tended to be more positive about them, so helping to familiarise people with this topic could play an important role in shaping attitudes. 


\section{Introduction}

This report presents the findings of Health Foundation research on the opportunities and challenges for automation and artificial intelligence (AI) in health care, alongside some of the findings of a recent research study by the University of Oxford (henceforth 'the Oxford study'), supported by the Health Foundation, into the potential of automation in primary care in England (described further in Box 2). We explore the increasing number of areas in which automation, $\mathrm{AI}$ and robotic technologies are being applied to both clinical and administrative tasks, the challenges for making automation work on the front line, what automation might mean for the future of work in health care, and how the NHS can get this agenda right for the long term. As well as the Oxford study, the report draws on a wide range of other academic studies in this field, plus learning from across the Health Foundation's programmes, fellowships, research and evaluations. This research is also supplemented by surveys of the UK public and NHS staff, to explore views about automation and $\mathrm{AI}$ in health care.

By sharing learning from our programmes on how to make change happen, our aim is to increase understanding among policymakers, organisation and system leaders and frontline staff of what it takes to turn promising ideas into improvements in health and care. That requires bridging the gap between policy and practice. It also requires exploring the human side of health care as well as the technical, to understand what its social and relational dimensions mean for how we should go about improving services.

Nowhere are these concerns more relevant than with health technology and automation, where too often the temptation is to focus on the technology itself rather than on how people use it or experience it. And where too often the temptation is to see the algorithm, the software or the new piece of kit as the answer, rather than as an enabler of change - one that will only help if responding to an accurate diagnosis of what is needed. It is these kinds of issues and concerns that we seek to explore in this report. 


\section{Box 1: Defining automation}

Automation, at its simplest, is the use of technology to undertake tasks with minimal human input. In this report, we use the term broadly to include:

- $\quad$ the full automation of tasks and also the partial automation of tasks (where only certain components of a task are automated)

- $\quad$ technologies that operate autonomously or semi-autonomously, and also technologies that automate tasks without operating autonomously

- $\quad$ the use of technologies to support humans in performing tasks (for example, the automation of information analysis to assist human decision making), as well as the use of technologies to replace humans in performing tasks (for example, the automation of all stages of a decision process)

- $\quad$ applications of technologies such as Al and robotics that are creating new opportunities for automation.

\section{The current context}

Recent advances in computing and data analytics, coupled with the increasing availability of large datasets, are pushing the boundaries of what is possible with automation, giving rise to a host of new opportunities, from driverless vehicles to robotic carers. Many believe automation will transform the labour market - not just in sectors like manufacturing, transport and financial services, but also in health care - leading to significant changes in the nature of work and the skills needed to succeed in the future job market. In health care, these technologies also hold great potential to improve the quality of care for patients and the quality of work for staff, something that has been recognised by policymakers across the UK - in England, for example, through the NHS Long Term Plan, the Department of Health and Social Care's Technology Vision, the creation of NHSX and the investment of $£ 250 \mathrm{~m}$ to create the NHS AI Lab.

The COVID-19 pandemic has also given fresh impetus to the use of technologies in health care, including technologies that could be classed as automation such as devices for monitoring health. And where they have been successful, there is hope in many quarters that the NHS will be able to build on this progress and embed these technologies as part of 'business as usual'. There is also hope that automation, AI and robotic technologies will be one important part of the answer to coping with the unprecedented demand pressures the NHS is facing as it moves beyond the emergency phase of the pandemic, including a huge backlog of elective care - pressures that will necessitate increased productivity as well as expanded capacity. In this sense, COVID-19 has only heightened the need for the NHS to have effective strategies for these technologies and a detailed understanding of how to support their design, implementation and use.

However, while there is rightly much excitement about the potential of automation, AI and robotics, what we also see from the Health Foundation's programmes is that deciding where these technologies should (and should not) be applied, and understanding how they can be implemented and used successfully, are challenging issues that will require careful consideration by policymakers, organisation and system leaders, and those leading change 
on the front line. And while it is the promise of new technologies that receives much of the policy and media focus, we believe the challenges and constraints require just as much attention.

It is precisely an awareness of these challenges and constraints that will be needed in developing effective automation strategies for the future. As the Health Foundation's report Shaping Health Futures highlights, policymakers and system leaders need a realistic understanding of the big trends on the horizon, like automation and AI, and need to factor them into strategic decision making. ${ }^{\top}$ This is also important for health and care professions, and the health and care workforce as a whole, which some have argued will be transformed by the current wave of technological change. It also has significance for those in industry, who will need to work closely with NHS staff and patients in developing new technologies. As automation and AI technologies continue to develop and their use in health care becomes more widespread, it is crucial we shape their impact for the benefit of staff, patients and society as a whole.

\section{Content overview}

Chapter 1 provides background on automation in health care. It briefly explores the concept of automation, its relationship to AI and robotics, and the impact it could have on the future of work. It also highlights some recent policy responses to automation and AI in the UK, and looks at public and professional attitudes to automation.

Chapter 2 considers the types of task most amenable to automation. It then explores some of the different ways in which automation and AI are being applied, or could be applied, in health care, to both clinical and administrative tasks.

Chapter 3 looks at the main constraints and challenges that will need to be understood and addressed in order to make the most of automation and AI in health care. These include the challenges of replicating human skills, the indispensability of human agency in certain aspects of health care and the complexity of many kinds of health care tasks. This chapter also explores some challenges of implementing and using automation and AI technologies effectively in practice.

Chapter 4 highlights the implications of these constraints and challenges for policymakers, organisation and system leaders, and those leading change on the front line. It reflects on how automation might affect work in health care, explores public and NHS staff views on the benefits and risks of automation in health care, and concludes with recommendations for policymakers, practitioners, organisation and system leaders (including leaders in providers, health boards, integrated care systems, and regional and national bodies) and industry. 


\section{Box 2: The Oxford automation study - The Future of Healthcare: Computerisation, Automation and General Practice Services}

The high volume of administrative work in health care is well documented, and a particular challenge in general practice. This study sought to assess the potential of automation technologies currently available on the market to conduct administrative tasks in primary care. Funded by the Health Foundation, it was led by the Oxford Internet Institute, the Oxford Department of Engineering Science and the Oxford Martin School during 2017-19.

Through over 350 hours of ethnographic observation at six primary care centres in England, the researchers identified 16 unique occupations performing over 130 different tasks. Using ratings of task automatability from a survey of automation experts and combining this with data from the O*NET database (a repository of US occupational definitions that describes the skills, knowledge and abilities different kinds of task require), the team then applied a machine learning model to assess the automatability of each task - ranging from 'not automatable today' to 'completely automatable today'. The results were then analysed to produce insights about the nature of work in primary care, and about where automation is most likely and where it could be most useful.

The findings of the research, published in BMJ Open ${ }^{2}$ and by the University of Oxford, ${ }^{3}$ show that:

- $\quad 44 \%$ of all administrative work performed in general practice can be either mostly or completely automated, such as running payroll, sorting post, transcription work and printing letters

- $\quad$ automating administrative tasks has the potential to free up staff to spend more time with patients, improving the quality of care and the quality of work

- $\quad$ while every occupation in general practice, including clinical roles, involves a significant amount of time performing administrative work, no single full-time occupation could be entirely automated. 


\section{A brief introduction to automation and $\mathrm{AI}$}

\subsection{What are automation and AI?}

Automation is the use of technology to perform rule-based tasks with minimal human input. Encyclopaedia Britannica describes it as 'performing a process by means of programmed commands combined with automatic feedback control to ensure proper execution of the instructions', ${ }^{4}$ while the International Society of Automation defines it specifically as 'the creation and application of technology to monitor and control the production and delivery of products and services'. ${ }^{5}$ While automation typically involves the execution of tasks previously done by humans, this is not necessarily a defining feature, with increasingly sophisticated technology enabling the automatic performance of tasks humans could not do, such as rapid analysis of large datasets.

Automation is a major theme in discourse about changing labour markets and the future of work. For many tasks, automated systems have the potential to improve on human performance, by reducing errors and improving productivity, ${ }^{6}$ and analysis conducted in 2019 by the Office for National Statistics (ONS) found that around 1.5 million jobs in England were at high risk of having some of their duties and tasks automated in future. This report will look at both the potential automation of tasks usually undertaken by health care workers, as well as the use of automation and AI to assist health care workers in performing tasks.

Advances in robotics and $\mathrm{AI}$ are extending the reach and capability of automation, both in the realm of physical tasks and increasingly the realm of cognitive tasks; ${ }^{8}$ as the AI Index puts it, 'robotics puts computing into motion and gives machines autonomy. AI adds intelligence, giving machines the ability to reason'. ${ }^{9}$ A 2016 House of Commons Science and Technology Committee report describes AI as statistical tools and algorithms that 'enable computers to simulate elements of human behaviour such as learning, reasoning and classification'. ${ }^{10}$ Recent years have seen advances in AI due to the increasing availability and quality of data, and improvements in technology and processing power. These include developments in machine learning, where algorithms are trained to make predictions using large datasets, and especially in 'deep learning', a type of machine learning using artificial neural networks. Among other things, these systems can learn to recognise and classify patterns in digital representations of sounds, images and text.

Given the significant overlap between these fields, this report will often refer to AI and robotics alongside automation, including situations where these technologies are used to automate some parts of a task (such as information analysis for decision making) but not others (such as decision selection). 


\subsubsection{Modes of automation: replacing versus assisting}

It's useful to distinguish between some different ways in which automation can relate to human task performance in health care.

Replacing: As highlighted above, in some cases automated systems are intended to perform tasks previously carried out by humans, replacing human input.

- This can happen where an automated system is able to perform tasks to a similar level to human workers (or at least to a 'good enough' standard), and so using an automated system to perform these tasks can free up health care staff to focus on other work. In Figure 1, this mode of automation is described as substituting for human input.

- On other occasions, the performance of an automated system might significantly exceed human capabilities, so by replacing human input it provides an opportunity to improve task performance (for example, where an automated system can execute tasks at much greater speed), and this may provide a rationale for automation independently of the benefits of releasing staff time. In Figure 1, this mode of automation is described as superseding human input.

Assisting: More commonly, automated systems can be used in health care to assist workers, rather than replace them.

- This can happen by using technology to automate just one component of a task or to provide additional capacity or functionality in a way that allows a worker to improve task performance - not because they can't do what the technology is doing, but simply because having the technology effectively increases their capacity and allows them to focus on other aspects of task performance (for example, using dictation software to take notes). In Figure 1, this mode of automation is described as supporting human input.

- On other occasions, technologies designed to assist human task performance may also extend human capabilities, even though they are not intended to operate autonomously. For example, surgical robots may allow a greater degree of precision than humans alone, while AI-driven clinical decision support tools may exceed human information-processing capabilities. ${ }^{11}$ In Figure 1, this mode of automation is described as strengthening human input. Indeed, research suggests that while AI systems can match or even exceed humans in some 'high end' tasks (those requiring a high level of cognitive ability), when these systems are combined with human experience, intuition and knowledge, the impact of AI and robotics can be increased..$^{12}$

Figure 1 illustrates these different modes of automation. Note that the same technology could be used in different ways; the mode of automation will depend on how it is deployed on any particular occasion. It is worth noting that when technologies are deployed for supporting or substituting (the bottom row), the primary motivation is often to free up staff time, whereas when technologies are deployed for strengthening or superseding (the top row), the primary motivation is often to improve task performance. 


\section{Figure 1: Modes of automation}

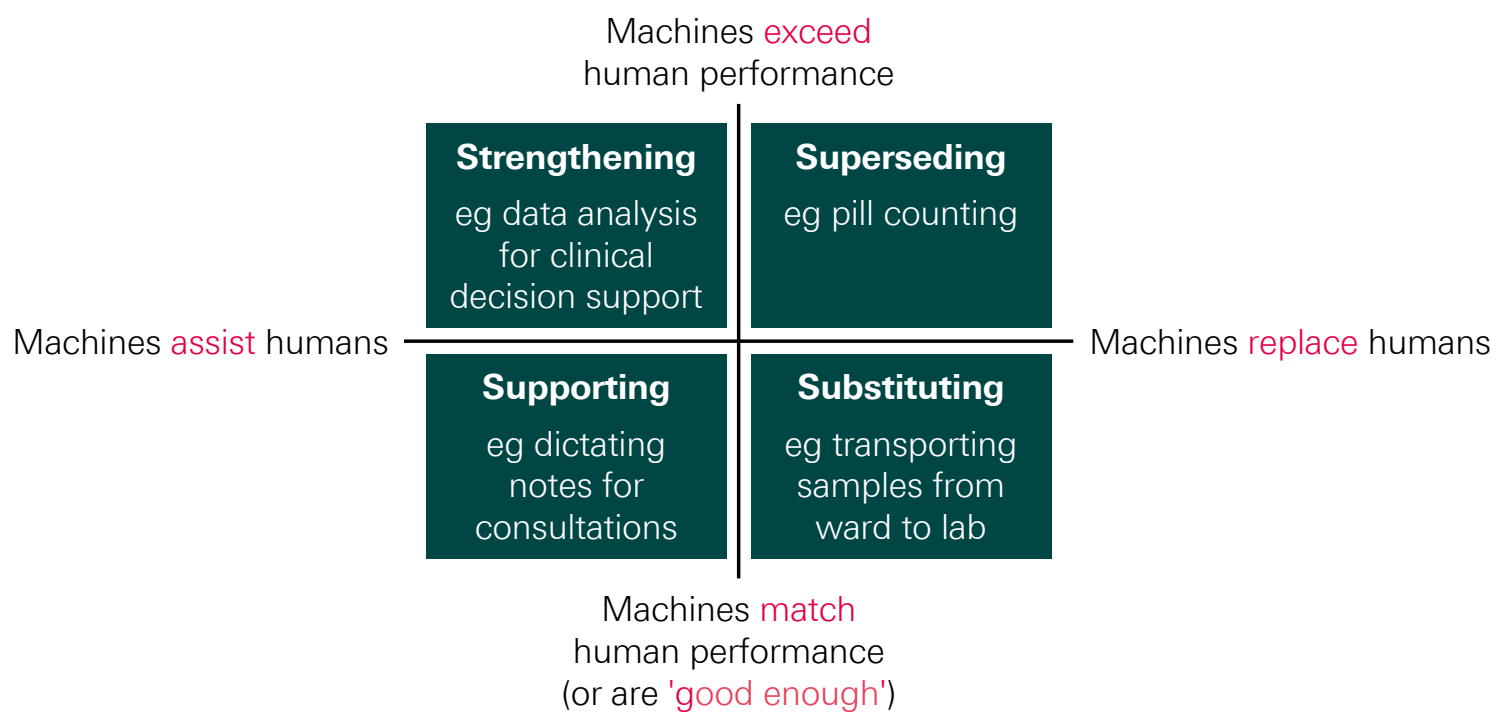

The use of automation to assist (and enhance) rather than replace is one way in which the impact of automation in health care can differ from other sectors. In industries such as agriculture and manufacturing, new technologies have often replaced labour (for example, the combine harvester or industrial robots for painting), a trend that continues today. ${ }^{13} \mathrm{~A}$ 2019 report by Oxford Economics estimates that around 1.7 million manufacturing jobs have been replaced by robots since 2000, including 400,000 in Europe. ${ }^{14}$ In health care, by contrast, new technologies have for the most part tended to supplement rather than replace labour, providing the means for health care workers to improve care or do their job more efficiently. 'This is partly because, as we explore in Chapter 3, many tasks in health care are difficult to automate. Instead, it is the potential of automation to assist NHS staff to manage high workloads that has attracted interest as demand for staff continues to increase.

\section{Box 3: A brief history of automation in health care}

Automation has its roots in the Industrial Revolution when the introduction of the steam engine enabled the generation of vast amounts of energy, allowing the mechanisation of tasks previously undertaken by craftsmen or by individual artisans..$^{15}$ Since then, innovations such as the spinning jenny, assembly line and personal computer have seen the automation of many types of work. ${ }^{16}$ Brynjolfsson and McAfee argue that automation can be divided into two periods: the first, in which machines were introduced to conduct physical tasks (such as assembling a product), and the second enabled by the development of computing, in which machines also conduct cognitive tasks (such as record-keeping).

Automation has a long history in health care. Many examples are now so well established that we might not think of them as automation. For instance, in the early 1900s the first electrocardiogram was developed to monitor heart rate, something previously done manually. From the 1940s onwards, the kidney dialysis machine evolved to become automatically functioning. In the late 1970s, the desktop computer began to enable the automation of administrative tasks, for example clerical tasks such as financial calculations. Computers also began to be integrated into clinical pathways, initially to enter orders and report results and then to hold databases, images and patient records, as well as for the continuous monitoring

One fact that is often cited is the ongoing growth of the health care workforce. See for example The health care workforce in England: Make or break? The Health Foundation, The King's Fund and the Nuffield Trust; 2018. 
of patients. Pharmacists have also seen the automation of several aspects of their work; for example, the first digital pill counter was deployed in the late 1960s.

Robots, too, have been used in medicine and health and social care for over 30 years, from robot-assisted surgery and rehabilitation, to personal robots serving as companions or motivational coaches, or assisting people with domestic activities..$^{19}$ In surgery, robots are being used to perform movements once made by humans, though typically requiring teleoperation or supervision by a health care professional. In addition, the ongoing miniaturisation of electronics is expanding the types of procedures that surgical robots can support, ${ }^{2}$ although it is important to note that the evidence base for the clinical effectiveness of robots in surgery is still developing."

The potential of new data analytics and Al to support clinical decision making, such as image analysis and risk prediction tools, understandably attracts considerable excitement. ${ }^{21}$ At the same time, there remains vast potential for the automation of less complex tasks, including work that has administrative components such as processing prescriptions, referrals and bookings, ${ }^{22}$ through technologies that are currently available or are already in the NHS but not being used to their full potential. For example, the 2016 Carter Review found that trusts were not getting 'full meaningful use' from technologies they had invested in such as e-prescribing software. ${ }^{23}$

\subsubsection{Automation and the future labour market}

While automation is not a new concept (see Box 3 for a brief history of automation in health care), the evolving capabilities of $\mathrm{AI}$ and robotics to undertake increasingly complex cognitive tasks, as well as an ever-growing range of manual tasks, have become a key consideration in analyses of how jobs and occupations could change in the coming decades.

Studies modelling the impact of automation on the future labour market have produced a wide range of estimates, but suggest the impact could be both far-reaching and unevenly distributed. For example, Frey and Osbourne estimate that $47 \%$ of occupations could be automated over the next 20 years, with roles in office and administrative support, production, transportation and service occupations highly susceptible. ${ }^{24}$ On the other hand, the Organisation for Economic Co-operation and Development (OECD) estimates that only $9 \%$ of occupations are at high risk of automation because many still contain a substantial share of tasks that are hard to automate. ${ }^{25}$ The ONS, investigating work in England, suggests that the impact of automation will vary across the labour market, with lower-skilled roles more susceptible to automation and women, young people and parttime workers most likely to work in roles that are at high risk of being automated.

Predicting the precise effects of automation on employment is difficult, however. The OECD study argues that even if a job is at high risk of automation, it will not necessarily result in job losses because workers can adapt by switching tasks and expanding their roles, and because technological change will also create new jobs. Similarly, a 2019 European

\footnotetext{
Some are concerned by the use of robotic surgery for common surgical procedures with limited evidence and unclear clinical benefit. A recent UK study found no evidence of a difference in 90-day postoperative hospital days between robotic and laparoscopic ventral hernia repair. Sheetz and colleagues argue that the use of robotic surgery has outpaced the generation of evidence to demonstrate its effectiveness. See Olavarria O, Bernardi K, Shah S, Wilson T, Wei S, Pedroza C, Avritscher E, Loor M, Ko T, Kao L, Liang M. Robotic versus laparoscopic ventral hernia repair: multi-center, blinded randomized controlled trial. BMJ. 2020; 370; Sheetz K, Claflin J, Dimick J. Trends in the Adoption of Robotic Surgery for Common Surgical Procedures. JAMA Network Open. 2020; 3(1): e1918911.
} 
Commission report argues it is unclear whether the net effect of automation will be job replacement or augmentation, given that $\mathrm{AI}$ and robotics will create new jobs as well as eliminate others. ${ }^{26}$

Modelling also suggests the impact of automation will vary by sector. In line with the observations above that automation in health care has tended to supplement rather than replace labour, studies estimate the future impact of automation on jobs in health and care to be lower than in other sectors. For example, PricewaterhouseCoopers (PwC) estimates the proportion of jobs at high risk of automation in health care could rise from around 3\% in the early 2020 s to $20 \%$ by the mid-2030s, with financial services seeing the biggest effects over the short term and the transport sector over the longer term. ${ }^{27}$ The PwC model suggests the impact on jobs in health and care, as well as in education, will be lower than in other sectors.

In light of these trends, policymakers are grappling with how to respond to the labour market impacts of automation. The 2016 Taylor Review, for example, explored how employment practices need to change in order to keep pace with the modern economy. Specifically in relation to automation, the Review highlighted the importance of supporting people to gain appropriate skills for the future workplace - in particular, skills that are less likely to be affected by automation, such as relationship building, empathy and negotiation, which over time could become more valuable. ${ }^{28}$ It also highlighted the importance of lifelong learning to enable people to adapt to, and remain relevant in, a changing labour market.

\subsection{Policy approaches to support automation and $\mathrm{AI}$ in health care}

In health and care, policymakers are also focusing on helping providers and patients exploit the potential of new technologies. In England, the Department of Health and Social Care (DHSC) and NHS England and NHS Improvement have focused on several broad challenges relating to digital technology and information technology (IT). The aim in particular has been to ensure the NHS has the right basic infrastructure in place, with systems that are interoperable and enable the exchange of data, as well as addressing challenges around leadership and skills. Key initiatives include:

- The 2016 Wachter Review of health IT in secondary care, noting that the quality of IT systems across the NHS remains patchy, interoperability continues to be a challenge and progress towards digitisation of records is slow, made a series of recommendations to achieve digitisation. ${ }^{29}$

- The DHSC's 2018 'vision' for digital, data and technology in health and care ${ }^{30}$ aspires to harness fast-developing technologies including AI and robotics, but also acknowledges the need to 'get the basics right' and ensure the NHS has appropriate digital infrastructure in place. This is essential not just for basic clinical and administrative functions, but also as a platform to enable the use of more sophisticated technologies. 
- In 2018, NHS England and NHS Improvement launched the Local Health and Care Record Exemplars Programme, designed to enable the safe and secure sharing of health and care information across different parts of the NHS and social care. ${ }^{3}$

- $\quad$ The NHS Long Term Plan, published in January 2019, also committed to making better use of digital technology, including providing better digital access to services and ensuring health records and care plans are available to clinicians and patients electronically. It also restated ambitions to make greater use of AI to support clinical decision making and to put in place IT infrastructure that is secure and allows interoperability between systems. ${ }^{32}$

- NHSX, a joint unit between the DHSC and NHS England and NHS Improvement, created in 2019, provides leadership for digital technology in health and social care and will play an integral role in NHS England and NHS Improvement's transformation directorate (see Box 7 on page 30 for further information). ${ }^{33}$ The 2019 Topol Review looked at how to equip the health care workforce to work effectively with new technologies, to inform the development of Health Education England's (HEE's) workforce strategy. ${ }^{34}$ HEE is seeking to address the workforce requirements set out in the Topol Review through the Digital Readiness Programme. ${ }^{38}$

In Scotland, the Scottish government, the Convention of Scottish Local Authorities and NHS Scotland see digital technology as a critical enabler for improving health and care. The 2018 Digital Health and Care Strategy for Scotland seeks to empower citizens to manage their own health, live independently and access services through digital means, and also to put in place the architectural and information governance 'building blocks' necessary for the effective flow of information across the whole care system. ${ }^{36}$ Digital technology is also an important part of the Welsh government's vision for health and care. A Healthier Wales: Our Plan for Health and Social Care seeks to use digital, data and communications technologies to help raise the quality and value of health and social care services. ${ }^{37}$ To help embed the development and use of digital services in health and care in Wales, the Welsh government launched a new special health authority, Digital Health and Care Wales, in April 2021. ${ }^{38}$

The term 'automation' is not especially prominent in UK health care policy discourse, perhaps because it is often taken to mean the full automation of tasks (replacing human labour), whereas many of the technologies in question are seen primarily as tools to support staff to undertake tasks rather than to wholly automate them. Where automation has been discussed, the focus has been mainly on reducing the burden of administrative work for clinical staff, and improving efficiency and productivity, on the assumption that automation can free up time for patient care. ${ }^{34,39}$ Notwithstanding this lack of prominence of automation as a theme, there has been considerable policy interest in digital and datadriven technologies that have the potential to automate tasks, including AI:

- $\quad$ As part of the Industrial Strategy's 'AI Grand Challenge', in 2019 the UK government set an ambition of using data, $\mathrm{AI}$ and innovation to transform the prevention, early diagnosis and treatment of diseases like cancer, diabetes, heart disease and dementia. This included launching five new centres of excellence in digital pathology and imaging with $\mathrm{AI}^{40}$ 
- In 2019, NHS England and NHS Improvement set an ambition for the NHS to become a world leader in AI and machine learning within five years, inviting technology innovators to submit proposals for 'how the NHS can harness innovative solutions that can free up staff time and cut the time patients wait for results'. ${ }^{4}$

- $\quad £ 250 m$ was invested in the creation of a new NHS AI Lab, that sits within NHSX and focuses on areas such as regulation, imaging, disease detection, ethics and supporting the development of AI products. ${ }^{42}$ As part of this, the Artificial Intelligence in Health and Care Award is making $1140 \mathrm{~m}$ available over three years to accelerate the testing and evaluation of AI technologies that support the aims of the NHS Long Term Plan. ${ }^{43}$ The AI Lab has also launched an ethics initiative to ensure that AI products used in the NHS and care settings do not exacerbate health inequalities, in partnership with the Health Foundation, the National Institute for Health and Research, the Ada Lovelace Institute and HEE. ${ }^{4}$

- The Accelerated Access Collaborative, a partnership between government, industry and the NHS, was established in 2018 to identify promising technologies, including AI, that the NHS should prioritise for adoption..$^{45}$

- In 2019, the DHSC and NHS England and NHS Improvement launched a code of conduct (since updated to become the Guide to good practice for digital and datadriven health technologies) to guide the development and use of digital and datadriven technologies, designed to protect patient data and ensure only high-quality technologies are used by the NHS. ${ }^{46}$

- Prior to the announcement of the new National Institute for Health Protection, Public Health England's Strategy 2020 to 2025 had set an ambition to develop 'personalised prevention' of ill health and enhance the data and surveillance capabilities of the public health system using technology such as $\mathrm{AI} .{ }^{47}$

- In 2018, the UK government announced the creation of a new AI health research centre in Scotland. Based in Glasgow, the Industrial Centre for Artificial Intelligence Research in Digital Diagnostics (iCAIRD) is focused on the exploration of how AI could improve patient diagnosis. ${ }^{48}$

- The Welsh government is currently supporting several AI projects, including the use of AI to detect harmful or potentially harmful incidents in real time for people affected by falls, people with dementia and people with cognitive impairments. ${ }^{49}$

- In 2020, the House of Lords Liaison Committee on AI published the report AI in the UK: No Room for Complacency, ${ }^{50}$ which considers the UK government's progress against the recommendations made by the Select Committee on AI in its 2018 report, AI in the UK: ready, willing and able? ${ }^{51}$

- In 2021, the UK AI Council, an independent expert committee that provides advice to the UK government, published a road map to help the UK become one of the best places in the world to live with, work with and develop AI. ${ }^{52}$ 


\subsection{Public, patient and professional attitudes to automation and AI}

Several themes recur in surveys exploring public views of automation and AI in health care. While access, speed and accuracy are often cited as potential benefits, many people clearly value human agency, interaction and judgement and don't want to see them compromised or removed. For example:

- An international survey in 2016 found that, while there is some support for using $\mathrm{AI}$ and robotics to meet health care needs, people in the UK were more sceptical compared to other countries. ${ }^{53}$ For example, UK respondents were least willing to undergo 'surgery performed by a robot'. UK respondents felt that the main advantages of $\mathrm{AI}$ and robotics in health care were quicker and easier access, and faster and more accurate diagnosis. However, the main disadvantages cited were inability to trust automated decision making, the belief that only humans can make the right decisions and the view that health care needs a 'human touch'.

- $\quad$ A 2017 UK poll found that while many would be happy with AI playing a supportive role, there were concerns about the automation of work typically done by doctors and nurses. In particular, the poll showed that while many respondents would welcome the use of AI to help diagnose diseases, most did not think AI should be used for other tasks usually performed by doctors and nurses, such as suggesting treatment. ${ }^{+, 54}$

- Another 2017 UK poll found that people were optimistic about the potential of the technology to improve the accuracy and speed of diagnosis and were also 'happy with the idea of doctors and machines working together to provide a better service'. Their main concern was the prospect of human interaction being lost. For example, respondents cited the importance of human involvement in final diagnosis and treatment planning, which they felt should be reviewed, authorised and communicated by a human doctor..$^{55}$

Turning to the perceptions of health care professionals and managers on the prospects for, and impact of, automation, there is a mixture of optimism and scepticism. For example:

- In a 2018 US survey of radiologists exploring views about job security, respondents said that AI would make their job radically different in the next 10-20 years, but very few felt that it would make their roles obsolete. ${ }^{\ddagger 56}$ Most respondents were planning to learn about $\mathrm{AI}$ in relation to their jobs and a smaller majority were willing to help train an algorithm to do some of the tasks of a radiologist. In the UK, the Royal College of Radiologists has similarly taken a positive view of AI, welcoming the introduction of appropriately regulated technologies to enhance clinical practice, ${ }^{57}$ citing the potential to improve outcomes and efficiency, and release time for direct patient care and research.

Respondents were asked for their views on a range of hypothetical scenarios.

A total of $45 \%$ felt that $\mathrm{Al}$ should be used for helping to diagnose diseases, as opposed to $34 \%$ who did not. On the other hand, $63 \%$ felt that $\mathrm{Al}$ should not be used for taking on tasks usually performed by doctors or nurses, compared with only $17 \%$ who felt it should be.

‡ Survey of 69 trainees and resident diagnostic radiologists at a single radiology residency training programme. 
- A 2018 survey of managers and clinicians working in NHS trusts, clinical commissioning groups and NHS England and NHS Improvement found that while senior managers showed enthusiasm about AI, clinicians were more cautious, emphasising the need for safeguards..$^{58}$

- There appears to be less professional caution around the prospect of automating administrative tasks compared to clinical tasks. For example, a recent UK survey of GPs showed that while the majority were sceptical about the potential for future technology to perform most primary care tasks as well as or better than humans, many were optimistic that in the near future technology would have the capacity to fully replace GPs in undertaking administrative duties related to patient documentation. ${ }^{*} 59$ The Royal College of General Practitioners has highlighted the automation of administrative tasks as one of four key areas where technology could be particularly beneficial. ${ }^{\dagger, 60}$

\section{Box 4: Public and NHS staff attitudes to automation and $\mathrm{Al}$ in health care}

To further investigate attitudes to automation and $\mathrm{Al}$ in health care, we commissioned surveys of the UK public and NHS staff, conducted online by YouGov in October 2020, the results of which are described at various points throughout this report. ${ }^{.}$

To start with, we asked people about their familiarity with the topic: specifically, how much they'd heard, seen or read about automation and Al in health care (respondents were provided with definitions and examples of these technologies). ${ }^{\S}$ Some $29 \%$ of the public said they'd heard, seen or read 'nothing at all' about it. This was also true of $24 \%$ of the NHS staff surveyed - a striking reminder that, while there is real interest in this topic in many policy, academic and clinical communities, it remains far removed from the working lives of many NHS staff. While majorities of both the public and NHS staff surveyed had encountered something on this issue before, only $2 \%$ of the public and $3 \%$ of NHS staff surveyed said they'd heard, seen or read 'a lot', with $17 \%$ of the public and $18 \%$ of NHS staff saying 'a fair amount' and $48 \%$ of the public and $52 \%$ of NHS staff saying 'not very much'. So there is clearly work to be done to engage with patients, staff and society as a whole to inform decisions about the future use of automation and $\mathrm{Al}$ in health care.

Most GPs believed it unlikely that technology will ever be able to fully replace physicians for diagnosing patients $(68 \%)$, referring patients to other specialists $(61 \%)$, formulating personalised treatment plans $(61 \%)$ and delivering empathic care $(94 \%)$. On the other hand, $80 \%$ believed it likely that future technology will be able to fully replace humans in undertaking documentation.

$+\quad$ The other three are enhanced diagnostic decision making; delivery of remote care and self-management tools; and seamless sharing of patient information between care providers.

‡ UK public survey fieldwork done online by YouGov, $26-28$ October 2020; total sample size 4,326 adults (85\% from England, 8\% Scotland, 5\% Wales and 3\% Northern Ireland); figures have been weighted and are representative of all UK adults (aged 18+). NHS staff survey fieldwork done online by YouGov 23 October-1 November 2020; total sample size 1,413 adults (80\% from England, 13\% Scotland, 6\% Wales and 1\% Northern Ireland); sample comprised the main occupational groups within the NHS's clinical workforce (allied health professionals; medical and dental; ambulance; public health; nurses and midwives; nursing or health care assistants).

$\S \quad$ Specifically, respondents were given the following information: 'Automation is when computers and robots are used to do tasks that humans have traditionally done. In health care, examples of automation include using a machine to monitor a patient's heart rate or using a robot to dispense medicines in a pharmacy. Artificial intelligence (Al) is when computers are able to copy aspects of human intelligence like learning and problem solving. In health care, examples of Al include using computers to predict which patients are more at risk of falling ill, or to analyse X-ray images in order to spot illness or injury.' 


\section{Figure 2: Public and NHS staff familiarity with automation and Al}

In general, how much, if anything, have you heard, seen or read about automation and Al in health care (eg in the news, on social media, or from family, friends, colleagues, etc.)?

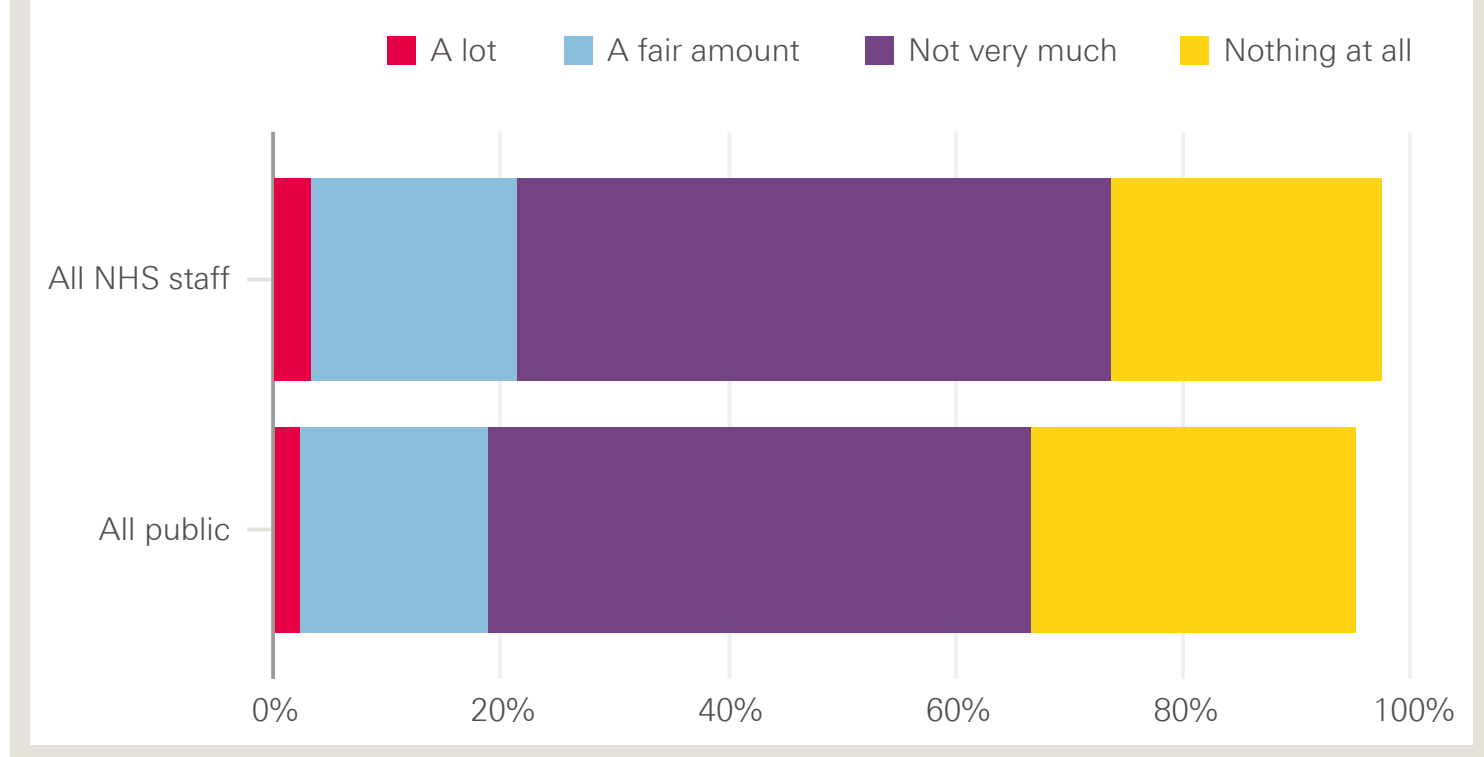

Our surveys also asked how positive or negative people felt about the use of automation and Al in health care - as a crude 'temperature test'. In both the public and NHS staff surveys, more felt positive than negative, but opinion was closely balanced, with the public feeling more positive than negative by $40 \%$ to $37 \%$ and with NHS staff surveyed feeling more positive than negative by $40 \%$ to $36 \%$.

There were some interesting differences underneath these headline figures. In the public survey, some groups were less positive about automation and Al in health care than others, including women, people with a health condition or disability and people with a carer. While men felt more positive than negative about the use of automation and $\mathrm{Al}$ by $48 \%$ to $33 \%$, women felt more negative than positive by $41 \%$ to $33 \%$. Similarly, people with a carer felt more negative than positive by $42 \%$ to $34 \%$, as did those with a health condition or disability by $41 \%$ to $38 \%$. Age is also sometimes highlighted as a factor affecting attitudes to technology, and there were some modest age differences within our results, with younger people (aged 18-34) feeling more positive than negative by $41 \%$ to $31 \%$, while for older people (aged 55 or older) this margin was just 1 percentage point: $41 \%$ to $40 \%$. More research is needed to understand why these differences exist, but they underline the importance of engaging with patients and the public in the development and deployment of automation and Al to co-design solutions, in order to help make sure these technologies work for everyone and that different preferences are taken into account.

Among the NHS staff surveyed, there were some differences by professional group - perhaps reflecting the different perspectives that different staff groups will have on what these technologies might mean for health care. For example, medical and dental staff surveyed felt more positive than negative about the use of automation and $\mathrm{Al}$ in health care by $43 \%$ to $36 \%$, and nurses and midwives by $39 \%$ to $38 \%$, but health care assistants felt more negative than positive, by $41 \%$ to $33 \%$.

However, these differences were dwarfed by the impact of familiarity with the topic. Among the public, those who said they had heard, seen or read 'a lot' or 'a fair amount' about automation and $\mathrm{Al}$ in health care felt much more positive than negative about the use of these technologies, by $70 \%$ to $26 \%$, while those who answered 'not very much' or 'nothing at all' felt more negative than positive, by $41 \%$ to $35 \%$. A similar pattern was evident in the NHS staff survey: those who said they had heard, seen or read 'a lot' or 'a fair amount' felt much more positive than negative about the use of automation and $\mathrm{Al}$ in health care, by $71 \%$ to $21 \%$, while those who answered 'not very much' or 'nothing at all' felt more negative than positive, by $40 \%$ to $32 \%$. This suggests that helping to familiarise people with this topic could play an important role in shaping attitudes to this agenda in future. 
Figure 3: Public and NHS staff attitudes to the use of automation and $\mathrm{Al}$ in health care

Overall, how positive or negative do you feel about the use of automation and $\mathrm{Al}$ in health care?

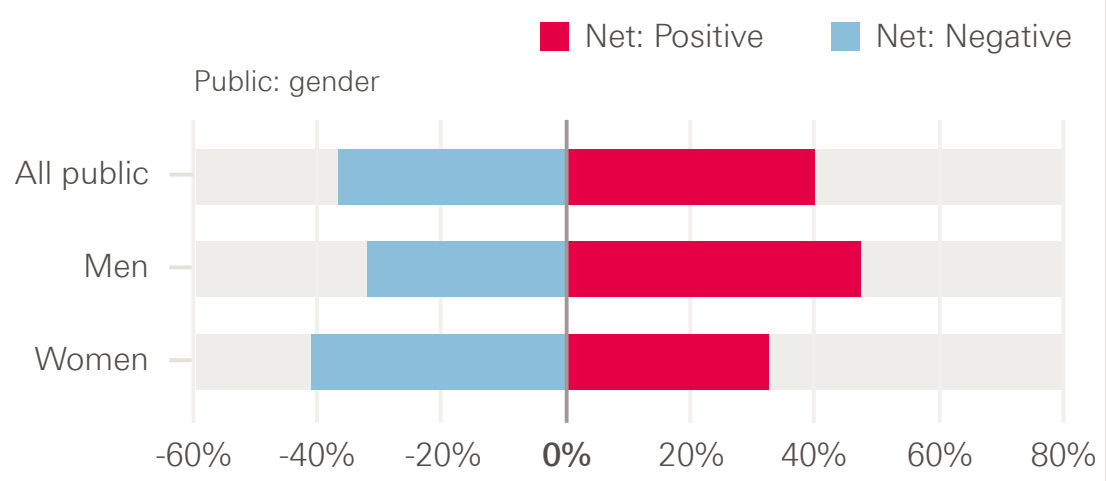

Public: people with a carer and people with a disability or health condition

People with a disability or health condition

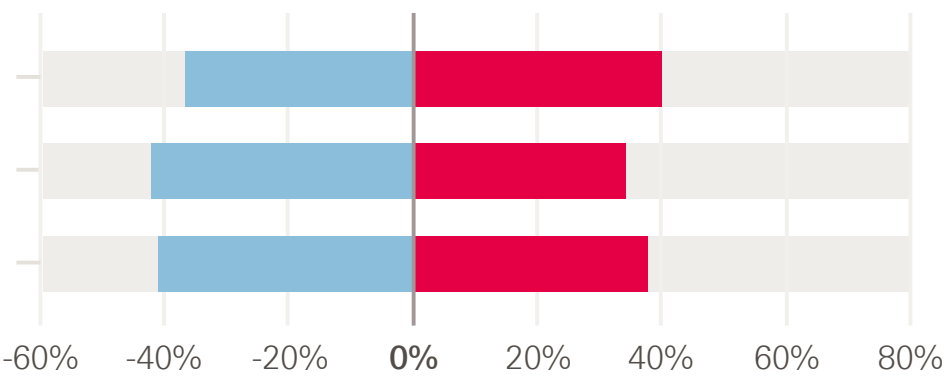

Public: age

All public

Young people (18-34)

Older people (55 and over)

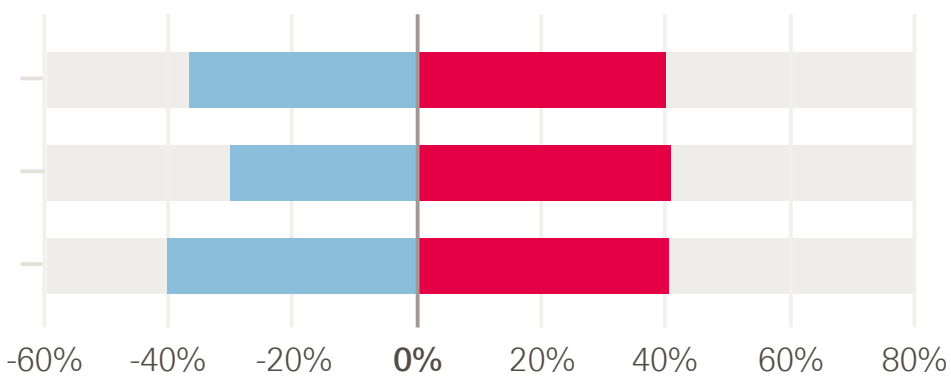

Public familiarity

All public

Public with familiarity of the subject

Public without familiarity of the subject

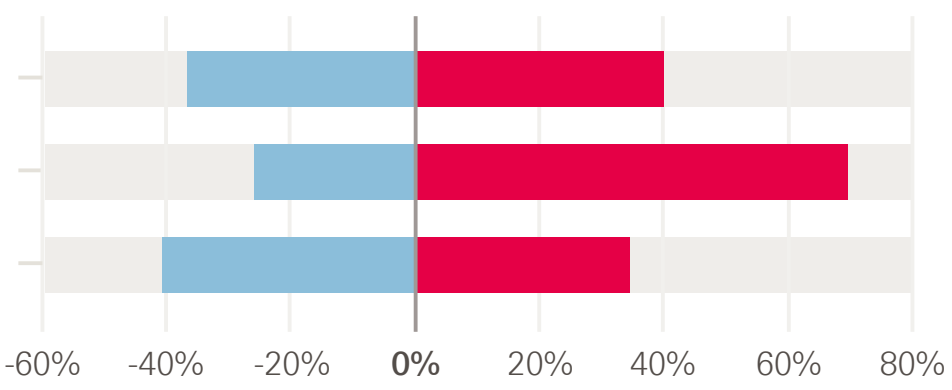




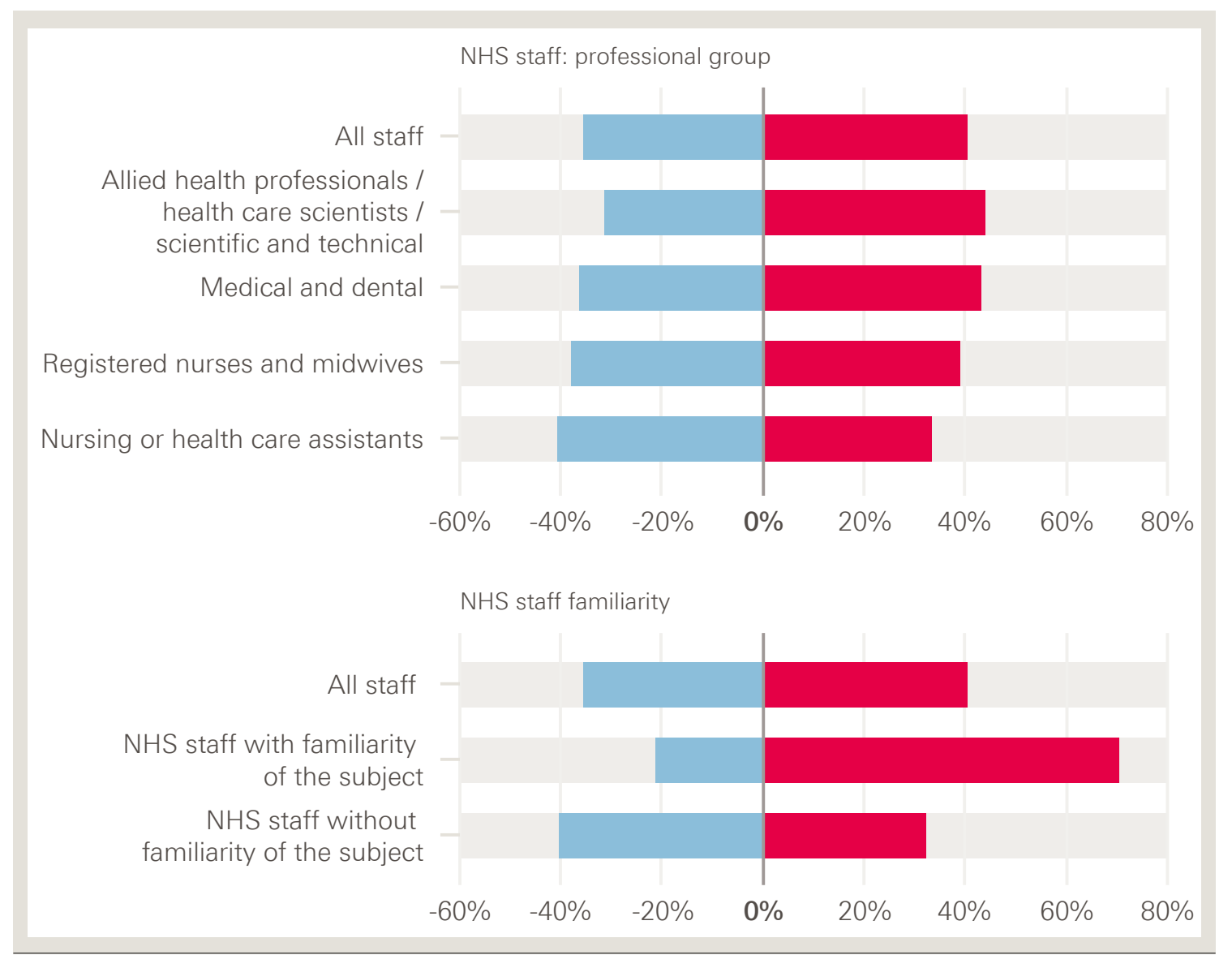

Having explored the current context for automation and AI, in the next chapter we look at some of the opportunities to apply these technologies in health care. 


\section{The potential for automation and AI in health care}

\subsection{Types of task amenable to automation}

There are different ways of analysing and understanding tasks when considering what kinds of work can be automated and what cannot.

One influential approach, by economist David Autor, focuses on the broad nature of tasks and views the degree of routine involved in a task as a key determinant of automatability. ${ }^{6}$ Autor categorised tasks based on two properties: routine versus non-routine, and manual versus cognitive. Routine manual tasks require what Autor calls a 'methodical repetition of an unwavering procedure', such as picking and sorting items and repetitive assembly the kind of repetition that could be explicitly programmed and performed by machines. Non-routine manual tasks, on the other hand, such as caretaker work and truck driving, are considered to have more limited scope for automation in Autor's model. Routine cognitive tasks include record keeping and repetitive customer services like bank clerk work, and these are thought to offer substantial room for automation. Finally, non-routine cognitive tasks, which include medical diagnosis, legal writing and sales, are not seen to be candidates for automation and are viewed as more likely to remain (at least partially) in the domain of human performance.

Autor's analysis has shone a light on labour market trends such as the 'disappearing middle', whereby - contrary to earlier predictions - many manual, non-routine jobs have remained resistant to automation, while other 'white collar' jobs, such as clerical work, have been automated. In these cases, it has been routine work that has been susceptible to automation, whether manual or cognitive, while non-routine work has proved harder to automate.

Autor's analysis has been influential over many years, though technological advancements have led to certain non-routine tasks becoming easier to automate - truck driving, for example. ${ }^{62}$ Due to these advancements, some argue that automation can be extended to any non-routine task that is not subject to any 'engineering bottlenecks', which we discuss in more detail in Chapter $3 .^{63}$

This way of looking at tasks suggests that automation will tend to have most impact when applied to tasks that are frequent or time consuming, important and repetitive (though there can sometimes be benefits to applying automation to infrequent tasks too - for example, when a drug is rarely prescribed - as it is often these types of task where mistakes are most likely to occur). Such repetitive, rule-based tasks frequently lend themselves to a form of automation known as robotic process automation (RPA), which uses software to enable transaction processing, data manipulation and communication across multiple IT systems. ${ }^{64}$ RPA has successfully been deployed in many sectors to process invoices, claims and payments, monitor error messages and respond to routine requests from customers 
and suppliers. ${ }^{3}$ While RPA is not widespread in health care, a number of NHS trusts have successfully used it to manage scheduling and other processes, and NHSX is exploring how RPA can be scaled in the NHS through its Digital Productivity Programme. ${ }^{65}$

A second approach to considering which kinds of task are amenable to automation is to analyse the skills and knowledge they require. The Oxford study used the O*NET database's 'occupation features' to analyse how predictions of a task's automatability related to the different skills and knowledge required. O*NET is a database of hundreds of standardised descriptors of almost 1,000 occupations in the US economy, which includes information on the skills, knowledge, work activities and interests associated with these occupations. The researchers looked at which features were clearly predictive of automatability and also at where an increase in the presence of a particular feature led to an increase in predicted automatability.

Table 1 presents the five largest (positive) percentage differences in $\mathrm{O}^{*} \mathrm{NET}$ occupational features for tasks that were rated automatable, not automatable and partly automatable, when compared to the entire dataset of health care tasks. Health care tasks predicted as 'not-automatable' require $26.0 \%$ higher personnel and human resources knowledge, $17.0 \%$ higher education and training knowledge and $18.7 \%$ higher management and financial resources skills. By contrast, 'automatable' tasks require $24.4 \%$ higher clerical skills.

Table 2 presents the occupational features with the largest positive influence on predicted task automatability, given an increase of the particular feature. Telecommunications and clerical knowledge have the largest gradient, meaning that if a task requires more of this, then its automatability score will increase to a greater extent than increasing other features. ${ }^{*}, 3$

So these analyses suggest there might be a range of tasks in health care, especially clerical tasks, that could be promising candidates for automation. level of requirement increased, contributes to increasing the automatability score $(+0.166$, Table 2$)$. Another occupational feature, such as the amount of customer and personal service knowledge required to perform a task, is on average $13 \%$ greater in the automatable group when compared to the population, however increasing this knowledge does not increase the automatability of a task but decreases it (by a negative gradient of -0.023). The full list of global average gradients is provided in the Oxford study. 
Table 1: Largest feature differences relative to dataset by automatable category

\begin{tabular}{|c|c|c|}
\hline Automatable category & O*NET feature & Feature difference \\
\hline \multirow[t]{5}{*}{ Not automatable } & Installation (skill) & $+62.6 \%$ \\
\hline & Building and Construction (knowledge) & $+27.2 \%$ \\
\hline & $\begin{array}{l}\text { Personnel and Human Resources } \\
\text { (knowledge) }\end{array}$ & $+26.0 \%$ \\
\hline & $\begin{array}{l}\text { Management and Financial Resources } \\
\text { (skill) }\end{array}$ & $+18.7 \%$ \\
\hline & Education and Training (knowledge) & $+17.0 \%$ \\
\hline \multirow[t]{5}{*}{ Automatable } & Clerical (knowledge) & $+24.4 \%$ \\
\hline & $\begin{array}{l}\text { Customer and Personal Service } \\
\text { (knowledge) }\end{array}$ & $+13.2 \%$ \\
\hline & Service Orientation (skill) & $+5.0 \%$ \\
\hline & Economics and Accounting (knowledge) & $+4.7 \%$ \\
\hline & Computers and Electronics (knowledge) & $+4.5 \%$ \\
\hline \multirow[t]{5}{*}{ Partly automatable } & Medicine and Dentistry (knowledge) & $+30.8 \%$ \\
\hline & Therapy and Counselling (knowledge) & $+22.0 \%$ \\
\hline & Psychology (knowledge) & $+13.4 \%$ \\
\hline & Clerical (knowledge) & $+13.2 \%$ \\
\hline & Biology (knowledge) & $+12.1 \%$ \\
\hline
\end{tabular}

Source: Willis $\mathrm{M}$, et al. ${ }^{3}$ 


\begin{tabular}{ll}
\hline O*NET feature & Feature gradient \\
\hline Telecommunications (knowledge) & +0.167 \\
\hline Clerical (knowledge) & +0.166 \\
\hline Wrist-finger Speed (ability) & +0.153 \\
\hline Number Facility (ability) & +0.118 \\
\hline Mathematics (skill) & +0.093 \\
\hline Depth Perception (ability) & +0.092 \\
\hline Building and Construction (knowledge) & +0.09 \\
\hline Mathematical Reasoning (ability) & +0.088 \\
\hline Economics and Accounting (knowledge) & +0.085 \\
\hline Control Precision (ability) & +0.082 \\
\hline
\end{tabular}

Source: Willis $\mathrm{M}$, et al.

A third approach to thinking about the types of work that can be automated is to look at different task 'functions' and consider what level of automation might be appropriate in each case. To take one example, drawing on the different stages of human information processing, Parasuraman and colleagues describe four system functions that can potentially be automated: information acquisition, information analysis, decision and action selection, and action implementation. ${ }^{66}$ For each type of function there are different possible levels of automation. For example, with regard to decision making, a computer could suggest options to support human decision making, on the one hand, or it could actually make a decision and act autonomously, on the other; and there may be further levels in between, such as having a computer make the decision but still with the ability of a human operator to override it if necessary. Parasuraman and colleagues argue that a variety of factors will be relevant to determining the appropriate level of automation in different cases, especially the reliability of the automation technology, the potential impact on human performance in the resulting system and, crucially, the risks associated with decisions. So, for example, looking at air traffic control systems, they suggest that in the case of information acquisition and analysis, high levels of automation could be appropriate, while in the case of decision selection and implementation high levels of automation would only be appropriate for low-risk situations. 
Work in health care is often complex and carries particular risks, with different kinds of tasks and work environments compared to other industries, and different legal, governance and institutional requirements. These factors might make it hard to translate some applications of automation from other industries to health care. This is explored in more detail in Chapter 3. First, we take a look at some specific areas where automation can be, and is being, applied in health care.

\subsection{Application to administrative tasks in health care}

Here we use the term 'administrative' loosely to mean tasks involved in the management or organisation of health care services, rather than in the direct delivery of them. Some administrative tasks may sit separately from clinical work, such as managing finances and payroll, while others may be embedded within it, such as processing prescriptions and managing hospital bed capacity.

Given that much administrative work involves routine information processing, the discussion above suggests that there may be significant opportunities for the automation of administrative tasks in health care. And with a high volume of administrative work in the NHS, it is easy to see why there is such appetite to take advantage of these opportunities, with the NHS Long Term Plan and NHSX both highlighting the potential of technology for reducing the burden of administrative work. Some administrative processes in health care are already being automated in particular settings, such as appointment booking and scanning letters in GP practices. However, advances in data availability, computational power and machine learning are creating possibilities for further automation.

The Oxford study estimated that around $44 \%$ of administrative tasks in general practice are 'mostly' or 'completely' automatable using current technology, based on its model derived from the opinions of automation experts (though, notably, the study also found that no single full-time role in general practice could be entirely automated). The research suggested that tasks such as managing finances and payroll, checking and sorting post, printing letters, texting patients, note-taking and letter scanning could all theoretically be automated. Given that such tasks require a considerable amount of time in any GP practice (including the time of GPs themselves), automating them could have a significant, positive impact in reducing the administrative burden and freeing up staff to focus on other work, particularly in light of current financial and workforce pressures.

Automation could make a particular difference with information-processing tasks that are time consuming and which have an important bearing on resources and patient care, such as in the management, scheduling and planning of clinical services. For example, in order to address high outpatient non-attendance rates, East Suffolk and North Essex NHS Foundation Trust has automated patient appointment reminders and cancellations using a simple text messaging process, reallocating free bookings when cancellations are made. The Trust claims that in 2018 this prevented 1,356 appointments being missed over a period of eight weeks, equivalent to a value of $£ 216,960 .{ }^{67}$ Given the issue of nonattendance is common across health care services, this type of application could be useful in a range of other settings beyond secondary care, such as primary, community and mental health services. 
Appointments and scheduling are also an area where $\mathrm{AI}$ and predictive analytics could add an extra dimension to automation. For example, Beth Israel Deaconess Medical Center in Boston is using the automated analysis of historical data to predict how much time a patient might need in the operating theatre and then using this to inform scheduling. ${ }^{68} \mathrm{AI}$ can also help with the management of resources such as hospital beds. For example, funded by the Health Foundation, Chelsea and Westminster NHS Foundation Trust has developed a model to predict rises in acute hospital bed occupancy (discussed in more detail in Chapter 3), which could be deployed to provide an early warning system that gives staff sufficient time to avert occupancy crises.

Advances in natural language processing (NLP), which can extract structured (machine analysable) data from unstructured narrative texts (such as clinical notes and letters), mean that automation technologies have increasing potential to support text-based administrative work, for example processing and producing letters - activities that require a significant amount of time across the NHS. In general practice, the Oxford study found that letter work - such as opening letters, triaging, scanning and redirecting them to relevant staff members, and responding to them in different ways - entails a large amount of work, which is typically undertaken by receptionists and secretaries, but also often by GPs. The study also found that a significant amount of time is spent trawling through letters to find small amounts of relevant information. Automation technologies using NLP could therefore be used to scan for relevant information and present it to health care professionals, prioritising information by context and urgency, as well as to produce letters automatically as patients have their examinations. In addition to helping make letter management in the NHS more efficient and less time consuming, such approaches could also open up opportunities for a wider range of communications options for patients, tailored to their needs and preferences, such as emails, texts, large print, braille, audio recordings and language translations. Another way NLP can be of particular value is in analysing and categorising patient feedback, which can then be used to target quality improvement work.

\section{Box 5: Automated analysis of patient feedback}

\section{Imperial College Healthcare NHS Trust (Innovating for Improvement, 2017-18)}

Free-text patient experience feedback within the NHS Friends and Family Test (FFT) offers rich information for quality improvement. But many providers find it difficult to analyse and interpret because of the large volume of unstructured data and the challenge in linking the information to other quality indicators. Beyond missing out on opportunities to improve quality, asking for patient feedback without being able to analyse and act on it also raises ethical questions.

At Imperial College Healthcare NHS Trust (ICHNT), the patient experience team received around 20,000 comments a month and were only able to analyse a small fraction of them. To address this issue, a multidisciplinary team from ICHNT and Imperial College London, supported by the Health Foundation, developed a tool which uses NLP to analyse free text comments in the FFT. The resulting analysis is then used to create easily digestible reports of patient experience at ward or service level, providing front-line staff with the information needed to devise effective quality improvement interventions. 
Free-text FFT comments were collected in outpatient, inpatient, maternity and A\&E services, with a view to improving care across these four areas. The team validated and then implemented the tool, which can analyse 6,000 comments in 15 minutes, compared with four days if the same analysis was undertaken by a member of staff. The time saved allows the patient experience team to spend more time supporting staff to act on patient feedback and improve services. For example, staff in the outpatient department were quickly able to identify improvements such as better informing patients of their position in the clinic queue and making water fountains available. Elsewhere, improvements were made to discharge processes through developing checklists.

While the project has enjoyed early success," to have greater impact and ensure sustainability for the long term the team are leading a drive to embed the tool into the workflows of all services in the Trust - helping to create a culture of 'measurement for improvement'. This includes a strong focus on quality improvement methodologies, to ensure the patient feedback leads to positive change.

The team are also working with NHS England and NHS Improvement to spread the tool to other NHS trusts in England. A further Health Foundation grant is supporting the team to test and evaluate the wider application of this NLP platform across NHS trusts, in combination with quality improvement methodology.

'For successful implementation, use and sustainability, you have to think beyond the shiny tool. It's also about quality improvement, which takes thought, time and effort to embed.'

Erik Mayer, project lead

Given AI-driven advances in speech recognition, there is also significant potential for the automation of speech-related administrative tasks. For example, speech recognition could be used to streamline documentation tasks by using NLP to analyse patient-clinician conversations and create notes, turning a discussion into a text transcript, summarising and annotating it to provide clinically relevant information and categorising it to appropriate sections of the medical record. After the consultation, the clinician could review a summary for editing and saving (though see Chapter 3 on potential challenges with the automation of note-taking). An application such as this could also make connections with information already in the patient's record, or with analysis of similar patients, to support clinical decision making. For example, Nuance Communications and Microsoft have developed a system that records each patient interaction and uses AI to convert it to text, which is then saved into the electronic health record. ${ }^{7}$

\subsection{Application in clinical services}

Beyond some of the established uses of automation in health care highlighted in Chapter 1, advances in computing, the codification of clinical knowledge and the availability of large datasets are creating scope for further automation of clinical tasks, or at least components of clinical tasks, especially those that relate to data analysis and decision selection. There is particular interest in the potential of data analytics and AI to support clinical decision making around diagnosis and treatment, where - as discussed above - the spectrum of automation could range from clinical decision support systems that assist human decision making all the way to scenarios in which decisions could be delegated to machines. 
In many cases, these technologies are still in the early stages of development, testing and adoption, and the excitement about their potential currently outstrips the reality on the front line. Often, more real-world testing is required to investigate how technologies that have shown potential in the lab can be best deployed. ${ }^{71}$ For example, recent systematic reviews of studies comparing the diagnostic accuracy of AI-driven medical image analysis with that of health care professionals found that while many AI models demonstrated comparable accuracy, few studies were prospective or randomised trials in live clinical settings, ${ }^{72}$ nor did many present externally validated results. ${ }^{73}$ Nevertheless, there are a growing number of examples of automation and AI that have shown their potential, ranging along the whole patient pathway - from promotion and prevention, through diagnosis and treatment, all the way to rehabilitation and supporting people to live with long-term conditions. We highlight a few examples below.

Diagnosis: While AI has been applied to analyse a range of diagnostic data, some of the most impressive advances in recent years relate to diagnostic imaging. ${ }^{74}$ Machine learning potentially enables a high degree of accuracy in pattern recognition and the classification of images, with the ability to identify abnormalities, in some cases more acutely than the human eye. The application of machine learning in the analysis of medical scans and pathology slides therefore holds significant potential for supporting and improving the detection of diseases. Significant progress has been made in radiology, with AI being used in screening for conditions such as breast cancer. Studies show AI-powered screening systems can be a useful addition to the breast screening pathway; for example, one study by McKinney and colleagues showed that, while only tested using retrospective data, an AI system using deep learning improved specificity and sensitivity in predicting the development of malignancy when compared to a first clinical assessor and performed no worse in comparison to a second clinical assessor, including a reduction in the incidence of false positives and false negatives. ${ }^{75}$

Risk assessment and prediction: AI can also assist clinical decisions by using data to assess risks and make predictions - for example, predicting if a patient's condition is likely to deteriorate. For example, a project funded by the Health Foundation and led by King's College London to improve outcomes in stroke care (described in more detail in Box 6) has developed a machine learning model that could be used to predict which patients are at highest risk of mortality after stroke. At a population level, AI could also be used for risk stratification and public health surveillance, ${ }^{76}$ such as for disease outbreak prediction and surveillance, something that could be particularly helpful in anticipating future waves of COVID-19 as well as the spread of other diseases. 


\section{Box 6: Machine learning analytics for quality improvement in stroke care}

King's College London (Insight, 2017-2021)

Variation in stroke outcomes is a complex phenomenon, meaning it can be difficult to predict the likelihood of disability after stroke. While there is an increasingly large and detailed amount of health data available, it can be challenging to translate this into knowledge that can be used to improve care quality.

This project, led by King's College London, funded as part of the Health Foundation's Insight programme, sought to address these challenges by using more sophisticated methods to analyse clinical audit data contained in the Sentinel Stroke National Audit Programme (SSNAP). The project developed machine learning algorithms to predict mortality after stroke, which were trained using SSNAP data from 488,497 patients. The performance of these machine learning methods was then compared to models using traditional statistical methods.

Compared to logistic regression, the machine learning model was slightly more accurate in predicting 30-day mortality after stroke. The largest accuracy gains were demonstrated when a wider range of potential variables were available to make predictions from, which underlines the importance of high-quality data if the benefits of using more advanced forms of predictive analytics such as machine learning are to be realised in health care.

More accurate predictions of outcomes after stroke could potentially be used to aid patient management, such as identifying early which patients might benefit from more intensive monitoring and management. They could also be used to analyse how services are performing, to support quality improvement and identify best practice where services are delivering better than expected care. The project team are also now looking at the potential of this technique to predict stroke-associated pneumonia.

'Health services will need to invest resources in generating better quality data, otherwise the gains from using more advanced methods for predictive analytics will be limited.'

Ben Bray and Wenjuan Wang, project leads

Triage: There is also increasing interest in the potential of AI to help clinicians make triage decisions and to help patients assess their own symptoms. Several AI triage tools are currently being tested, although these are currently intended to support clinicians in decision making, rather than to make triage decisions themselves. For example, a Health Foundation-funded project led by Barking, Havering and Redbridge University Hospitals NHS Trust is developing a system to assist the emergency department triage process by quickly identifying high-risk patients needing urgent care, described in more detail in Box 13 (page 46).

Patient-facing symptom checkers: A number of companies have also developed patientfacing symptom checkers that are currently available in the UK. These are 'chatbots' that use AI to compare data gathered from the patient with medical knowledge, with the aim of helping people get a better understanding of when to seek medical attention and connecting them to the appropriate service. For example, Your.MD and Babylon Health have both developed symptom checkers that ask users a series of questions to build a picture of their symptoms, before suggesting the most appropriate course of action, such as recommending a visit to the GP or hospital or providing reassurance that the person can take steps to recover at home. Babylon claims its chatbot has been trained to recognise the 'vast majority of health care issues seen in primary care', ${ }^{78}$ although as of May 2021 it also says it is not suitable for people with mental health concerns, skin problems, and 
pregnancy or post-natal concerns, among others, recommending an appointment with a doctor. ${ }^{*} 79$ University Hospitals Birmingham NHS Foundation Trust is now working with Babylon to use this technology to develop a pre-hospital triage app for people considering using $A \& E$ services, as part of a drive to reduce unnecessary $A \& E$ attendances. ${ }^{80}$

Treatment decisions and planning: As well as diagnosis and triage, data tools and AI can also be used to support better treatment decisions and planning, by suggesting treatment options or creating prompts and reminders to optimise the delivery of treatment. AI can be coupled with a range of patient data, including genomics data, as well as research and best practice, to help tailor treatments to individual patients. Electronic prescribing systems, for example, can incorporate decision support tools to check dosages and potential interactions with other drugs or conditions, and suggest safer or better-value alternatives. Used in this way, decision support systems - while stopping well short of complete automation - can be a useful tool in promoting adherence to best practice and helping reduce errors and unwarranted variation. In the case of electronic prescribing systems, for example, studies suggest that when used effectively these systems can reduce medication errors and adverse drug events, ${ }^{81,82}$ although there is more work required to ensure they are consistently safe and effective. ${ }^{\dagger, 83}$

Health promotion and self-management: Automation and AI are also increasingly supporting people to manage their own health. For example, a range of technologies, such as apps, wearables and medical devices, are enabling health monitoring and management in homes and residential care settings. One example is the latest generation of insulin pumps, which combine continuous glucose monitors with smart algorithms that automatically adjust dosage. ${ }^{84}$

Quality improvement: These technologies can also play an important role in supporting quality improvement by helping to generate data and analysis about how services are performing and how they can be improved - critical components of a learning health system. The projects at Imperial College Healthcare NHS Trust and King's College London described above, which are using machine learning to analyse patient feedback and clinical audit data, demonstrate how AI can be used to help identify where improvements can be made.

In many of the areas highlighted above, robotics can be combined with AI to automate tasks that require movement as well as information processing. The example of surgery has already been highlighted. Another area where this has potential is medication dispensing and stock management in hospitals and community pharmacies; robotic dispensers can operate with greater speed and precision than humans, with a significantly lower risk of error. ${ }^{\ddagger} 85$ A further application of robotics in clinical settings is transportation. For example, Moxi is a robotic assistant with a mobile base, arm and gripper, reportedly being trialled in the US, designed to assist clinical staff by transporting supplies to patient

It has been reported that the Medicines and Healthcare Products Regulatory Agency is developing a new regulatory framework to ensure that it can provide the right level of assurance for software-based medical products, such as symptom checkers.

Recent studies show that some electronic prescribing systems can be prone to failures that risk patient harm. For example, during the five years following installation in 2011, the University of California, San Francisco Medical Center operated a robotic pharmacy system with 100\% accuracy, finding, dispensing and delivering drugs around the hospital. 
rooms and delivering lab samples. ${ }^{86}$ Robotic technologies also present opportunities to provide therapy, whether in the home or in a variety of care settings. For example, Paro is a therapeutic AI robot, designed to look like a seal, to support people with dementia, which has shown signs of being able to reduce agitation and improve verbal and visual engagement among users. ${ }^{87}$

While at present several of the technologies reviewed here currently require human supervision or input, and so are not examples of full automation, they could conceivably become more independent in future. Either way, used effectively, they have the potential to improve outcomes, experience and efficiency, as well as to help alleviate workforce pressures.

\section{Box 7: NHSX}

NHSX, a joint venture between NHS England and NHS Improvement and the Department of Health and Social Care, provides leadership for digital transformation in health and social care, focused on five missions:

- $\quad$ reducing the burden on clinicians and staff, so they can focus on patients

- $\quad$ giving people the tools to access information and services directly

- $\quad$ ensuring clinical information can be safely accessed, wherever it is needed

- $\quad$ improving patient safety across the NHS

- $\quad$ improving NHS productivity with digital technology.

Through setting policy and targeting investment, NHSX supports the NHS to take advantage of the opportunities presented by technology, including Al and automation. The NHSX report Artificial Intelligence: How to get it right ${ }^{88}$ set out some of the main opportunities where Al could be used to automate or augment medical or care-related tasks traditionally done by health care workers - illustrated below. These include diagnostics, knowledge generation, public health, system efficiency and 'P4 medicine', which is another way of describing precision medicine, emphasising its predictive, preventative, personalised and participatory characteristics.

Figure 4: Range of potential uses for $\mathrm{Al}$ in health and care
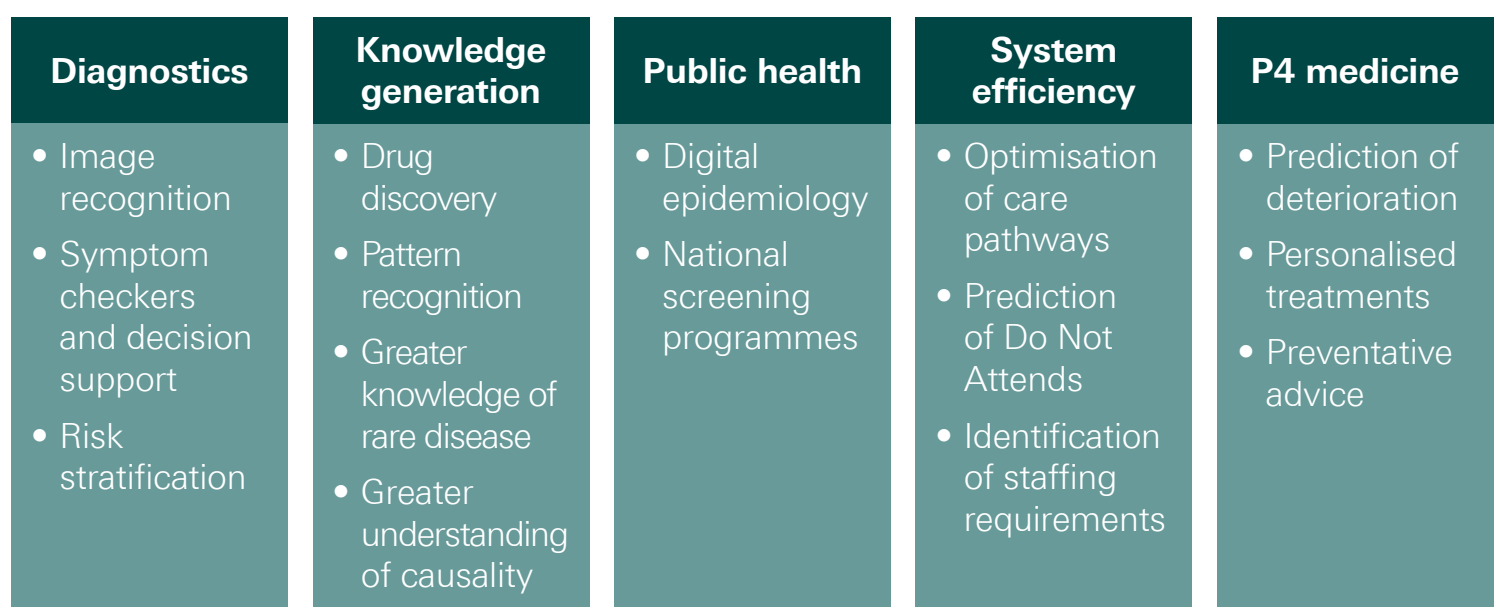

Source: NHSX, Artificial Intelligence: How to get it right, 2019 


\section{Box 8: NHS staff views on the biggest opportunities for automation and $\mathrm{Al}$ in health care}

As part of our NHS staff survey, we asked which of the many ways in which automation and Al can be applied to health care represented the 'biggest opportunities' for improving health care. Respondents were presented with a list of ten possible uses of these technologies in health care and asked to pick up to three of these.

The application of automation and $\mathrm{Al}$ that clearly ranked highest was 'analysis of images and test results', picked by $40 \%$ of respondents. This was followed by three other applications, all chosen by $28 \%$ : 'risk prediction and screening', 'use of robots in surgery' and 'demand and capacity management, scheduling and rostering'. Notably, only $2 \%$ of respondents thought 'robotic carers and assistants' represented one of the three biggest opportunities.

\section{Figure 5: Views of NHS staff on the biggest opportunities for automation and Al in health care}

Which, if any, of the following do you think represent the biggest opportunities for using automation and Al to improve health care?

Analysis of images and test results

Risk prediction and screening

Use of robots in surgery

Demand and capacity management, scheduling and rostering

Analysis and processing of patient notes and letters

Transcription of consultations

Triage tools

Symptom checkers

Personalised treatment planning

None of these

Robotic carers and assistants
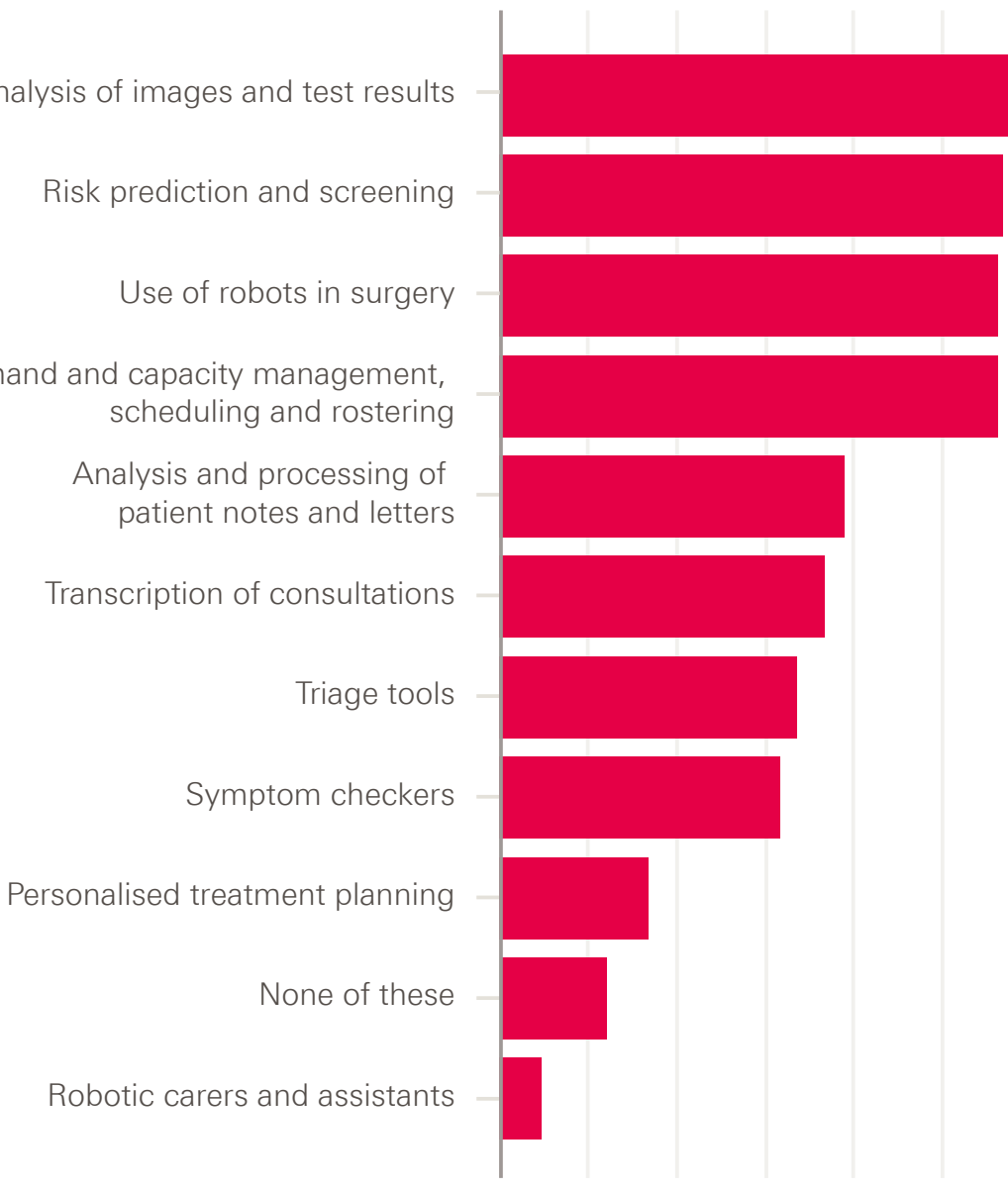

$\begin{array}{lllllllllll}0 \% & 5 \% & 10 \% & 15 \% & 20 \% & 25 \% & 30 \% & 35 \% & 40 \% & 45 \%\end{array}$

Because it is a question that relied on more detailed knowledge of health care processes and activities, it was not deemed suitable for the public survey. 
There were a few differences in the pattern of results among different occupational groups, mainly that groups tended to pick options that were particularly relevant to their work. For example, ambulance staff gave triage tools a higher rating than average (29\% compared to $17 \%$ for all respondents) while public health professionals gave them a lower rating than average $(13 \%)$. But the ranking of opportunities was broadly similar across occupational groups.

The list of opportunities provided was certainly not comprehensive, and it is worth noting in this respect that $6 \%$ of respondents thought that none of these listed opportunities were in their top three biggest opportunities (represented by the bar labelled 'none of these' in the figure above). 


\section{Challenges for applying automation and AI in health care}

There is clearly great potential for the use of automation and $\mathrm{AI}$ in health care. But there are also some important constraints on where and how these technologies can be applied, along with a range of design and implementation challenges if they are to be successfully deployed. It is perhaps understandable that the promise of automation and AI typically excites the most attention. But given that the introduction of technologies into health care settings necessarily creates new risks and potential points of failure, we believe the challenges require just as much focus if we are to get automation right.

In this chapter, we explore some of these challenges and constraints by exploring different characteristics of tasks in health care. One set of challenges emerges from tasks requiring uniquely human traits or human presence. Another stems from the complexity of tasks and work environments in health care. We also explore the challenges of implementing and using automation technologies effectively in practice. While some of these issues might pose absolute constraints on the use of automation and AI in health care, others can be addressed through effective design and implementation.

We do not consider here challenges that relate specifically to the technologies themselves (such as interoperability with other systems) or the data they rely on (such as data protection), which are beyond the scope of this report - though Box 9 briefly highlights some important challenges related to machine learning. Rather, our focus is on the application and use of automation and $\mathrm{AI}$ in health care.

\section{Box 9: Some data and algorithmic challenges for automation and $\mathrm{Al}$ in health care}

There are a range of risks and challenges relating to the data and algorithms used in automation and $\mathrm{Al}$ in health care, which have attracted significant attention in recent years.

Bias

Automation and Al systems require design, programming and training in order to function and are therefore susceptible to the biases of the datasets used for training, as well as biases within the environment in which the system is built. Many of the data sources typically used by these technologies present possible issues of bias including patient self-selection, inconsistent availability of outcome data, incomplete data and poor representation of certain populations, which can all result in inadvertent bias in machine predictions. ${ }^{89,90,91}$ In addition, these technologies will be shaped by the biases of the teams that research, design and develop them. * These issues in turn create the risk of biased outcomes that disadvantage particular populations, raising important questions about the fairness and accuracy of decisions made by automation and Al systems.

According to a 2018 report by Tech Nation, diversity and inclusion is still a challenge in tech companies, with gender and ethnic make-up not representative of UK society. If the teams that research, design or develop Al and automation technologies lack diversity this could increase the risk of bias, whether conscious or not. See Tech Nation. Chapter 5: Jobs and Skills. In Tech Nation Report 2018. Tech Nation; 2018 (https://technation.io/ insights/report-2018/jobs-and-skills/). 


\section{Transparency}

Automation and Al systems challenge conventional conceptions of moral responsibility because of their ability to influence and make decisions and potentially act with a degree of autonomy. While it may not be possible to attribute moral responsibility to a technological system, many agree that the need for clear accountability ${ }^{2}$ requires the ability to explain and justify the actions of a system. Such systems therefore need to be transparent and understandable. However, this can be a challenge because the inner workings of automated decision-making systems, particularly those incorporating machine learning, can be so complex that they cannot be explained or audited, leaving only the outputs visible (sometimes called 'black box' decision making). ${ }^{93}$ This can make it difficult for those who have been adversely affected by algorithmic decisions to understand the reasons on which they were based. ${ }^{94}$

\section{Sensitivity}

Challen and colleagues highlight some further important challenges arising from a potential lack of sensitivity of an automated system to its context, with important safety ramifications. These include situations where an automated system attempts to make decisions despite possessing insufficient information; situations where an automated system does not take into account the impact of its decisions (for example, the impact of a false positive prediction); and situations where an automated system trained on historical data cannot adapt quickly enough to new populations or sudden policy changes.

These risks and challenges highlight the importance of regulation and standards to ensure that health care technologies are safe, ethical and deliver high quality outcomes for all - discussed further in Chapter 4.

\subsection{The human dimension}

Many tasks in health care require human traits that cannot (yet) be replicated by machines. For other tasks, there is an intrinsic value of human agency or relationships meaning the task cannot be delegated to a machine. Both create limitations on the scope for automation.

\subsubsection{Human traits that technology cannot (yet) replicate}

Frey and Osborne's influential work on the future of employment highlights three types of human ability that are difficult for technology to replicate: perception and manipulation; creativity; and emotional and social intelligence. ${ }^{24}$

- Perception and manipulation: Replicating humans' ability to understand and respond to external stimuli remains a challenge. Consider the use of a robot to assist a hospital patient to move from a bed to a toilet, or to clean the kitchen for someone needing help at home. While on the face of it these tasks might appear simple, they involve a vast number of distinct movements and the ability to respond to external stimuli in order to navigate through changing environments. Every possible movement and response requires codification; as Brynjolfsson and McAfee note, 'low-level sensorimotor skills require enormous computational resources'. ${ }^{17}$ While machines can increasingly copy many aspects of human perception and movement, the ability to interpret the world and act appropriately remains much harder.

- Creativity: The psychological processes and values underlying human creativity are difficult to specify and therefore hard to automate. Creativity involves generating new ideas, or making new connections between familiar ideas. While this is 
not hard in itself, the issue is that creativity requires not just novelty but also value - which novel ideas or connections 'make sense'? The challenge here lies in describing our creative values in a clear enough way for them to be programmed into a system. ${ }^{17,24}$ Later we discuss one example of where the need for creativity may constrain the scope of automation: in the strategies health care workers use to improvise and adapt when faced with unpredictable events.

- Emotional and social intelligence: Emotional and social intelligence, which are required in activities such as caregiving and managing people, pose challenges for automation. They include the ability to 'read' and deal effectively with the feelings of other people and to manage relationships. ${ }^{95}$ Automating this type of intelligence is a challenge not only because of the difficulty of recognising human emotion in real time, but also of knowing how to respond in an appropriate way, which requires a complex combination of skills and knowledge. Box 10 explores the role of emotional intelligence in health care.

\section{Box 10: Emotional intelligence in health care}

Emotional intelligence - 'the ability to perceive and express emotion, assimilate emotion in thought, understand and reason with emotion, and regulate emotion in yourself and others' 96 - enables individuals to build relationships, moderate conflict and foster harmony. ${ }^{97,98}$ It is widely recognised as crucial for quality and safety in health care, including for creating an environment of trust and openness.

In particular, empathy - the clinician's willingness to appreciate the patient's perspective - which is one component of emotional intelligence, ${ }^{+, 99}$ underpins good patient-clinician communication and is critical in delivering person-centred, compassionate care. ${ }^{100}$

As the Institute for Healthcare Improvement argues, 'staff and providers' skills in understanding and meeting the patient's emotional needs are essential to creating an excellent experience of care'. ${ }^{101}$ It is hard to envisage, at least in the short term, how a computer could address these needs given the level of emotional and social intelligence required.

Even where the role of emotional and social intelligence is less obvious, such as with administrative tasks, it might still be important for avoiding undesired results. An example is rostering. This might appear to be a good candidate for automation because it is rulesbased, routine, frequent and time consuming - and there has been much recent interest in 'e-rostering' in the NHS, most recently in the Carter Review. However, exploration of how rostering works in practice reveals it is not just a technical task, but a social one too, requiring careful planning and consideration of a range of factors, such as a team's sense of fairness and when discretion about rostering rules should be applied. ${ }^{102}$ While this doesn't mean that rostering can't be automated, it highlights the importance of considering tasks carefully to understand where human intelligence adds value, so an informed judgement can be made about whether they should be automated or not.

According to Stanton and Noble, for example, 'clinical leaders need to be able to react in an emotionally intelligent manner to the intensely emotional events that inevitably occur in health care', and being able to regulate their feelings 'creates an environment of trust and openness that is palpable to others and vital to improving patient safety'.

$\dagger \quad$ Psychologist Daniel Goleman argues that emotional intelligence has five component characteristics: selfawareness, self-regulation, motivation, empathy and social skill. 


\subsubsection{Tasks requiring human presence}

The use of automation in health care will not be determined simply by whether it is technically possible. We also need to understand where it is desirable, and where human input should be retained.

One key issue is the importance of human agency in care giving, particularly for treating patients with dignity and respect. While some patient-facing applications of automation, such as automated online appointment booking, might be considered perfectly compatible with treating patients with dignity and respect, others, such as robotic carers, are more contentious. A recent survey of 4,000 US adults on attitudes towards in-home robotic carers found that more were worried about the idea (47\%) than enthusiastic (44\%). ${ }^{103}$ The loss of human interaction was the predominant theme mentioned by respondents who said they wouldn't want a robotic carer. In cases like these, people may feel that interacting with another human is necessary for, and indeed constitutive of, being treated with dignity and respect. There are a range of tasks in health care - such as informing a patient of a diagnosis of a serious illness - which for similar reasons may simply not be 'delegable' to a machine. As Liu and colleagues note, this type of communication requires 'considerate assessment of a patient's hopes, fears and expectations', much of which is non-verbal and happens at an 'innate level', which an algorithm cannot replicate. ${ }^{104}$

Another fundamental issue, as Batalden has observed, is that health care is not a product but a service that is co-produced with patients and families. ${ }^{105}$ Human relationships are fundamental for this co-production and shared decision making, which lie at the heart of person-centred care. In areas like care planning, for example, the need for genuine partnership between health care professionals and patients may pose 'hard' constraints on the use of automation.,

On other occasions it may not be that the use of automation is incompatible with dignity and respect, but simply that there is a preference for human contact. For example, in the Oxford study's fieldwork, the researchers observed patients bypassing the touchscreen check-in at the GP surgery and choosing to check in with (and say hello to) the receptionist instead.

There are also a range of concerns that arise where automation and AI are used in decision making., ${ }^{+, 95}$

Relating to the decision process are important issues of procedural fairness and acceptability concerning how decisions are made and resources allocated, where the increased use of automation and $\mathrm{AI}$ in decision making could have important ramifications. A significant finding of social psychology in recent decades is that people can care about the processes of decision making independently of the outcomes. ${ }^{106}$ For example, people who lose court cases may nevertheless feel more satisfied if they believe they've had a fair chance

As the Health Foundation's Person-centred care made simple puts it, 'for care to be enabling, the relationship between health care professionals and patients needs to be a partnership... It is a relationship in which health care professionals and patients work together to understand what is important to the person, make decisions about their care and treatment, and identify and achieve their goals.'

For example, Yeung highlights several kinds of issues, which apply to both fully automated decision-making systems and algorithmic 'recommender' systems - including issues relating to the decision process and to decision outputs. 
to have their argument heard compared to those who feel they haven't. ${ }^{107}$ If automation and $\mathrm{AI}$ are used in diagnosis, triage and treatment decisions, interesting questions arise as to whether patients will feel these processes are fair and acceptable. For example, some patients might feel that algorithmic triage is acceptable as a process due to its potential to be consistent and free from certain kinds of human bias (though note the potential for data bias described in Box 9); whereas others might feel that having a human listen to and consider their case is a key component of being treated fairly and respectfully. More research is needed to understand perceptions of procedural fairness and acceptability surrounding automated decision making in health care; it is an area where the distinction between full and partial automation, and perceptions of the extent of machine involvement in decision making, may assume particular significance.

Where tasks have a direct impact on patient health, human participation in decision making may also be necessary for reasons of safety and accountability. For while automation can reduce the scope for human error, human oversight is often necessary to guard against machine error; in this sense, automated systems always require a 'wrapper of human control'. ${ }^{108}$ Furthermore, the fact that machines can learn, make decisions and potentially act with a degree of autonomy raises important questions of accountability when mistakes occur. While attributing responsibility for problems can be complex (for example, when are they the responsibility of the machine operator and when of the manufacturer?), there is nevertheless general consensus that accountability must lie with humans rather than machines. ${ }^{* 109}$

\subsection{The complexity of work in health care}

Another potential challenge for automation is the sheer complexity of tasks and work environments in health care - a prominent theme of sociological, ethnographic and human factors studies. Very often, there is more going on in a task than meets the eye. Attempts to introduce automation and reorganise work based on a simple interpretation of the task will therefore lead to problems or 'unintended consequences' - with potential risks to quality and safety.

Here we briefly discuss three potential challenges for automation arising from the complexity of work in health care: task multidimensionality (the fact that single tasks can fulfil multiple functions), task variation (the fact that tasks can look very different on different occasions and in different settings) and task unpredictability (the fact that tasks can evolve in ways that require flexibility and adaptation).

\subsubsection{Task multidimensionality}

One characteristic of many tasks in health care is their 'multidimensionality' - the fact that even in a single task there can be multiple things going on. Sometimes it might make sense to think about a task as comprising a range of 'sub-tasks' (in which case, the question of

For example, a 2018 statement on these technologies by the European Group on Ethics in Science and New Technologies concluded that moral responsibility cannot be attributed to autonomous technology, arguing that the 'ability and willingness to take and attribute moral responsibility is an integral part of the conception of the person on which all our moral, social and legal institutions are based'. 
automation can move down a level to consider which sub-tasks can be automated). In other cases, it might make sense to think of the same task as serving multiple functions, and in these cases if you automate the task with the aim of fulfilling its 'primary' function, it will mean the other functions get lost.

The Oxford study identified a powerful example of this. While clinical documentation can be automated, ${ }^{110,111,112}$ which might well save time, the GPs in the study's focus groups pointed out that this could remove an important opportunity for them to reflect on their cases. Such reflection is valuable not only for ensuring they make the best decisions about diagnosis and treatment, but also for reflecting on their practice more generally, which matters for professional development. Echoing Bansler's observation that documentation can serve as a 'tool of thinking, ${ }^{113}$ the Oxford team observed how clinical notes were often kept open on screens for periods of time in order to enable GPs to consider, revise and make sense of the material, particularly notes for new or complex cases. Willis and Jarrahi comment that 'If the practice of writing and thinking through writing is wholly removed from the clinicians' workflow... it removes an opportunity for the clinician to think and reflect critically in the way they practice medicine. ${ }^{114}$ So the task of note-taking is potentially about more than recording information, and simply automating it and assuming this fulfils all the functions of the task would be wrong. Alternatively, clinical documentation could be automated but with GPs still taking time out to analyse and reflect on their cases in other ways. Some GPs may prefer this, though it wouldn't necessarily result in the productivity gains that a simple interpretation of note-taking might lead one to expect.

In the same way that documentation can be about more than recording information, communication can be about more than transferring information. Ash and colleagues observe that communication can also be about generating an effect on the person you're communicating with, testing their assumptions, receiving feedback, and establishing and maintaining relationships. ${ }^{115}$ Important functions like these can get lost if automated systems displace human communication and social interaction in the workplace.

Another kind of multidimensionality is where a decision-making task tacitly involves two different elements: the appraisal and decision making itself (decision selection); and the checking and 'sign off' of the decision (decision authorisation). When one person is performing the task, these two elements are usually elided. But while an alternative worker or computer might be able to perform the appraisal and decide on a course of action, this may not remove the need for a stage of checking and authorisation, and it may be undesirable to delegate this authority to the alternative worker or computer - particularly where the decision carries significant risk. So even when a decision-making task has been delegated or automated, there may still be a need for a suitably qualified worker to check the decision and sign it off." In some cases, this might still be more efficient than the previous arrangement; in other cases, the level of engagement required for the suitably qualified

With some types of automation, this may create a new role, whereby a worker becomes the operator of the automated system and responsible for checking its outputs. The Oxford study hypothesises that, due to their privileged knowledge, it could well be that the worker who is displaced by the automation technology subsequently becomes the operator, for example, a prescription clerk could take responsibility for operating and maintaining an automated system for processing prescriptions. This is one reason why automation may not simply be about replacing human labour but rather complementing it. 
worker to familiarise themselves with the case and authorise the decision may be almost as much as if they were performing the whole task themselves, in which case the delegated arrangement may reduce productivity.

Studies of health care roles, including literature on 'hidden work', ${ }^{116}$ identify other examples of tasks fulfilling multiple functions. Health care assistants, for example, typically perform a range of tasks, including taking blood samples, monitoring vital signs, serving meals and helping patients move around. However, through the contact they have with patients in carrying out these tasks they also provide emotional support and identify patient needs (for example, needs around pain management), something that enables them to act as advocates for patients and bridge the relationship between patients and other clinicians. ${ }^{117}$ While it is conceivable that in future robots and automated systems may be used to assist patients with meals and mobilisation, and take measurements and samples, ${ }^{22}$ this could weaken an important dimension of patient support if it significantly reduced contact between health care workers and patients.

While none of the issues highlighted here are absolute barriers to automation, it is clearly important that proposals for automation are grounded in a detailed understanding of the work in question. What the literature on 'unintended consequences' reveals is that changes are sometimes made without this understanding.

\subsubsection{Task variation}

Many tasks and work activities in health care resist standardisation. This is not simply because patients and cases may differ, but also because roles, processes and workflows may be organised differently on different occasions and in different contexts, depending on the staff, skills and resources available. The Oxford study documents many types of variation across tasks in primary care (both within practices and between practices), including variation in the content of tasks (for example, phone calls), variation in the process for completing tasks (for example, handling correspondence) and variation in who performs tasks (for example, letter writing). According to the authors, 'variance in tasks can occur in the order parts of the task are performed, duration, the occupational role of the person performing the task, the importance of the task or how time-critical it is, and how many individuals become involved in completing it'. ${ }^{3}$

That tasks can be organised in different ways on different occasions may pose challenges for automation. For example, if the performance of a task is distributed between workers in different ways in different settings, then some task and work reorganisation may be necessary to make automation possible. ${ }^{118}$ For administrative tasks in primary care, the Oxford study found that the extent of task sharing - and therefore the way tasks are organised - varies depending on practice size, with more sharing of tasks at single-site practices than at large, multi-site practices.

Related to this, another unintended consequence of task delegation is when it results in a far more precautionary approach because of the separation of decision making from a more senior source of authority or expertise. 
In other cases, variation in who performs a task may reflect not simply variation in how the roles, processes and workflows are organised, but variation in the underlying nature or content of the task. The Oxford researchers noted that what looks like an administrative task can suddenly get transformed into a clinical task requiring specialist medical knowledge - something they argue 'is what makes work in health care different and exceptional when compared to other fields with similar task descriptions'. ${ }^{3}$ Reviewing prescriptions, for example, an administrative necessity, can reveal information requiring a decision by a pharmacist with specialist knowledge. Medical coding is another type of task that can flip between administrative and clinical. ${ }^{119}$ Such variation in the nature of a task may render it less tractable to automation, or suggest only automating some aspects of it but not others.

Ultimately, variation itself need not be a challenge for automation provided that the nature of the variation is understood. But there are cases in health care where the parameters within which a task might vary can't themselves be specified or constrained - the 'leftfield' piece of information from a patient, for example, that could require a totally different approach to handling their case. Much automation discourse is grounded in the paradigm of product manufacturing, where tasks might be more prone to standardisation and routinisation than tasks in health care. ${ }^{119}$ So caution will be needed in assessing the applicability of the wider automation literature to health care.

\subsubsection{Task unpredictability}

One important source of task variation in health care is unpredictability in the way tasks unfold over time. This is partly because much health care work is responsive in nature - to the needs of patients, staff and organisations - and takes place in a dynamic work environment that can create disruptions to workflow. It is also because tasks are often being carried out in non-ideal circumstances where workers have to navigate uncertainty and trade off conflicting goals (such as whether to spend more time with one patient or move on to the next). While some disruptions result from operational failures (such as the need to fetch missing equipment) that can in principle be prevented, others result from intrinsic aspects of health care (such as the need to respond to a change in a patient's condition).

Work interruptions are one example of this phenomenon that has been extensively studied. They pose challenges for task performance, ${ }^{120,121}$ but while in some cases they are irrelevant to the task underway, in others they are vital for the delivery of safe care, requiring an immediate response. .22,123 $^{-12}$

Managing fluid and unpredictable workflows safely requires flexibility, adaptation and improvisation from health care workers. But while automation technologies can potentially handle unpredictability, they can only do so if the appropriate strategies for handling it are understood. Ebright and colleagues highlight (in the context of nursing work) that not enough is known about the strategies and reasoning that front-line health care workers use to cope and adapt in complex work situations to be able to codify this knowledge. ${ }^{124}$ As Autor puts it, 'The tasks that have proved most vexing to automate are those demanding flexibility, judgement, and common sense - skills that we understand only tacitly. ${ }^{\prime 25}$ 
While no one is proposing to automate complex clinical work such as nursing work, there is a wider challenge for automation here: the use of technologies in clinical pathways will need to support health care workers' ability to improvise and adapt. One risk is if an automated system introduces unnecessary rigidities into the workflow, undermining flexibility and the capability to react. An example would be where an automated system won't allow progression to the next stage of a task until certain information has been entered, despite the fact that real-life situations sometimes demand that task steps are initiated early, in the absence of the information or in an unconventional order. Another risk is where reliance on automation technologies restricts communication or takes workers 'out of the loop', reducing the situational awareness needed to respond to unexpected events. ${ }^{126,127}$

So automation technologies need to be designed in ways that match the realities of complex workflows and hectic work environments (discussed further in Box 11). Coiera observes that technology is often designed on the incorrect assumption of a fully concentrating user in a single-task scenario; the reality is that health care workers may be carrying out several tasks simultaneously or interacting with colleagues to help them complete other tasks. ${ }^{128}$ Ash highlights a range of problematic design features of technologies in this respect, such as interfaces that are hard to use in an interruptive context or that unnecessarily increase the cognitive load on staff by requiring information to be entered in overly structured formats. ${ }^{116}$

In summary, while automation is best suited to routine work, work patterns on the front line are often adaptive and emergent as workers juggle competing demands under resource constraints. The successful design and deployment of automation technologies will need to support the ability of health care workers to flex and adapt in the face of task unpredictability.

\section{Box 11: The 'human infrastructure' on which technology depends}

Many of the challenges described here relate to the sociotechnical nature of health care. As Coiera observes, any health care technology does not sit in isolation, but is part of a larger 'sociotechnical system' which involves the people using the technology and the people they are interacting with, the other processes and tasks going on, and features of the surrounding work environment, which may well be complex and unpredictable. ${ }^{129}$ Results emerge from the 'sociotechnical coupling' of technology with people and processes - 'not as the injection of technology into a location, but as a process in which we mould together a unique bundle that includes technology, work processes, people, training, resources, culture, and more'. ${ }^{129}$

This means the effectiveness of a technology will be determined not just by how well it accomplishes the specific tasks for which it was designed in isolation, but by how well it can fit and is fitted into an organisation's processes, workflows and wider institutional norms. And understanding and modelling these processes and workflows is not trivial: many processes in health care have never been consciously designed, ${ }^{130}$ and often there can be significant gaps between 'work-as-done' and 'work-as-imagined'.

Problems can arise when there is a mismatch between the design of a technology and the reality of the work environment in which it is to be used. Indeed, this can be an important source of safety risks: as well as the risk of purely technological failures, the introduction of technology into a live health care setting will also create the possibility of failure occurring in the interface between the technology and the surrounding work processes. Work on 
patient safety is increasingly recognising the vulnerabilities that can be created through the introduction of technologies, which can give rise to adverse consequences that are hard to foresee. ${ }^{132}$

A variety of sociotechnical frameworks and models have been developed to describe the interplay of these different factors in the development and use of health technologies. ${ }^{133,134}$ For example, Sittig and Singh's eight-dimensional model, in addition to factors such as hardware, software, data and the human-computer interface, describes the importance of social and contextual factors such as people, workflow and communication, as well as internal organisational features such as procedures, processes and culture. ${ }^{134}$

More recently, Healthcare Improvement Scotland has developed a model to support service redesign, based on an approach from Tan Tock Seng Hospital in Singapore. The model, illustrated in Figure 6, highlights how technology needs to be seen as just one part of a broader process of role redesign and process redesign that must take place for the successful adoption of technologies like automation, Al and robotics.

\section{Figure 6: Interrelationship between technology, process redesign and workforce redesign}

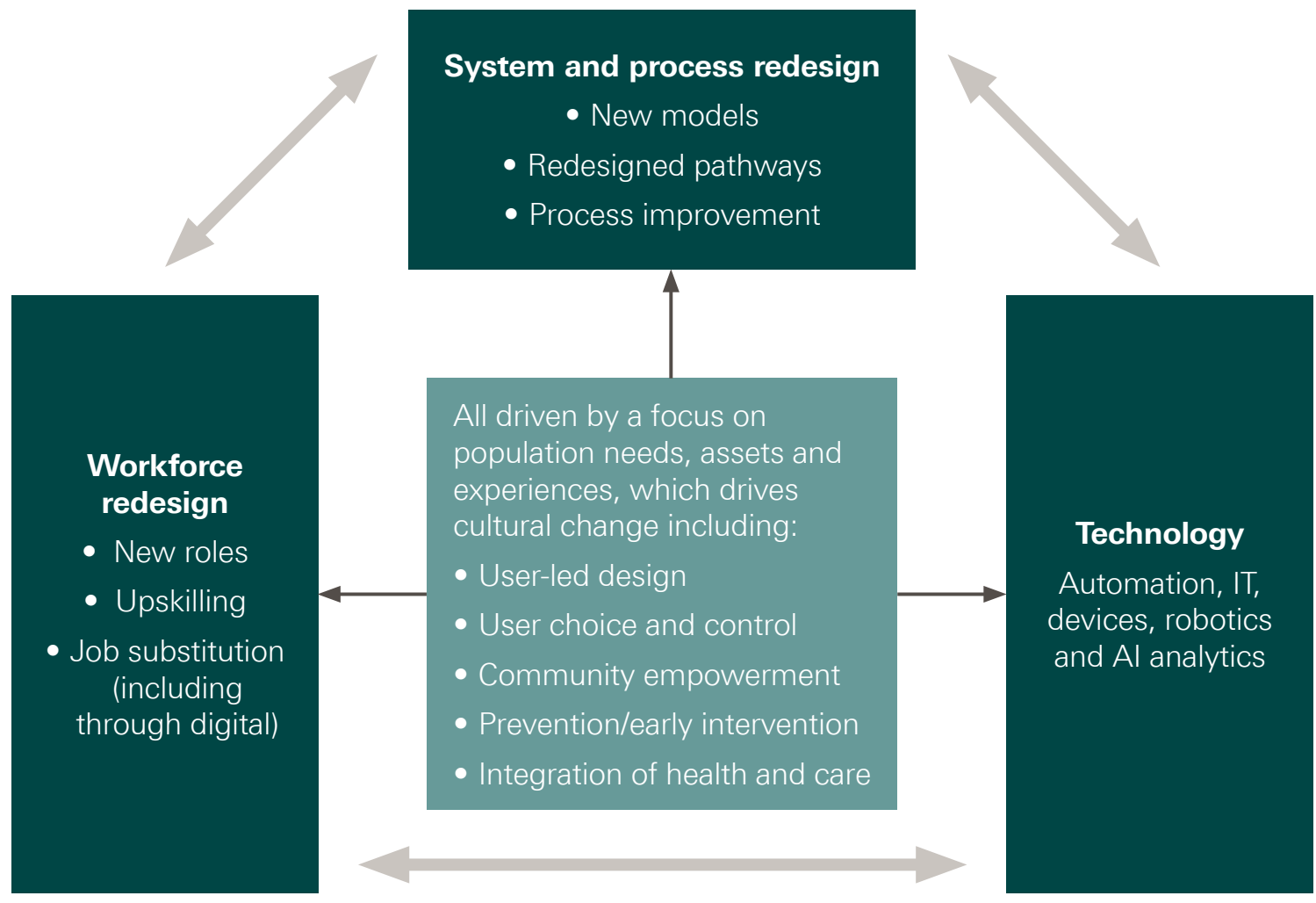

Underpinned by effective infrastructures

- Good governance through robust programme management, financial management and risk management

- Multidisciplinary change teams

Note: This model is based on an approach developed by Tan Tock Seng Hospital, Singapore

Source: Healthcare Improvement Scotland. Discussion Paper - an evolving approach to supporting the redesign and continuous improvement of health and care in Scotland. Healthcare Improvement Scotland; 2019 


\subsection{Challenges for implementing automation and $\mathrm{AI}$ in health care}

Even when automation systems are designed in appropriate ways for live health care settings, there still remain significant challenges in implementing them effectively. If the success of a technological intervention depends not just on the technology itself but also on a whole set of accompanying role, process and workflow elements, and if these role, process and workflow elements can vary from one setting to another, then implementation can be viewed as the practice of fitting the technology into the specific organisational context. And this can be a complex process. As the 2016 Wachter Review of health IT in England argued, implementing digital technologies is not a simple case of 'technical change' (like following a recipe) but of highly complex, adaptive change, ${ }^{29}$ which requires substantive and long-lasting engagement between those leading change and those on the front line responsible for making technologies work. ${ }^{1}$

The challenges of implementing automation technologies go beyond the usual set of challenges faced in implementing new health care interventions. First, there are specific challenges associated with the implementation and use of new technologies. Second, as highlighted in the literature on skill-mix change, there are specific challenges associated with 'task shifting' - work reorganisation that relocates the performance of a task. Automation potentially combines both technology and task shifting, making successful implementation far from straightforward.

As with many of the issues examined in the previous section, these kinds of challenge are not necessarily barriers to automation, but rather factors that will have to be addressed if automation is to work effectively. Failure to do so can lead to unintended consequences, such as operational failures, workarounds, decreased productivity and increased workloads.

\subsubsection{Challenges related to technology implementation}

A first set of challenges relates to the implementation of technologies. Here we highlight challenges related to the 'human' (sociotechnical) dimension of technological interventions; challenges relating specifically to the nature of technologies themselves or the data they rely on are beyond the scope of this report.

- $\quad$ Embedding new technology successfully in health care settings requires developing new organisational routines, ways of working and behaviours. The challenges of doing this are a recurring theme of evaluations of health technology interventions. ${ }^{136}$ They include the need to establish the implications of the new technology for organisational processes and workflows, the need to agree and coordinate the new ways of working required, and then - even when all of this is known - the need to actually change behaviours and ways of working, which may be deeply entrenched. Problems will arise if the workflow models used in developing the technology don't match real-life workflows. ${ }^{134}$ As noted earlier, the complexity of work in health care, where there can be significant gaps between 'work-as-done' and 'work-as-imagined', means there may need to be a stage of 
process and workflow mapping to understand existing work patterns and think through how automation could be successfully introduced. Problems will also arise if there are not appropriate strategies and protocols in place to ensure safety and continuity if things go wrong. Relevant here is the 'Safety II' approach, which focuses on purposefully enabling things to go right, rather than merely seeking to prevent failures, ${ }^{137}$ and on being proactive rather than reactive. Safety II also focuses on the importance of adaptation and flexibility to match the conditions of work, and the role of humans to 'absorb variability' and create resilience, which is essential if technology is to work safely and effectively.

\title{
Box 12: A learning health system approach to avoiding acute occupancy crises
}

\begin{abstract}
NIHR CLAHRC Northwest London and Chelsea and Westminster NHS Foundation Trust (Innovating for Improvement, 2017-18)

Many acute NHS providers currently face high bed occupancy rates, with peaks that frequently exceed capacity. This leads to emergency department overcrowding, delayed care and patients being in inappropriate wards, all of which impact on patient experience and outcomes, including length of stay. When demand for beds reaches a critical level, hospitals may attempt to absorb additional patients by expediting discharge of existing inpatients. However, without a means of early warning, the problem often only becomes apparent once it has started to have an impact, leaving little time to begin an effective mitigating response.
\end{abstract}

Supported by the Health Foundation, this project aimed to develop a model which would use data about patient characteristics to predict which inpatients would be likely to remain in hospital in two days' time (residual occupancy) and therefore the risk of a bed occupancy crisis. The idea is that if a hospital could have prior warning of an impending bed crisis, this could trigger a response with sufficient time to deploy accelerated discharge strategies, for example, prioritisation of discharge-related diagnostics, ambulatory care or social care.

The project team interviewed acute care staff to identify data that could help to predict residual occupancy. This aided the design of a statistical model that was based on data from 86,000 patient spells in hospital. The model was able to predict residual occupancy two days in advance with an average error of $6 \%$. However, the initial model was static and could quickly become outdated over time, so the team is now developing a machine-learning version that will be able to learn from and adapt to changes in the causes of bed occupancy peaks.

For the model to be useful in routine practice, the team developed a software module to import, standardise and clean hospital admission and A\&E attendance data, and link them to hospital spells. This means the model could be deployed in other hospitals and be trained on each hospital's data on an ongoing basis, so that changes in patterns of occupancy and patient care can be learned by the model.

The next step will involve testing the model with prospective data before being run in live settings. Just as importantly, the team recognise that the tool is a means to an end, not an end in itself: using it to avoid occupancy crises in practice will rely on staff taking action before rates get too high. To support this, they are developing a protocol to standardise responses to rises in occupancy, including when responses should happen and who should lead them.

'The predictive model is an important component, but ultimately it is how you act on the data that counts. This means taking early action when a bed occupancy rise is flagged, which requires a big cultural shift.'

Paul Sullivan, project lead 
- Training and re-training are a critical part of successful implementation, ${ }^{14}$ particularly in light of the increasing complexity of automation, AI and robotic technologies, and functionalities that are new and unfamiliar. On this issue, the 2019 Topol Review argued there will need to be an increase in digital literacy among health care professionals., ${ }^{*} 141,34$ Health care workers will not only need to understand how to use new technologies safely; they may also need to understand how the technology works, at least at a basic level, in order to interpret the outputs of the system correctly or to explain the system's operation to others.

- There is a risk that automation and AI could create or widen health inequalities. In addition to the risks to health inequalities associated with data that were highlighted in Box 9, digital inclusion poses particular challenges given inequalities in access to technology and digital literacy, especially in cases requiring patient interaction with new technologies or with a digital interface. It has been estimated that 11.7 million people do not have the essential digital skills needed for day-to-day life in the $\mathrm{UK}^{142}$ and they are more likely to be older, poorer, live with disabilities and need health care services. ${ }^{143}$ Approaches that rely on expensive technologies purchased by patients, such as smartphone symptom checkers, can also present barriers to access. So steps to promote inclusion - for example, user training, or creating user interfaces to suit differing levels of digital literacy - will be important to ensure that the use of digital platforms and tools doesn't exclude particular groups. ${ }^{+}$This will likely require meaningful co-design with people from a range of demographic groups to ensure these technologies meet diverse needs. Furthermore, certain digital technologies may not work well for everyone and some people may prefer a non-digital option, so it is important that accessible and high-quality non-digital alternatives are available where appropriate. The Health Foundation is exploring some of these issues with the Ada Lovelace Institute, as part of a research project examining how the adoption of data-driven technologies and systems during COVID-19 may have affected health inequalities. ${ }^{144}$

\subsubsection{Challenges related to task shifting}

A second set of implementation challenges relates to the fact that automation often involves shifting the performance of a task from a human to a computer. The literature on skill-mix change shows that removing a task from a health care worker who has traditionally performed it and relocating it elsewhere can be tricky, and automation can be looked at as a radical case of skill-mix change. Here we highlight some challenges involved in task shifting, which are relevant for the implementation of automation.

- New ways of working will only be effective if there is consensus around, and ownership of, the new working arrangements. Involving staff in identifying the problems to be tackled and co-designing the solutions can be important steps

According to HEE, digital literacy involves developing the skills to be able to use the technology, and also the right attitudes, values and behaviours needed to thrive in a 'digitally-enabled workplace'.

Interestingly, a 2019 evaluation of Babylon's 'GP at hand' service found users to be predominantly younger, wealthier and healthier than the population as a whole (see Ipsos MORI and York Health Economics Consortium, Evaluation of Babylon GP at hand. Hammersmith and Fulham Clinical Commissioning Group and NHS England; 2019). 
to achieving this, as well as increasing the likelihood that the changes made are the optimum ones. Conversely, particular challenges might arise if there is suspicion about the underlying motivation for work reorganisation - for example, if staff think it is driven by cost-cutting and therefore potentially a threat to care quality. There is also a risk that work reorganisation results in workers feeling their role is being devalued, or creates anxiety about job security, ${ }^{145}$ potentially having a negative impact on staff morale. So it is important that proposals for reorganisation address a recognised challenge and are accompanied by a broader vision of role development, and that the stated reasons for change resonate with the intrinsic motivations of health care staff to deliver high-quality care. The example given in Box 13 highlights the importance of gaining consensus for the successful development and implementation of AI.

\section{Box 13: Predictive analytics for triaging patients in emergency departments}

\section{Barking, Havering and Redbridge University Hospitals NHS Trust (Advancing Applied Analytics 2018-19) \\ The A\&E department at Queen's Hospital in Romford is one of the busiest in the UK, with 240,000 attendees and more than 50,000 admissions a year. While some people present with very serious symptoms, who clearly need to be seen quickly and admitted, and while others are clearly non-urgent, there is uncertainty with regard to a substantial number of patients. Nurses usually only have a short time of around 5-10 minutes to triage patients, which can be challenging when a case is not straightforward.}

Funded by the Health Foundation, this collaboration between Barking, Havering and Redbridge University Hospitals NHS Trust and the Alan Turing Institute aimed to support the triage process by using advanced health analytics to help identify high-risk patients. Drawing on data from over a million health records at the Trust, the project created a risk prediction tool that uses machine learning algorithms to identify the severity of presenting cases, predict the probability of admission and flag three major pathologies - stroke, myocardial infarction and sepsis - when they might be present. As part of this, the team developed a dashboard to capture clinical metrics, demographic information, recent attendance history and free text comments in the electronic record and to present the predictive analysis in visual format.

The tool was then tested in a pilot, at first retrospectively (on completed cases) and then in real time, supervised by clinicians, to assess its usability in everyday practice. The early results have been promising, with the tool increasing triage accuracy, compared to the standard process, by $7 \%$ with regard to over-triaging (over-estimating the urgency of a patient's condition) and $2 \%$ with regards to under-triaging - providing initial evidence that it could be a useful support for A\&E staff during triage. ${ }^{147}$

According to the project team, gaining buy-in at the outset was essential - from nurses and patients, as users of the triage system, and from executive-level sponsors. Gaining support from nurses, in particular, involved providing reassurances that the technology would be deployed to support decision making, rather than replace staff, and that nurses would retain decision-making authority.

While the tool is designed primarily to be used in live clinical settings, the project team is now exploring opportunities to develop a version that can be used as a simulation environment for training staff in triage. In response to COVID-19, the team is also exploring whether the model can be used to help identify which patients with COVID-19 have a high risk of deterioration.

'If you are doing work that involves nurses and patients you need their buy-in right from the start. Executive level sponsorship is also essential.'

Nik Haliasos, project lead 
- Clarity around roles and responsibilities is essential, especially if the task requires team coordination. Without this, task shifting can create confusion about the division of labour and professional responsibilities. This in turn can risk tensions over the ownership of tasks, lead to staff being deployed inappropriately and create inefficiencies - for example, duplication of efforts if work is not fully handed over as intended. ${ }^{148,149}$ So carefully articulated role and task definition is vital to create shared understanding regarding new working arrangements.

- Another challenge is to consider the implications of task shifting for workloads and job quality. While removing tasks from someone's role can potentially free up time, if they are expected to use the time freed up for more demanding or stressful work (for example, overseeing more complex patient caseloads), this could result in increased burnout - unless support is provided to help them meet the demands of their new responsibilities. ${ }^{150}$ Another risk is if task shifting means health care workers have less patient interaction, which could lead to reduced job satisfaction. For example, Verghese observes that monitoring patients using technology can draw clinicians away from the bedside, reducing the opportunity to experience the professional satisfaction that can come from bedside examination. ${ }^{113}$

\subsubsection{Specific implementation considerations for automation}

If embedding technology in care pathways is a challenge, and shifting tasks around is a challenge, and automation combines both of these, then it is reasonable to expect implementing automation to involve many of the considerations outlined above. Beyond this, some specific challenges arise in relation to automation, which we highlight here.

- One challenge is avoiding the loss of skills and confidence among staff who are no longer required to perform certain tasks frequently, and therefore lose opportunities to practise these skills, even though they may still be required in the future. ${ }^{151}$ This de-skilling is often inadvertent; workers can actively contribute to it as they naturally take advantage of and accommodate to innovations in their everyday work. ${ }^{152}$ Health care organisations can help to mitigate this risk through continuing professional development and providing relevant opportunities for workers to practise important skills.

- The handover problem is where reliance on an automated system reduces the ability of staff to know how and when to take back control in the event of system failure or other risks. ${ }^{153}$ This is partly related to the issue of de-skilling highlighted above, but is also a product of the loss of situational awareness by staff, and sometimes also a lack of agreed strategies for taking back control. ${ }^{128}$ For example, Wears, Cook and Perry describe the unexpected failure of an automated drugdispensing unit in an emergency department, which, with no agreed protocol for dealing with such a system failure, gave rise to a serious patient safety risk. ${ }^{154}$ This type of problem can be mitigated with the right planning - anticipating 
vulnerabilities, scenario modelling to help teams imagine different potential eventualities and devising appropriate protocols for what to do when there is a system failure, rather than having to invent such protocols in the moment. ${ }^{155}$

- A third challenge is avoiding automation bias, where humans place excessive faith in the decisions made by automated systems, uncritically following their recommendations. ${ }^{155}$ This can distort professional judgement ${ }^{94}$ - for example, studies show medics' diagnostic accuracy falls when they are simultaneously presented with inaccurate computer-aided diagnoses. ${ }^{156}$ A related phenomenon is 'automation complacency', where those charged with monitoring automated systems fail to pick up on errors as a result of placing too much trust in those systems and failing to challenge their outputs sufficiently. Research suggests that humans monitoring automated systems can be particularly susceptible to this when they have other concurrent tasks. ${ }^{157}$ The requirements of properly overseeing automated systems should therefore be factored into assumptions about staff time 'freed up' through automation.

\section{Box 14: The NASSS framework}

The NASSS framework is a tool developed by Greenhalgh and colleagues ${ }^{158}$ to help inform technology design, implementation and spread, as well as to identify innovations that have a limited chance of large-scale adoption and to retrospectively explain programme failures.

Recognising that failures and partial successes are common with technological innovations, the framework sets out the different factors that influence the adoption, non-adoption, abandonment, spread, scale-up and sustainability of health and care technologies. Based on a systematic review of individual, team, organisational and system influences on the success of technology-supported programmes, the framework (illustrated in Figure 7) consists of 13 questions in six different domains: the condition, the technology, the value proposition, the adopter system, the organisation, and the wider (institutional and societal) context. The framework also includes a seventh domain that considers interactions and adaptations over time. 
Figure 7: The NASSS framework

\section{Embedding and adaptation over time \\ 7A Scope for adaptation over time \\ 7B Organisational resilience}

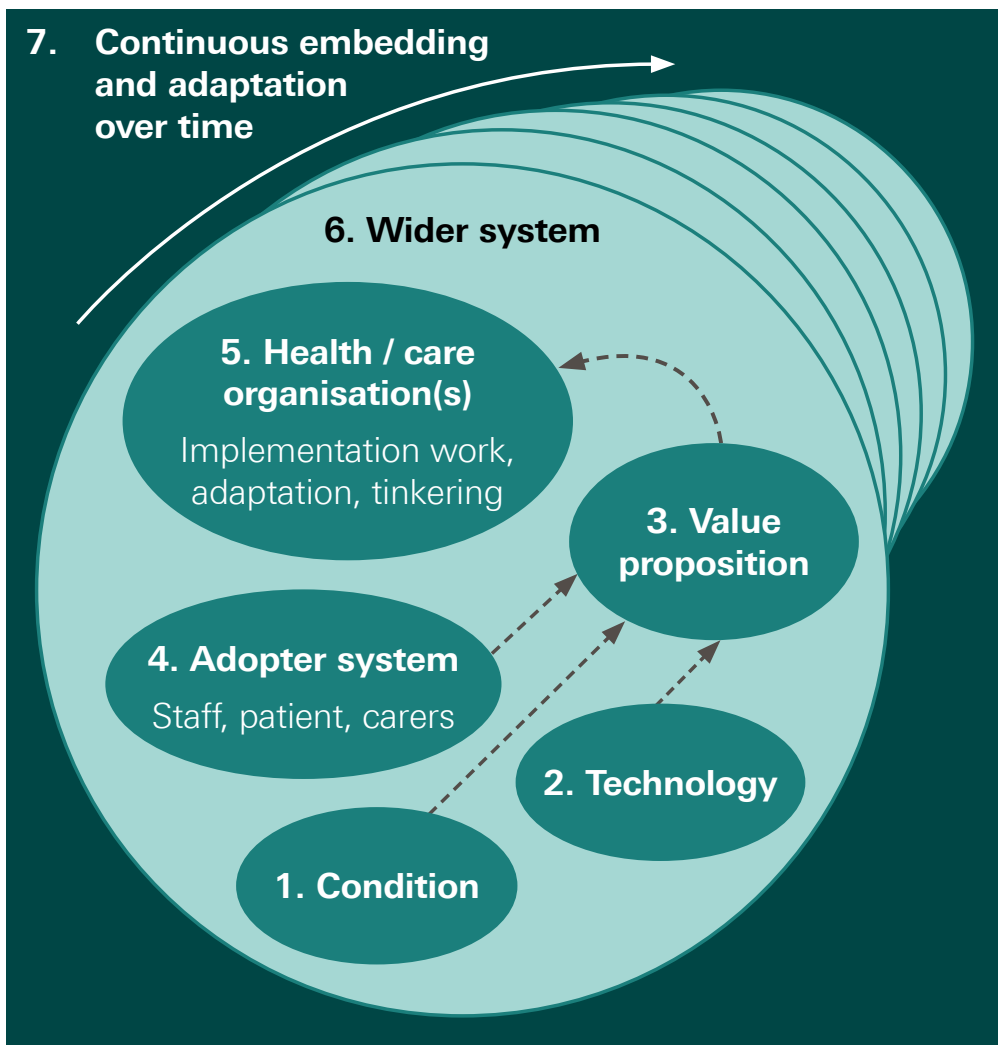

1. Condition

1A Nature of condition or illness

1B Comorbidities, sociocultural influences
2. Technology

2A Material features

2B Type of data generated

2C Knowledge needed to use

2D Technology supply model
6. Wider system

6A Political / policy

6B Regulatory/legal

6C Professional

6D Socio-cultural

4. Adopter system

4A Staff (role, identity)

4B Patient (simple v complex input)

4C Carers (available, nature of input)

3. Value proposition

3A Supply-side value (to developer)

3B Demand-side value (to patient)

Source: Greenhalgh et al.

\section{Box 15: Views of NHS staff on the biggest implementation challenges for automation and $\mathrm{Al}$ in health care}

We used our NHS staff survey to ask about implementation challenges for making automation technologies work on the front line."

Respondents were presented with a list of common implementation challenges and asked to pick up to two they thought would be the biggest challenges for using automation and $\mathrm{Al}$ effectively. The highest ranked challenge was 'Patients might not accept these technologies or be suspicious of them', picked by $45 \%$ of respondents, followed by 'Staff shortages or 
inadequate equipment might make it difficult to use these technologies properly', picked by $39 \%$ of respondents.

\section{Figure 8: NHS staff views on the biggest challenges for making automation technologies work on the front line}

Which one or two of the following do you think will be the biggest challenges for using automation and Al effectively in delivering health care?

Patients might not accept these technologies or be suspicious of them

Staff shortages or inadequate equipment might make it difficult to use these technologies properly

It might require large shifts in culture and ways of working

Staff might resist the use of these technologies and be sceptical of them

It might require a large amount of training for staff and patients

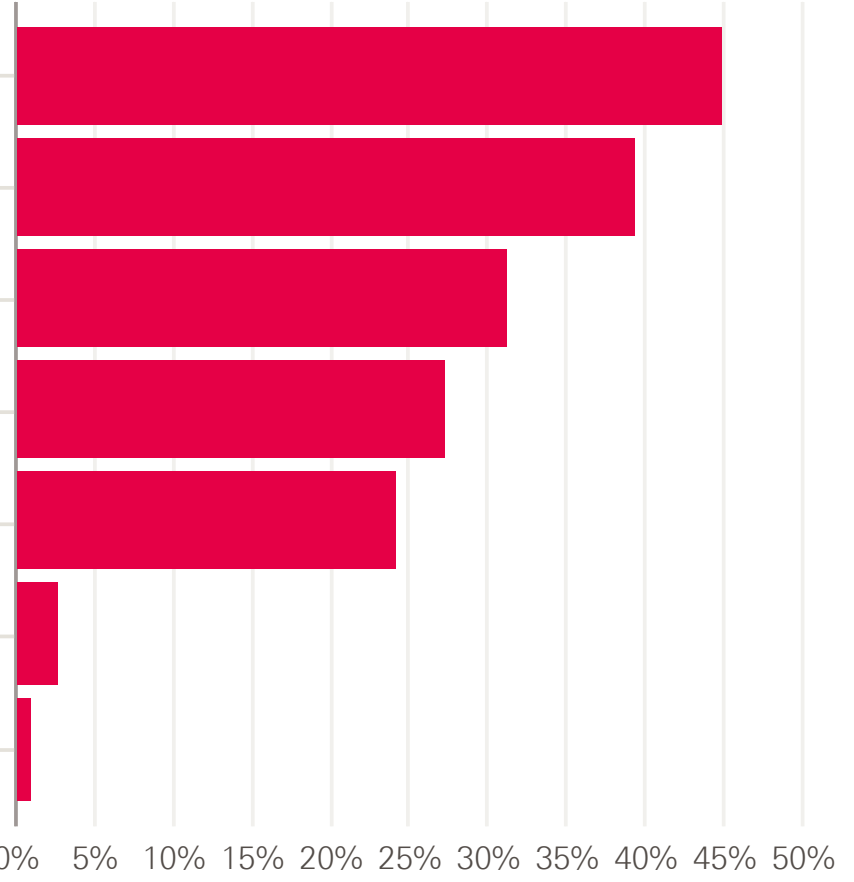

Not applicable - I don't think that there will be any challenges

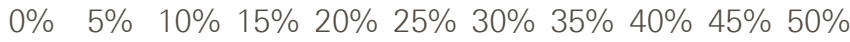

The ranking of challenges was broadly similar across different occupational groups, with patient suspicion being the most highly ranked challenge for all staff groups. Health care assistants were slightly more likely than other staff groups to pick patient suspicion as a challenge (picked by $49 \%$ ). Furthermore, nurses, midwives and health care assistants were slightly more likely to pick staff shortages/inadequate equipment as a challenge (picked by $43 \%$ of these groups).

These results highlight the importance of engaging with patients to ensure support for the use of new technologies - for example, through consultation and co-designing changes as an integral part of the process of adoption and implementation. They also highlight the importance of ensuring sufficient staff capacity to support change and adequate equipment and infrastructure - issues that are discussed further in the final chapter.

Having reviewed some opportunities and challenges for automation and AI in health care, in the final chapter we consider the implications for the future of work and look at what will be required in order to get the automation agenda right in practice. 


\section{Implications for automation and AI in health care}

\subsection{How automation will affect work in health care}

What will automation and AI mean for the future of work in health care? As the analysis in Chapter 3 suggests, and as the Oxford study concluded, it will in many cases be about supporting workers in their roles, rather than replacing them. This is partly because many tasks in health care are not wholly automatable and few occupations consist of wholly automatable tasks. It is also because human agency is such an important factor in health care - so even where tasks could be automated, it does not necessarily follow that they should be. And as we have seen, in many cases where automation is applicable, it tends to change, rather than eliminate, the type of human involvement required. ${ }^{10}$

Some labour market predictions have raised the prospect of widespread redundancies from automation. But in health care it seems that, rather than threatening jobs, automation and AI have, in many cases, the potential to improve the quality of work (and with it job satisfaction) as well as the quality of care - provided, of course, that these technologies are deployed in a way that works for patients and staff. For example, automation could be used to remove some of the burden of repetitive, everyday tasks, allowing staff to focus on those activities where they add most value.

This bears emphasis given that the policy narrative around automation is often focused on improving productivity or compensating for workforce shortages. Health Foundation analysis shows that demand for health care professionals will continue to grow, driven by an ageing population and a growing burden of chronic disease (see Figure 9). ${ }^{159}$ There is hope that new technologies, including automation and AI, could help the NHS increase the volume of care provided and alleviate some of this rising demand by freeing up staff time (though of course technology cannot be the only answer to meeting rising demand, and without adequate staffing it will not be possible to take advantage of new technologies). ${ }^{160}$ But productivity gains will depend on how any staff time released is used, and could emerge in a number of ways. For example, productivity gains could emerge through using time released to improve the quality of existing care, such as allowing longer consultations. On other occasions, time released might instead be used to enable more sustainable management of the current volume of care (for example, by reducing unpaid overtime), which wouldn't necessarily increase productivity, but would still have long-term benefits. And there is also substantial scope for automation and AI to improve the quality of care in ways that do not release staff time, for example through the use of AI-driven clinical decision support systems. 
Figure 9: Future supply of and demand for NHS staff
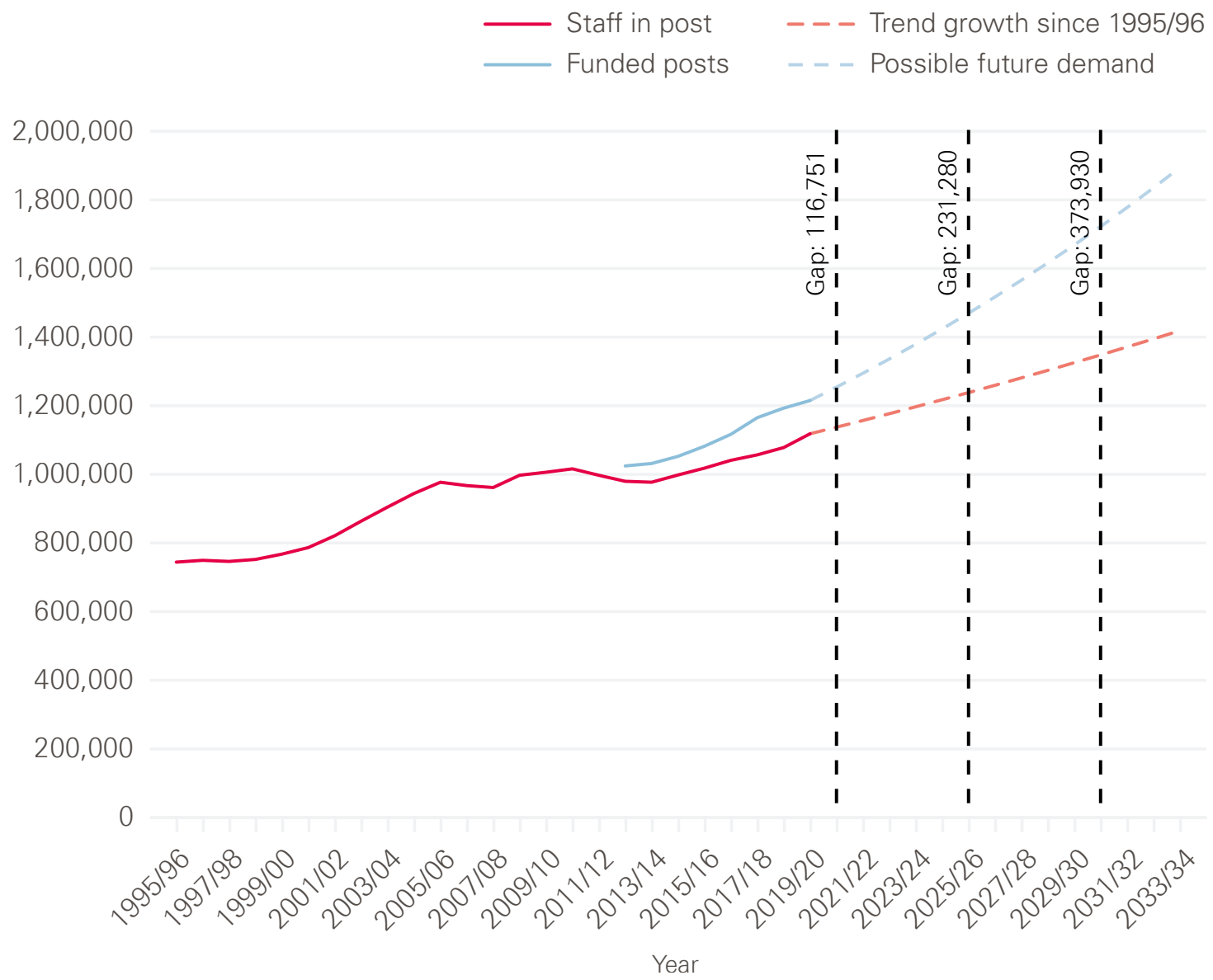

Note: These projections are based on data released up to February 2020 and do not account for any COVID-19 impacts Source: Health Foundation projections, based on workforce data from NHS Digital and HEE

Even where automation and AI are primarily deployed in a supportive capacity, existing roles may nevertheless evolve in response, allowing staff to focus on what humans do best. In the words of David Autor, 'as our tools improve, technology magnifies our leverage and increases the importance of our expertise, our judgement and our creativity'. ${ }^{16}$ For example, the Oxford study found that many of the tasks a GP receptionist typically undertakes are potentially automatable, such as email management and processing prescriptions. Automating these types of task would allow the receptionist role to shift towards more face-to-face interaction with patients, focusing on more complex but also potentially more rewarding aspects of patient management such as coordinating care and helping patients navigate the system. Given the important impact GP receptionists have on patient experience, ${ }^{162}$ using automation to enable them to spend more time with patients could help improve service quality.

Automation and AI will also create new roles to monitor system outputs and ensure technologies are used appropriately. For example, the Oxford study speculates that those roles containing mostly automatable tasks, such as the prescription clerk (a member of the general practice team who processes prescriptions and deals with repeat prescriptions), could subsequently evolve to deploy their skills and knowledge to oversee automated systems. 
As many have argued, it is through the partnership between humans and machines that the greatest benefits will accrue. Brynjolfsson and McAfee, for example, suggest that while AI systems could ultimately become better than humans at performing diagnostic tasks, they will not be able to cover all medical cases, so the partnership between doctor and machine will be 'far more creative and robust than either of them working alone'. ${ }^{17}$ Radiology is one area where automated systems could help improve care, by using AI to analyse medical images quickly, identify potential malignancies (including those that the human eye cannot see) and triage images prior to review by a radiologist. As the Royal College of Radiologists argues, such systems could enable clinical radiologists to increase the scope of their diagnostic capacity, releasing time for direct patient care and research. ${ }^{57}$ If the greatest benefits will come from the partnership between humans and machines, then how health care professions respond to the rise of automation and AI - how they shape new models of working and the extent to which they encourage or discourage change - will be a critical determinant of its impact. 


\section{Box 16: Views of the public and NHS staff on the future role of automation and $\mathrm{Al}$ in health care}

Given expectations that automation and Al will play a greater role in health care in the future, we wanted to ask the public and NHS staff for their views on the future role of these technologies.

First, we asked people if they would like to see more or less use of automation and Al in health care in future, or about the same. In both the public and NHS staff surveys, more respondents said they would like to see more use of these technologies in future $36 \%$ in the public survey and $44 \%$ in the NHS staff survey) than said they would like to see less use of them (21\% in the public survey and $14 \%$ in the NHS staff survey) or about the same (24\% in the public survey and $26 \%$ in the NHS staff survey).

This is also an area where familiarity with the topic had a clear impact. Among members of the public who said they had heard, read or seen a lot or a fair amount about automation and Al in health care, $61 \%$ said they would like to see more use of these technologies in future, with just $15 \%$ wanting to see less; among the equivalent group of NHS staff surveyed, $64 \%$ said they would like to see more use of these technologies in future, with just $12 \%$ wanting to see less.

\section{Figure 10: Views of the public and NHS staff on the future use of automation and $\mathrm{Al}$ in health care}

How much more or less would you like to see automation and Al used in health care in the future, or would you like to see about the same amount?*

Net: More Net: Less

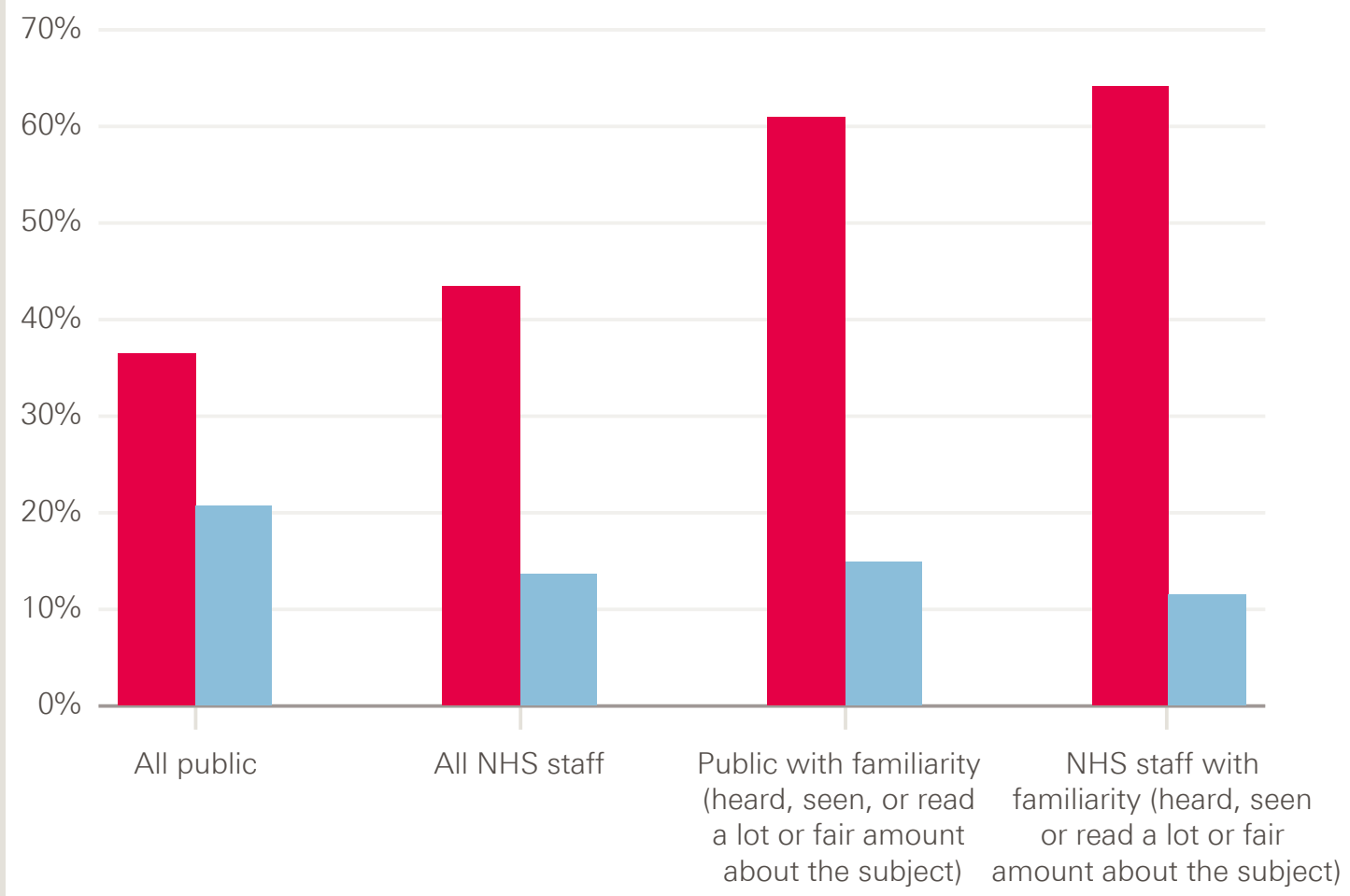

Second, we asked people how they thought automation technologies might impact on the nature of work in health care and the future roles of health care professionals.

The public survey asked people if they thought machines would ever replace doctors and nurses. The answer was a clear 'no', with $87 \%$ saying no and just $5 \%$ saying yes.

'Net more' is a combination of the two response categories, 'much more' and 'a little more'. 'Net less' is a combination of the two response categories 'a little less' and 'much less'. 
The NHS staff survey asked respondents to choose between two contrasting statements, one suggesting the primary impact of automation and Al would be positive for health care workers (improving the quality of work by supporting them and enhancing their capabilities) and one suggesting the primary impact would be negative (threatening jobs and status as technologies replace humans in an increasing number of areas of health care). More chose the positive statement than the negative, by $45 \%$ to $36 \%$, and this margin increased to $57 \%$ to $32 \%$ among those who said they had heard, seen or read a lot or a fair amount about this topic.

\section{Figure 11: Views of NHS staff on the main impact of automation and $\mathrm{Al}$ in health care}

If you had to choose, which one of the following statements comes closer to your view?
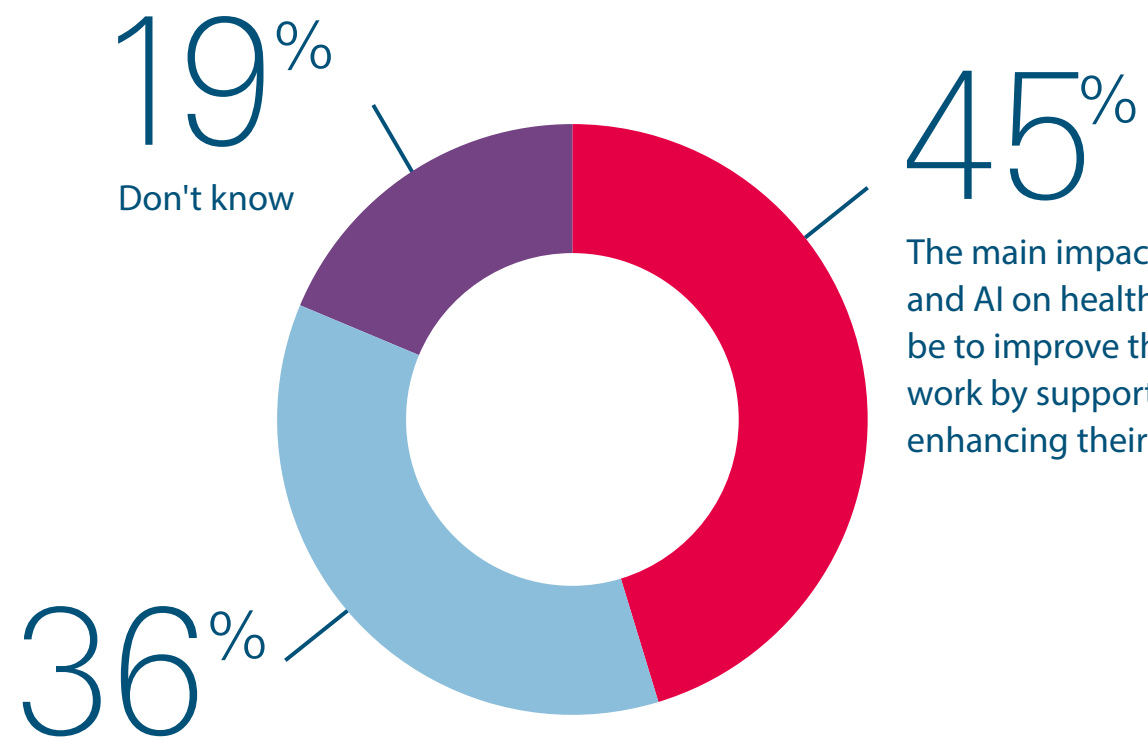

The main impact of automation and $\mathrm{Al}$ on health care workers will be to improve their quality of work by supporting them and enhancing their capabilities

The main impact of automation and $\mathrm{Al}$ on health care workers will be to threaten jobs and professional status as these technologies replace humans in an increasing number of areas of health care

Nevertheless, there were some contrasts in responses between occupational groups, highlighting the fact that automation and Al may have different impacts for different occupations. For example, the medical and dental staff surveyed opted for the statement that automation and Al would improve the quality of work by a margin of 23 percentage points $(51 \%$ to $28 \%$ ), while for nurses and midwives this margin was just 11 percentage points (48\% to $37 \%$ ), and by contrast health care assistants opted for the statement that automation and $\mathrm{Al}$ would threaten jobs and status by a margin of 4 percentage points (41\% to $37 \%$ ). In managing the impact of automation and $\mathrm{Al}$ on the health care workforce, and helping workers to adapt to the impact of these technologies, it will be important to be aware that the impact may be different for different occupational groups, and mindful of the social inequalities that could be created or exacerbated as a result - in terms of how this impact may differ by gender, ethnicity and socioeconomic status.

Despite these differing views about the potential impact of automation and $\mathrm{Al}$, it is worth noting that in all occupational groups more respondents surveyed said they would like to see more use of automation and $\mathrm{Al}$ in future rather than less - for example medical and dental staff by $53 \%$ to $9 \%$, nurses by $42 \%$ to $17 \%$ and health care assistants by $32 \%$ to $19 \%$. So trepidation about the potential impact of these technologies on the future of work by no means translates into blanket opposition to them. 


\subsection{Perceptions of the benefits and risks of automation and $\mathrm{AI}$ in health care}

While there are many potential benefits from different applications of automation and $\mathrm{AI}$ in health care, a range of risks and challenges also need to be overcome. Some of these risks relate directly to the technology itself or the data being used, such as risks concerning data protection, data bias and 'black box decision making', while others relate to the effective deployment of technologies, such as redesigning workflows, training staff and ensuring safety.

We used our survey to explore UK public and NHS staff views of the benefits and risks of automation and AI, including some of those highlighted in earlier chapters.

Respondents were presented with a list of commonly cited benefits of automation and AI in health care and asked to pick up to three they thought were the biggest benefits. In both the public and NHS staff surveys the top three benefits chosen were the same: greater efficiency/freeing up staff time (picked by $40 \%$ in the public survey and $37 \%$ in the NHS staff survey), followed by quicker results/service (32\% in the public survey and $35 \%$ in the NHS staff survey) and enabling more accurate tests/treatment (23\% in the public survey and $24 \%$ in the NHS staff survey). The pattern of responses was broadly similar across different NHS occupational groups. 
Figure 12: Views of the public and NHS staff on the benefits of automation and Al in health care

Which, if any, of the following do you think are the main benefits of using automation and $\mathrm{Al}$ in health care?

All public All NHS staff

Makes things more efficient and frees up doctors and nurses to care for patients

Provides quicker results and service

Enables more accurate tests and treatment

Helps the NHS identify which patients are most in need of care

Not applicable - I don't think there are any benefits in particular

Enables health care to be better tailored to each patient's needs

Helps the NHS understand how it is performing and how it can improve

Empowers patients to manage their own health

Other

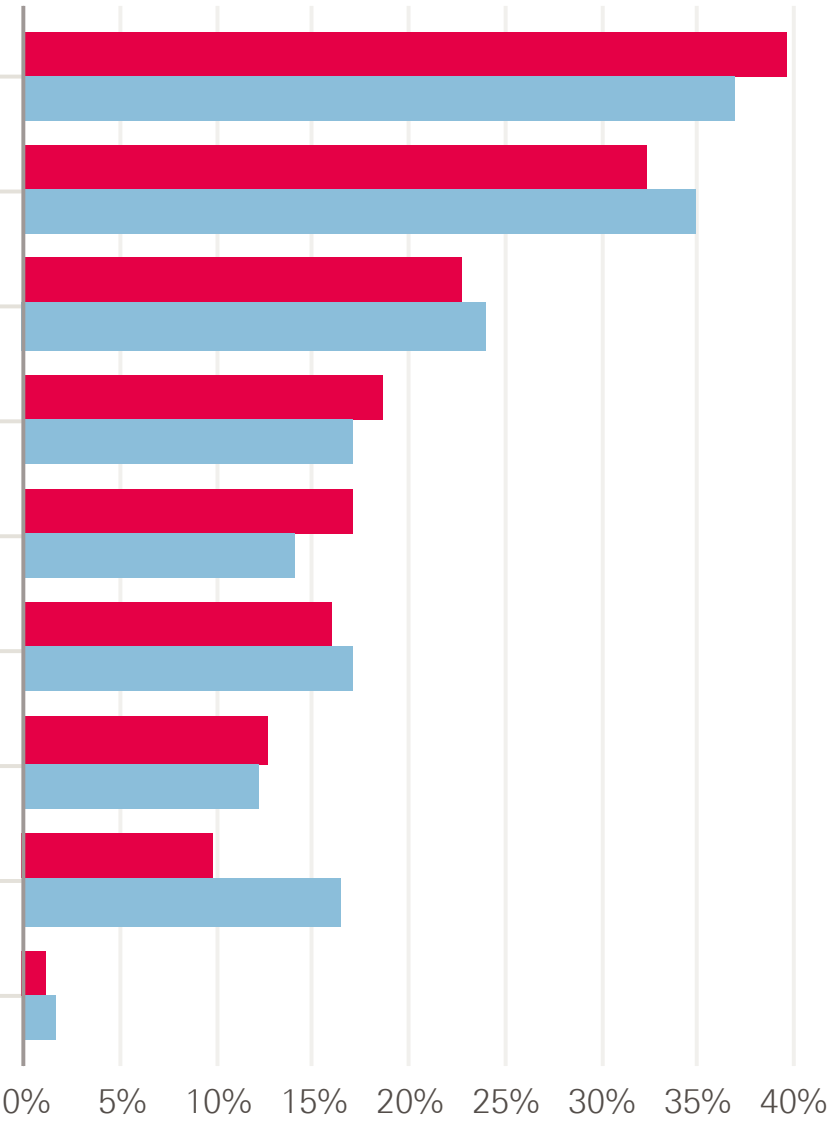

Similarly, respondents were presented with a list of commonly cited risks of automation and $\mathrm{AI}$ in health care and asked to pick up to three they thought were the biggest risks. For the public, the biggest risk was that 'Health care will become more impersonal, with less human contact' (picked by $45 \%$ ), followed by 'Health care professionals won't question the decisions computers make, creating risks to patient safety' (picked by $44 \%$ ) and 'It will be hard to know who's accountable when things go wrong' (picked by $32 \%$ ). The top two risks chosen by NHS staff surveyed were the same, with loss of human contact picked by $51 \%$ and failure to question computer decisions picked by $42 \%$. The third ranked risk, picked by $39 \%$ of staff surveyed, was that 'These technologies might not work properly and might end up creating more work for staff'.

Again, the pattern of responses was broadly similar across different NHS occupational groups, with a few specific differences. For example, more medical and dental staff were concerned about technology not working or creating more work (which they ranked as the second biggest risk after loss of human contact) than were concerned about the failure to question computer decisions (which they ranked third). Also, slightly more nurses, 
midwives and health care assistants were concerned about the potential loss of human contact than with other occupational groups, with $55 \%$ from each group picking this as one of the biggest risks.

\section{Figure 13: Public and NHS staff views of the risks of automation and Al in health care}

Which, if any, of the following do you think are the main risks of using automation and $\mathrm{Al}$ in health care?

Health care will become more 'impersonal', with less human contact

Health care professionals won't question the decisions computers make, creating risks to patient safety

It will be hard to know who's accountable when things go wrong

These technologies might not work properly and might end up creating more work for staff

Health care professionals will lose important skills because they won't have to use them anymore

These technologies might work better for some groups of patients than others, creating or widening inequalities

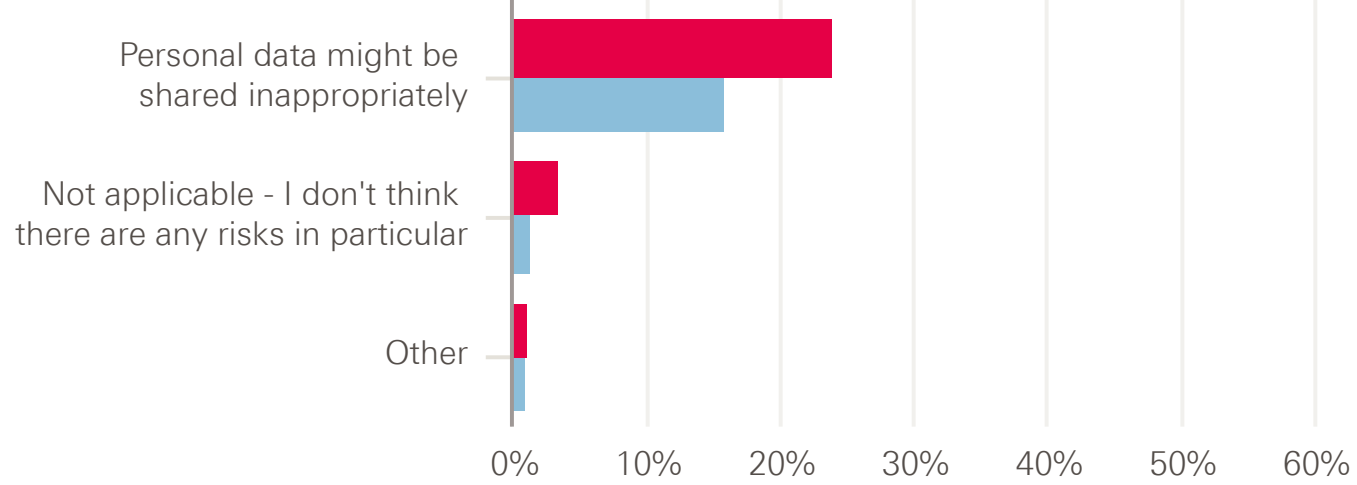

These findings echo the results of other surveys, including those cited in Chapter 1, that one of the biggest concerns about the use of these technologies in health care is the potential loss of human interaction. So it will be important to ensure automation and AI in health care are developed and used in ways that protect important clinician-patient interactions and are mindful of patient preferences. The survey responses also show that the phenomenon of automation bias (the failure to question computer decisions), a common theme in the academic literature, is a real concern for both patients and health care workers, and highlights the need to ensure strategies are in place to avoid it. Interestingly, 
despite some well-publicised controversies in recent years about the protection of personal data in health care, the risk that 'Personal data might be shared inappropriately' ranked lowest as a concern in both surveys.

It's also worth noting that a sizeable minority of both the public (17\%) and NHS staff surveyed (14\%) said they did not think there were any benefits to using automation and $\mathrm{AI}$ in health care, while very few respondents said there weren't any risks ( $3 \%$ in the public survey and $1 \%$ in the NHS staff survey). This suggests there may be a small segment of the population who are particularly sceptical about the use of these technologies in health care, and who it will be important to engage in attempting to build public confidence.

Finally, in addition to exploring views on the potential benefits and risks of automation and AI in health care, we also wanted to investigate how people weigh the benefits against the risks. All respondents who identified at least one benefit and at least one risk in response to the questions above were asked whether the benefits outweighed the risks or vice versa.

Opinion is balanced on this issue, with majorities of both the public (51\%) and NHS staff (59\%) saying the benefits and risks are 'finely balanced'. And among the remainder of respondents, in both the public and NHS staff surveys, the numbers saying the benefits outweigh the risks (23\% in the public survey and $16 \%$ in the NHS staff survey) were only marginally bigger than the numbers saying the risks outweigh the benefits (17\% in the public survey and 15\% in the NHS staff survey). Interestingly, this was an issue where greater knowledge or familiarity with the topic made less difference: majorities of those who said they had heard, seen or read a lot or a fair amount about automation and AI also said the benefits and risks are finely balanced (50\% in the public survey and $58 \%$ in the NHS staff survey).

\section{Figure 14: Views of the public and NHS staff on the balance of benefits and risks of automation and $\mathrm{Al}$ in health care}

Which one, if any, of the following statements comes closest to your view?

The benefits of automation and Al in health care generally outweigh the risks

- The benefits and risks of automation and $\mathrm{Al}$ in health care are finely balanced

- The risks of automation and Al in health care generally outweigh the benefits

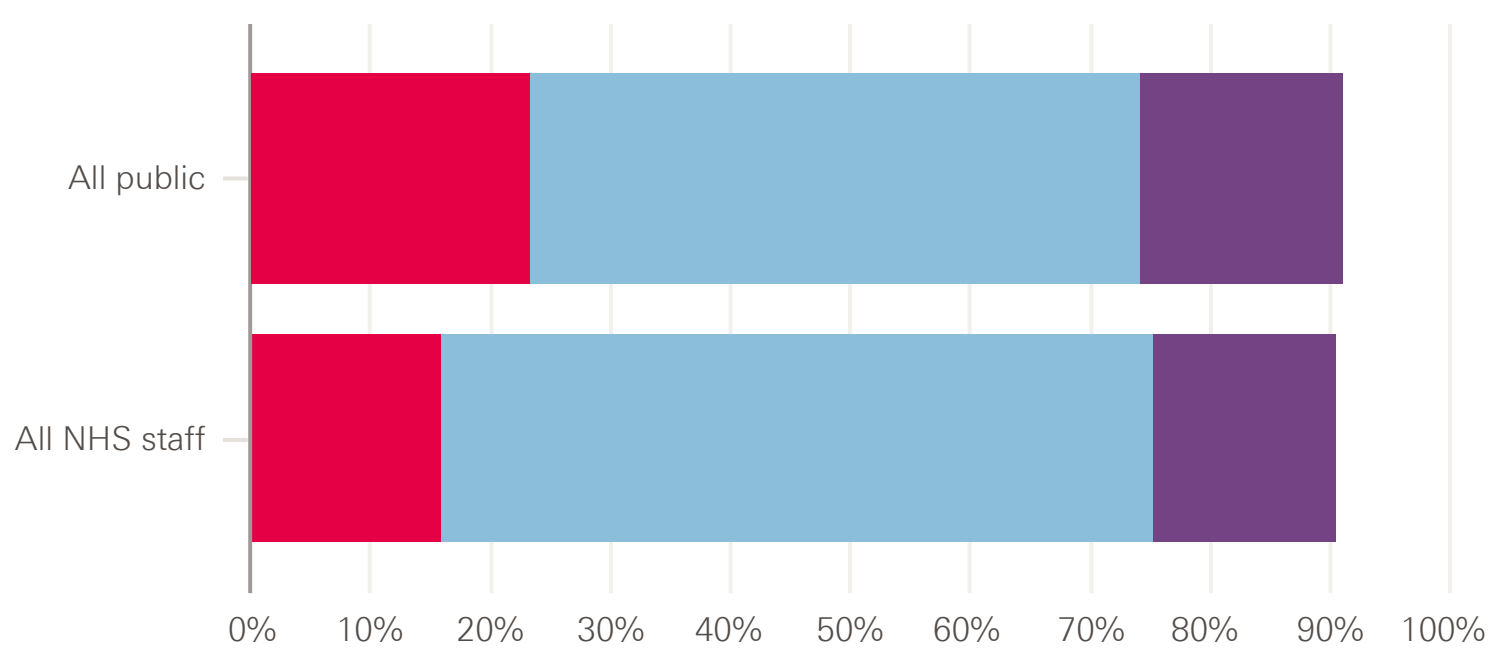


This not only highlights the importance of attending to the risks of automation and AI and developing ways of mitigating and managing them, but also of ensuring that the public and NHS staff have confidence in the oversight and regulation of these technologies and the systems in place to manage these risks.

\subsection{Considerations for policymakers, organisation and system leaders, and practitioners}

There is clearly significant potential for automation and AI to improve health care. But success will depend on how this agenda is taken forward in practice. Here we highlight some key considerations for various groups, including policymakers, practitioners, and organisation and system leaders (including leaders in providers, health boards, integrated care systems, and regional and national bodies).

\subsubsection{Key considerations for the design and implementation of automation technologies}

In Chapter 3, we saw that the effective use of automation and $\mathrm{AI}$ in health care poses some important design and implementation challenges. Given that the introduction of a new technology into a live health care environment creates new risks (including risks to patient safety), a sophisticated approach to design, implementation and use with safety at its core will be essential. And because the full benefits of a new technology will only come from successfully embedding it into health care settings and pathways, it is crucial that support is in place to ensure the effective implementation and use of technologies in practice. This is particularly important to remember in light of the speed with which some technologies have been rolled out and implemented during COVID-19; while this speed has been impressive, it also makes it more likely that teams and organisations will need to revisit, evaluate and improve the use of these technologies in order to ensure they are being used safely and effectively and to maximise their benefits over the long term.

\section{Considerations for designers and evaluators}

- Given the importance of human agency in health care it is critical that automation technologies are designed and used in ways that support and do not undermine person-centred care, and treat patients with dignity and respect. Our survey showed that the potential loss of this human dimension was a strong area of public concern. Further research is needed on public and staff attitudes here, as well as on the range of ethical and quality issues that automation and AI present, in order to better understand where some of the boundaries lie in how these technologies should and should not be used in health care. And there should be proper emphasis in the evaluation of these technologies on assessing factors such as acceptability, feasibility and impact on patient experience.

- Where technologies are patient-facing, it is essential that designers work with a wide range of patients to identify and define their needs, and co-design solutions to meet those needs. Various resources exist to help to ensure service design is rooted in a deep understanding of the needs of citizens, such as the Scottish 
Approach to Service Design. ${ }^{163}$ Given the need to address health inequalities and make sure health technologies work well for all, designers will need to engage with and use data from a broad and diverse sample of potential users and consider the impact of new technologies on those who face particular challenges or barriers.

- If benefits only emerge from successfully embedding new technologies into live work environments, then it is important to recognise that those designing health care technologies are also potentially designing and shaping roles, pathways and workflows. It is therefore important that technology designers work closely with health care staff to understand what they want, what will work and what will make their lives easier; otherwise, there will be a risk of poor fit between the technology, the needs of staff and the realities of the work environment. This should be a key focus for programmes supporting the development of new technologies, such as relevant Accelerated Access Collaborative programmes. Academic Health Science Networks (AHSNs) as well as bodies representing staff groups can play an important role here in facilitating dialogue and collaboration between industry and NHS staff. Technologies need to be capable of being customised and adapted to changing work environments and designed in ways that enable staff to take back control from them when situations require it. ${ }^{164,154}$

- The success of a technology depends on how well it performs in live health care settings, not the laboratory. ${ }^{*}, 155$ Problems will arise if design assumptions don't reflect the complexity of the work environment in which the technology will be used. So testing and evaluation in high-quality simulation environments and real-world settings is essential before concluding that technologies are safe and effective. ${ }^{\dagger}, 165$ The necessity of real-world testing was highlighted in the Long Term Plan in England, and it is important that the NHS continues to expand the infrastructure and funding available for real-world testing and evaluation, including through initiatives such as the Test Beds programme, NIHR's Applied Research Collaborations and the Improvement Analytics Unit (a partnership that evaluates complex local initiatives in health care in order to support learning and improvement). A range of helpful guidance is also available to help innovators understand the evidence required for new technologies by the NHS, including the DHSC's Guide to good practice for digital and data-driven health technologies and NICE's Evidence Standards Framework for Digital Health Technologies. ${ }^{166,167}$

\section{Considerations for organisational leaders and those responsible for implementing change}

- Successful adoption of automation and AI technologies may well require pathway redesign and the creation of new roles, processes and ways of working. So it is necessary to consider the 'human infrastructure' and processes required for the safe and successful operation of these technologies as well as the technical infrastructure. Staffing requirements are likely to be higher during initial implementation as staff will need time and space for changes to be tested and

Validation of individual device design is not enough to understand performance in context.

Landman $A B$ et al. describe the different ways in which simulation environments can be used to develop and test health care technologies. ${ }^{165}$ 
iterated, and for new ways of working to evolve and bed in. Quality improvement skills and knowledge of methods such as Plan-Do-Study-Act cycles and simulation models can be particularly helpful for the effective implementation of new technologies. ${ }^{168}$

- Successful adoption requires training to equip staff to use new technologies safely and to their full potential, which in turn entails dedicated resources and staff time. Where automation technologies supplement or replace humans in performing specific tasks, it may also be necessary to ensure that staff still have opportunities to practice and develop important skills, in order to avoid de-skilling. This is important not only to ensure that staff have the capability to take over if an automated system fails, avoiding the 'handover problem' discussed in Chapter 3, but also to handle situations that may not be suitable for automation.

- $\quad$ Successful adoption will rely on the support of those expected to use new technologies. This will require making the case for changes and co-designing them with patients and staff as an initial stage of any implementation plan. Without support for the use of automation, and ownership of new working arrangements, there is a risk that patients and staff end up being sceptical of or even rejecting these technologies, potentially because legitimate concerns have not been addressed. Indeed, in our survey of NHS staff, the risk that patients might not accept automation technologies or be suspicious of them was viewed as the biggest of several possible implementation challenges. Various resources are available that can support this process, such as the Health Foundation's Using communications approaches to spread improvement. ${ }^{169}$

- Organisational leaders have an important role to play in creating a culture and environment conducive to implementing new technologies. This includes engaging with their workforce to build a shared vision around technologyenabled care, and setting out how new uses of technology align with wider organisational strategies and values. It might also include facilitating collaboration across teams and specialisms, such as finance, clinical governance, technology and innovation, public and patient engagement, HR and procurement.

\section{Considerations for policymakers and system leaders to support implementation}

- Policymakers and system leaders need to fund 'the change', not just 'the tech'. The implementation issues highlighted earlier (training, engagement, testing, evaluation, etc.) have resource implications and highlight the potential gap between the costs of the technology itself and the total costs required to adopt and use it effectively. It is therefore important that centrally-led programmes driving the uptake of automation and AI factor in these costs. More generally, the forthcoming multi-year spending review and the next stage of national workforce strategies should explicitly address the workforce, skills and infrastructure needs of the NHS in order to exploit new and established technologies successfully over the long term. 
- While support has historically often been provided to more advanced, 'digitally mature' organisations leading innovation, such as the Global Digital Exemplars programme, it is also critical to support organisations lower down the curve to build the infrastructure and capability that they need to be able to deploy automation and AI effectively. In England, NHSX's Digital Aspirant programme is a step in the right direction, though an enhanced and more regular central funding stream will be needed to bring digital maturity across the NHS up to an adequate level.

- Policymakers should ensure the right incentives and payment models are in place to support the development, testing and adoption of technologies at a local level. Without this, health care providers may not see automation and AI projects as financially viable and therefore be reluctant to support them, particularly in relation to technologies for which there is not yet widespread evidence to demonstrate financial benefit. In exploring new payment approaches, NHS England and NHS Improvement should consider models that support the upfront costs associated with adopting and implementing innovations - such as costs that arise from backfilling staff time, redesigning pathways and providing training, which are generally not covered by current payment models.

- Policymakers and professional bodies need to ensure that education and training for both clinical and non-clinical professions provides the knowledge and skills health care workers will need in future to use automation and AI technologies safely and effectively and supervise their operation. There is an important role for HEE, including through its Digital Readiness Programme and Health and Care Digital Capabilities Framework, as well as for the royal colleges in raising awareness and leading the development of these capabilities within the NHS. This may also help address the scepticism that our poll showed some NHS staff hold towards automation and AI. In addition, given that many of these technologies are data driven, there should also be recognition of the importance of analytical capability within the NHS, with support for the recruitment and training of skilled analysts. ${ }^{170}$

- Given the importance of building support around new proposals for automation, policymakers and system leaders need to promote the automation agenda in a way that helps generate support for it. In particular, while some automation technologies hold out the prospect of cost reductions, it would be a mistake to describe automation primarily in these terms. This is not only because staff and patients may resist such changes if they see them as driven by funding pressures or workforce shortages, but also because the gains these technologies offer for care quality, patient experience and staff experience are likely to resonate more deeply with the intrinsic motivations of those who work in and use the NHS. 


\subsubsection{Key considerations for automation strategy}

The European Commission's 2019 report The future of work noted that 'automation outcomes are not pre-determined and will be shaped by the policies and choices we make'. ${ }^{26}$ The Health Foundation's recent work on Shaping Health Futures highlights how major developments such as automation can be shaped with the right long-term planning and preparation. ${ }^{1}$ Policymakers and system leaders will need to scan the horizon for developments and opportunities, engage with the public, the NHS workforce and industry to shape the development of automation and AI, and plan for the future deployment of these technologies, ensuring it is supported with appropriate investment.

\section{Considerations for policymakers and system leaders in developing automation strategy}

\section{- It is important that policymakers and system leaders have realistic} expectations for the automation agenda. Health care is a complex, adaptive system. Problems cannot necessarily be fixed by a 'nice and clean' technological intervention; rather, technology will be one part of a wider sociotechnical solution. ${ }^{139}$ Furthermore, given the range of implementation challenges that exist, it is not surprising that, as the 2016 Wachter Review observed, deriving the full benefits of new technology can take time - in some cases several years. ${ }^{29}$ So while there will understandably be hope that new technologies can help the NHS meet the unprecedented demand pressures it will face over the coming years, there will also need to be realism about the timescales needed for quality and productivity gains to materialise (and expectations may need to be tempered further given the constraints posed by financial and workforce pressures, as well as the need to support staff recovery from the impact of COVID-19). On the other hand there could be opportunities for imminent gains from more established technology programmes that may now be maturing. So it will be important for the NHS to have strategies in place for getting the most out of existing and recently adopted technologies such as RPA, as well as supporting the development of new technologies like AI.

- $\quad$ Considering the ethical, safety and quality issues that arise from the use of automation and $\mathrm{AI}$ in health care, as new technologies are developed and tested it is important that government engages with patients, staff and society as a whole to inform decisions about where these technologies should and shouldn't be used. This will be particularly important given that public opinion is currently divided on whether automation and $\mathrm{AI}$ in health care are a good thing or a bad thing, and that a majority think the benefits and risks are 'finely balanced'.

- Given the nascent state of AI within health care, policymakers and research funders should provide long-term support to build the evidence base required for these technologies to be deployed in the NHS on a wider scale. A variety of important work is also underway to explore the specific requirements of evaluating and reporting evidence around applications of $\mathrm{AI}$ in health care, including the SPIRIT-AI and CONSORT-AI initiatives, designed to improve the transparency and completeness of reporting of clinical trials of interventions involving AI. 
As NICE will have an important role to play in assessing evidence and producing guidance on these technologies, it should also review health technology evaluation methods to ensure these are appropriate for $\mathrm{AI}$ and automation.

- The regime of regulation, standards and assurance will need to be developed and strengthened to address challenges such as bias, transparency and accountability - particularly in relation to autonomous decision making and to ensure that automation and AI technologies are safe, effective and ethical. As the AI Council's AI Roadmap notes, better regulation and standards, along with public engagement and transparency, will also help to build public trust and confidence in AI. ${ }^{52}$ As guides, frameworks and initiatives are developed, such as the DHSC's Guide to good practice for digital and data-driven health technologies and the AI Ethics Initiative, the critical challenge will be to ensure that principles and standards are translated into action, something that should be an important focus for government, regulators, royal colleges and the NHS.

- Most automation technologies are developed commercially, putting a premium on ensuring the health technology 'ecosystem' works in the interests of the NHS. Policymakers and system leaders should proactively work to influence the development of new technologies so they meet the priorities of the NHS, rather than simply allowing development to be shaped by the market. As part of this, the NHS can do more to identify its priorities for technology development and signal them to industry. Building on the ambitions outlined in the NHS Long Term Plan in England, this includes strengthening the role of NHS bodies in horizon scanning, aggregating intelligence and creating appropriate links across the NHS-industry interface to support technology development and testing. There also needs to be more emphasis on developing and adopting applications of technology that can support the NHS with administrative tasks that pose a significant burden, such as resource management and letter work. Technologies for these kinds of everyday tasks don't steal the headlines in the same way as cutting-edge medical technologies but could make a huge difference in freeing up staff and helping to address current pressures.

- $\quad$ Automation and AI will have important consequences for many occupations in health care. Some occupations will no longer need to do particular tasks that are wholly automatable, resulting in role changes - and in some cases the redeployment of staff to other work. More commonly, these technologies will expand the abilities of staff and provide an opportunity to redesign roles and improve job quality, as well as creating new roles. Workforce strategy and planning, and curriculum development, will therefore need to take into account the growth and impacts of automation and AI, including the impact on health care workers. Given the differing impact these technologies are likely to have on different occupational groups, it will be important that this includes a vision of role development for those groups most likely to be affected by the adoption of new technologies, along with actions to avoid automation entrenching and widening social inequalities across the NHS workforce. 
- The extent to which the potential of automation is realised will depend on whether health care professions and all parts of the health care workforce see it as an opportunity or a threat and how they respond. While it is easy to look at professions as 'indivisible lumps of endeavour' that will either be affected wholesale or not at all, the reality is that automation will impact on all professions and occupational groups on a task basis and provide an opportunity to redesign roles and in some cases develop new ones. ${ }^{172}$ In this respect, we believe health care professions should see automation as an opportunity, not a threat. The benefits of automation will be maximised if professions and health care workers are supported to adapt to technological change, to focus on where human abilities add most value, while ensuring care quality is protected. Examples of professional bodies that are engaging with the automation agenda include the Royal College of General Practitioners through its Tech Manifesto and the Royal College of Radiologists, which has issued a position statement on $\mathrm{AI}$ and is producing guidance for members to help them understand the potential role for $\mathrm{AI}$ in future clinical practice.

- While national health policies are keen to take a 'digital first' approach, there is a risk, highlighted in Chapter 3, that automation and AI technologies will create or widen health inequalities. So digital health policy must be as inclusive as possible, catering to the needs of diverse patient groups, supporting patients with the skills to access and use digital services, and ensuring that those who need to, or would prefer to, can access non-digital options in a way that doesn't exclude them from receiving high-quality care. ${ }^{173}$ More generally, policymakers and NHS leaders must ensure new technologies promote 'levelling up' on health rather than creating or widening health inequalities. This means evaluating the effects of new applications of automation and $\mathrm{AI}$ and taking actions to avoid or mitigate negative impacts for particular groups. It also means being much more proactive in identifying applications of technology that can reduce health inequalities and supporting their development and deployment in practice. 


\subsection{Conclusion}

In this report we have looked at a variety of opportunities and challenges for automation and $\mathrm{AI}$ in health care, including drawing on learning from the Health Foundation's programmes and research - particularly a recent study by the University of Oxford of the automation of administrative tasks in primary care - as well as a wide range of other academic studies. In doing so, it has been our intention not only to describe some of the major areas of application of automation and AI to health care but also to explore the challenges, constraints and practical reality of making these technologies work on the ground: to move beyond just considering their potential, to engaging with what it will take to realise long-term benefits for all parts of the health and care system.

Underlying much of the analysis is the fact that health care, and work in health care, is different from other sectors of the economy - particularly manufacturing, from which much automation thinking has developed. Health care is a service, co-produced with patients and families, not a product. Among other things, this means that health care always has a human dimension, that work in health care can be responsive and dynamic, and that tasks can be complex and unpredictable. This in turn means that the logic of automation applied to health care will be different to that applied in manufacturing and other sectors, often supporting rather than replacing workers.

There will be many exciting opportunities to apply automation and AI in health care in order to improve quality of care for patients and quality of work for staff. But, as this report has highlighted, we should also be mindful of the possible constraints on the application of these technologies in health care and the work required to realise the benefits in practice. 


\section{References}

1. Cameron G, Alderwick H, Bowers A, Dixon J. Shaping Health Futures: Preparing for tomorrow's possibilities today. The Health Foundation; 2019 (www.health.org.uk/publications/reports/shaping-health-futures).

2. Willis M, Duckworth P, Coulter A, Meyer ET, Osborne M. Qualitative and quantitative approach to assess the potential for automating administrative tasks in general practice. BMJ Open. 2020; 10:e032412.

3. Willis M, Duckworth P, Graham L, Osborne M, Meyer ET, Coulter A. The Future of Healthcare: Computerisation, Automation and General Practice Services. University of Oxford; 2020 (https://bit.ly/foh-report-jun2020).

4. Encyclopaedia Britannica [webpage]. Automation. Encyclopaedia Britannica; 2020 (www.britannica.com/ technology/automation).

5. International Society of Automation. What is Automation? [webpage]. International Society of Automation; 2020 (www.isa.org/about-isa/what-is-automation).

6. McKinsey Global Institute. A Future that Works: Automation, Employment, and Productivity. McKinsey Global Institute; 2017 (www.mckinsey.com/featured-insights/digital-disruption/harnessing-automation-for-a-future-that-works).

7. Office for National Statistics. Which occupations are at highest risk of being automated? ONS; 25 March 2019 (www.ons.gov.uk/employmentandlabourmarket/peopleinwork/employmentandemployeetypes/articles/ whichoccupationsareathighestriskofbeingautomated/2019-03-25). IBM. Apply intelligent automation to your operations. IBM; 2020 (www.ibm.com/automation/automationintelligence).

9. Stanford University. Artificial Intelligence Index 2017 Annual Report. Stanford University; 2017 (www.aiindex. org/2017-report.pdf).

10. House of Commons Science and Technology Committee. Robotics and artificial intelligence: Fifth Report of Session 2016-17. House of Commons; 2016 (https://publications.parliament.uk/pa/cm201617/cmselect/ cmsctech/145/145.pdf).

11. Jarrahi M. Artificial intelligence and the future of work: human-ai symbiosis in organizational decision making. Business Horizons. 2018; 61(4).

12. Wang D, Khosla A, Gargeya R, Irshad H, Beck A. Deep learning for identifying metastatic breast cancer. arXiv. 2016 (https://arxiv.org/pdf/1606.05718.pdf).

13. Adidas's high-tech factory brings production back to Germany. The Economist; 14 January 2017.

14. Oxford Economics. How robots change the world: What automation really means for jobs and productivity. Oxford Economics. 2019 (www.oxfordeconomics.com/recent-releases/how-robots-change-the-world).

15. MIT interview with David Mindell.

16. Dellot B, Wallace-Stephens F. The Age of Automation: Artificial intelligence, robotics and the future of low-skilled work. Royal Society for Arts, Manufactures and Commerce; 2017.

17. Brynjolfsson E, McAfee A. The Second Machine Age: Work, Progress, and Prosperity in a Time of Brilliant Technologies. W.W. Norton \& Company; 2014.

18. Novek J. Hospital pharmacy automation: Collective mobility or collective control? Soc Sci Med. 2000; 51(4):491-503.

19. Dahl T, Boulos M. Robots in health and social care: a complementary technology to home care and telehealthcare? Robotics. December 2013; 3(1): 1-21.

20. New surgical robots are about to enter the operating theatre. The Economist; 16 November 2017.

21. Harwich E, Laycock K. Thinking on its own: Al in the NHS. Reform; 2018.

22. Darzi A, Kibasi T, Quilter-Pinner H. Better health and care for all: A 10-point plan for the 2020s. Institute for Public Policy Research; 2018 (www.ippr.org/files/2018-06/better-health-and-care-for-all-june2018.pdf).

23. Department of Health. Operational productivity and performance in English NHS acute hospitals: Unwarranted variations. An independent report for the Department of Health by Lord Carter of Coles. Department of Health; 2016 (https://assets.publishing.service.gov.uk/government/uploads/system/uploads/attachment_data/ file/499229/Operational_productivity_A.pdf).

24. Frey C, Osbourne M. The Future of Employment: How susceptible are jobs to computerisation? University of Oxford; 2013 (www.oxfordmartin.ox.ac.uk/downloads/academic/The_Future_of_Employment.pdf).

25. Arntz M, Gregory T, Zierahn U. The Risk of Automation for Jobs in OECD Countries: A Comparative Analysis, OECD Social, Employment and Migration Working Papers, No. 189. OECD Publishing; 2016 (https://dx.doi. org/10.1787/5jlz9h56dvq7-en).

26. Servoz M. Al: The future of work? Work of the future! European Commission; 2019 (https://ec.europa.eu/digitalsingle-market/en/news/future-work-work-future).

27. Hawksworth J, Berriman R, Goel S. Will robots really steal our jobs? An international analysis of the potential long-term impact of automation. PwC; 2018 (www.pwc.co.uk/economic-services/assets/international-impact-ofautomation-feb-2018.pdf) 
28. Department for Business, Energy \& Industrial Strategy. Good Work: The Taylor Review of Modern Working Practices. Department for Business, Energy \& Industrial Strategy; 2017 (https://assets.publishing.service.gov.uk/government/ uploads/system/uploads/attachment_data/file/627671/good-work-taylor-review-modern-working-practices-rg.pdf).

29. Department of Health. Making IT work: harnessing the power of health information technology to improve care in England. Department of Health; 2016 (www.gov.uk/government/publications/using-information-technology-toimprove-the-nhs/making-it-work-harnessing-the-power-of-health-information-technology-to-improve-care-in-england).

30. Department of Health and Social Care. The future of healthcare: our vision for digital, data and technology in health and care. Department of Health and Social Care; 2018 (www.gov.uk/government/publications/the-futureof-healthcare-our-vision-for-digital-data-and-technology-in-health-and-care).

31. NHS England and Local Government Association. Local Health and Care Record Exemplars. NHS England and LGA 2018 (www.england.nhs.uk/wp-content/uploads/2018/05/local-health-and-care-record-exemplars-summary.pdf).

32. NHS England. NHS Long Term Plan. NHS England; 2019 (www.longtermplan.nhs.uk/wp-content/ uploads/2019/08/nhs-long-term-plan-version-1.2.pdf).

33. NHSX. Driving forward the digital transformation of health and social care. [webpage]. NHSX (www.nhsX.nhs.uk/).

34. NHS and Health Education England. The Topol Review: Preparing the healthcare workforce to deliver the digital future. An independent report on behalf of the Secretary of State for Health and Social Care. NHS and Health Education England; 2019 (https://topol.hee.nhs.uk/).

35. Health Education England. Digital Readiness Programme [webpage]. Health Education England (www.hee.nhs uk/our-work/digital-readiness).

36. Scottish Government, Convention of Scottish Local Authorities and NHS Scotland. Scotland's Digital Health and Care Strategy. Scottish Government, Convention of Scottish Local Authorities and NHS Scotland; 2018 (www. gov.scot/publications/scotlands-digital-health-care-strategy-enabling-connecting-empowering/).

37. Welsh Government. A Healthier Wales: Our Plan for Health and Social Care. Welsh Government; 2019 (https:// gov.wales/sites/default/files/publications/2019-10/a-healthier-wales-action-plan.pdf).

38. NHS Wales. New NHS Wales organisation for digital, data and technology [webpage]. NHS Wales (https://dhcw. nhs.wales/news/latest-news/new-nhs-wales-organisation-for-digital-data-and-technology/).

39. Gould, M. NHSX: giving patients and staff the technology they need [webpage]. UK Government; 2019 (https:// healthtech.blog.gov.uk/2019/06/24/nhsx-giving-patients-and-staff-the-technology-they-need/).

40. Department for Business, Energy \& Industrial Strategy. The Grand Challenge missions [webpage]. Department for Business, Energy \& Industrial Strategy; 2019 (www.gov.uk/government/publications/industrial-strategy-thegrand-challenges/missions\#early-diagnosis).

41. NHS England. NHS aims to be a world leader in artificial intelligence and machine learning within 5 years [webpage]. NHS England; 2019 (www.england.nhs.uk/2019/06/nhs-aims-to-be-a-world-leader-in-ai-andmachine-learning-within-5-years/).

42. NHSX. The NHS AI Lab (www.nhsx.nhs.uk/ai-lab).

43. NHS England. Artificial Intelligence in Health and Care Award [webpage]. NHS England; 2020 (www.england. nhs.uk/aac/what-we-do/how-can-the-aac-help-me/ai-award/).

44. NHSX. The Al Ethics Initiative [webpage]. NHSX (www.nhsx.nhs.uk/ai-lab/ai-lab-programmes/ethics/).

45. NHS England. NHS Accelerated Access Collaborative [webpage]. NHS England (www.england.nhs.uk/aac/)

46. Department of Health and Social Care. Code of conduct for data-driven health and care technology. Department of Health and Social Care; 2019 (www.gov.uk/government/publications/code-of-conduct-for-data-driven-healthand-care-technology/initial-code-of-conduct-for-data-driven-health-and-care-technology).

47. Public Health England. PHE Strategy 2020-25. PHE; 2019 (www.gov.uk/government/publications/phe-strategy2020-to-2025).

48. The Industrial Centre for Artificial Intelligence Research in Digital Diagnostics. What is iCAIRD? [webpage]. The Industrial Centre for Artificial Intelligence Research in Digital Diagnostics; 2020 (https://icaird.com/about/).

49. Digital Health.Wales. Projects [webpage]. Welsh Government (https://digitalhealth.wales/projects).

50. House of Lords Liaison Committee. Al in the UK: No Room for Complacency. Seventh Report of Session 201921. House of Lords; 2020 (https://publications.parliament.uk/pa/ld5801/ldselect/ldliaison/196/196.pdf).

51. House of Lords Select Committee on Al. Al in the UK: ready, willing and able? Report of Session 2017-19. House of Lords; 2018 (https://publications.parliament.uk/pa/ld201719/ldselect/ldai/100/100.pdf).

52. UK AI Council. Al Roadmap. UK AI Council; January 2021 (https://assets.publishing.service.gov.uk/government/ uploads/system/uploads/attachment_data/file/949539/Al_Council_Al_Roadmap.pdf).

53. PwC. What doctor? Why Al and robotics will define New Health. Survey results. PwC; 2016 (www.pwc.com/gx/ en/industries/healthcare/publications/ai-robotics-new-health/survey-results.html).

54. Future Advocacy. Artificial Intelligence: YouGov Poll 2017. Future Advocacy; 2017.

55. Ipsos Mori Social Research Institute. Public views of Machine Learning: Findings from public research and engagement conducted on behalf of the Royal Society. Ipsos Mori; 2017 (https://royalsociety.org/-/media/policy/ projects/machine-learning/publications/public-views-of-machine-learning-ipsos-mori.pdf).

56. Collado-Mesa F, Alvarez E, Arheart K. The role of artificial intelligence in diagnostic radiology: a survey at a single radiology residency training program. J Am Coll Radiol. 2018; 15:12, 1753-1757. doi: 10.1016/j.jacr.2017.12.021.

57. Royal College of Radiologists. RCR position statement on artificial intelligence [webpage]. Royal College of Radiologists; 2018 (www.rcr.ac.uk/posts/rcr-position-statement-artificial-intelligence). 
58. Feary SR. Artificial Intelligence in healthcare - what does the NHS workforce think? Politics Home; 2018 (www. politicshome.com/thehouse/article/artificial-intelligence-in-healthcare--what-does-the-nhs-workforce-think).

59. Blease C, Bernstein MH, Gaab J, Kaptchuk TJ, Kossowsky J, Mandl KD, Davis RB, DesRoches CM. Computerization and the future of primary care: A survey of general practitioners in the UK. PLoS One. 2018; 13(12): e0207418 (https://doi.org/10.1371/journal.pone.0207418).

60. Royal College of General Practitioners. All Systems GP. Royal College of General Practitioners; 2019 (www.rcgp. org.uk/-/media/Files/News/2019/RCGP-tech-manifesto-april-2019.ashx?la=en).

61. Autor D, Levy F, Murnane RJ. The Skill Content of Recent Technological Change: An Empirical Exploration. The Quarterly Journal of Economics. 2003; 118(4): 1279-1333.

62. Davies A. Uber's Self-Driving Truck Makes Its First Delivery: 50,000 Beers. Wired; 25 October 2016 (www.wired. com/2016/10/ubers-self-driving-truck-makes-first-delivery-50000-beers/).

63. Frey C, Osborne M. The future of employment: How susceptible are jobs to computerisation? Technological Forecasting \& Social Change. 2017; 114: 254-280.

64. Deloitte. Robotic Process Automation [webpage]. Deloitte (www2.deloitte.com/uk/en/pages/innovation/ solutions/robotic-process-automation.html).

65. Yorkshire \& Humber AHSN. Exploring Robotic Process Automation in the NHS [webpage]. Yorkshire \& Humber AHSN; 2021 (www.yhahsn.org.uk/blog/exploring-robotic-process-automation-in-the-nhs/).

66. Parasuraman R, Sheridan TB, Wickens CD. A model for types and levels of human interaction with automation IEEE Transactions on Systems, Man, and Cybernetics - Part A: Systems and Humans. 2000; 30(3); 286-297. doi: $10.1109 / 3468.844354$.

67. Thoughtonomy. East Suffolk and North Essex NHS Foundation Trust Case Study: Public Sector Healthcare. Thoughtonomy; 2018 (https://cdn2.hubspot.net/hubfs/4090201/2018-10\%20October\%20CONTENT/ ESNEFT-\%20Case\%20Study.pdf).

68. Tozzi, J. Amazon Gives Al to Harvard Hospital in Tech's Latest Health Push. Bloomberg; 4 March 2019 (www. bloomberg.com/news/articles/2019-03-04/amazon-gives-ai-to-harvard-hospital-in-tech-s-latest-health-push).

69. The Health Foundation. Listen, Learn and Improve: Language analysis of patient feedback [webpage]. The Health Foundation (www.health.org.uk/improvement-projects/listen-learn-and-improve-language-analysis-ofpatient-feedback).

70. Pifer R. Al clinical documentation player Nuance preps for nationwide expansion. Healthcare Dive. 25 February 2020 (www.healthcaredive.com/news/ai-clinical-documentation-player-nuance-preps-for-nationwideexpansion/572847/).

71. Topol, EJ. High-performance medicine: the convergence of human and artificial intelligence. Nature Medicine. 2019. 25(1): 44-56.

72. Nagendran M, Chen Y, Lovejoy CA, Gordon AC, Komorowski M, Harvey H, Topol EJ, loannidis JPA, Collins GS, Maruthappu M. Artificial intelligence versus clinicians: systematic review of design, reporting standards, and claims of deep learning studies. BMJ. 2020; 368: m689.

73. Liu X, Faes L, Kale AU, Wagner SK, Fu DJ, Bruynseels A, Mahendiran T, Moraes G, Shamdas M, Kern C, Ledsam JR, Schmid MK, Balaskas K, Topol EJ, Bachmann LM, Keane PA, Denniston AK. A comparison of deep learning performance against health-care professionals in detecting diseases from medical imaging: a systematic review and meta-analysis. Lancet Digital Health. 2019; 1(6):271-297. doi: 10.1016/S2589-7500(19)30123-2.

74. Jiang F, Jiang Y, Zhi H, Dong Y, Li H, Ma S, Wang Y, Dong Q, Shen H, Wang Y. Artificial intelligence in healthcare: past, present and future. Stroke and Vascular Neurology. 2017; 2: 230-243. doi: 10.1136/svn-2017-000101.

75. McKinney SM, Sieniek M, Godbole V, Godwin J, Antropova N, Ashrafian H, Back T, Chesus M, Corrado GS, Darzi A, Etemadi M, Garcia-Vicente F, Gilbert FJ, Halling-Brown M, Hassabis D, Jansen S, Karthikesalingam A, Kelly CJ, King D, Ledsam JR, Melnick D, Mostofi H, Peng L, Reicher JJ, Romera-Paredes B, Sidebottom R, Suleyman M, Tse D, Young KC, De Fauw J, Shetty S. International evaluation of an Al system for breast cancer screening. Nature. 2020; 577: 89-94. doi: 10.1038/s41586-019-1799-6.

76. Schwalbe N, Wahl B. Artificial intelligence and the future of global health. The Lancet. 2020; 395: 1579-1586.

77. The Health Foundation. Developing and implementing machine learning driven analytics for quality improvement in health care [webpage]. The Health Foundation (www.health.org.uk/research-projects/ developing-and-implementing-machine-learning-driven-analytics-for-quality).

78. Babylon Health. Ask Babylon [webpage]. Babylon Health (www.babylonhealth.com/product/ask-babylon).

79. Babylon Health. When not to use the Babylon chatbot [webpage]. Babylon Health (https://support. babylonhealth.com/hc/en-us/articles/213450625-When-not-to-use-the-Babylon-chatbot).

80. Tallon L. 2019/20 Annual Plan Progress Update. University Hospitals Birmingham NHS Foundation Trust; 25 July 2019 (www.uhb.nhs.uk/Downloads/pdf/Bod0719AnnualPlanProgressUpdate.pdf).

81. Radley DC, Wasserman MR, Olsho LE, Shoemaker SJ, Spranca MD, Bradshaw B. Reduction in medication errors in hospitals due to adoption of computerized provider order entry systems. J Am Med Inform Assoc. May 2013; 20(3): 470-476.

82. Nuckols TK, Smith-Spangler C, Morton SC, Asch SM, Patel VM, Anderson LJ, Deichsel EL, Shekelle PG. The effectiveness of computerized order entry at reducing preventable adverse drug events and medication errors in hospital settings: a systematic review and meta-analysis. Systematic Reviews. 2014; 3:56. doi: 10.1186/20464053-3-56.

83. Schiff G, Mirica MM, Dhavle AA, Galanter WL, Lambert B, Wright A. A prescription for enhancing electronic prescribing safety. Health Affairs. 2018; 37(11): 1877-1883. doi: 10.1377/hlthaff.2018.0725. 
84. Messer LH, Berget C, Forlenza GP. A Clinical Guide to Advanced Diabetes Devices and Closed-Loop Systems Using the CARES Paradigm. Diabetes Technology \& Therapeutics. May 2019; 21(8).

85. Pickett, M. Robots Are Now Handling Pills. Will Pharmacists Be Liberated or Out of Work? KQED Science; 28 April 2016 (www.kqed.org/futureofyou/153628/when-a-robot-counts-out-your-pills-what-will-your-pharmacist-do).

86. How Moxi, helper robot from Diligent Robotics, has joined Covid-19 fight. Austin Business Journal. 21 December 2020. (www.bizjournals.com/austin/news/2020/12/21/how-moxi-helper-robot-from-diligent-robotics.html).

87. Moyle W, Jones CJ, Murfield JE, Thalib L, Beattie ERA, Shum DKH, O'Dwyer ST, Mervin MC, Draper BM. Use of a Robotic Seal as a Therapeutic Tool to Improve Dementia Symptoms: A Cluster-Randomized Controlled Trial. J Am Med Dir Assoc. 2017; 18(9):766-773. doi: 10.1016/j.jamda.2017.03.018.

88. Joshi I, Morley J (eds). Artificial Intelligence: How to get it right. Putting policy into practice for safe data-driven innovation in health and care. NHSX; 2019.

89. Chen JH, Asch SM. Machine Learning and Prediction in Medicine - Beyond the Peak of Inflated Expectations. New England Journal of Medicine. 2017; 376: 2507-2509. doi: 10.1056/NEJMp1702071.

90. Char D, Shah N, Magnus D. Implementing Machine Learning in Health Care - Addressing Ethical Challenges. New England Journal of Medicine. 2018; 378(11): 981-983.

91. Grimm F. Predicting missed hospital appointments using machine learning - what are the risks? Towards Data Science. 2 August 2019 (https://towardsdatascience.com/predicting-missed-hospital-appointments-usingmachine-learning-what-are-the-risks-a388348109d).

92. Campolo A, Sanfilippo M, Whittaker M, Crawford K. A/ Now 2017 Report. Al Now Research Institute, New York University; 2017.

93. Challen R, Denny J, Pitt M, Gompels L, Edwards T, Tsaneva-Ttanasova K. Artificial intelligence, bias and clinical safety. BMJ Quality \& Safety. 2019; 28: 231-237.

94. Yeung, K. Why worry about decision making by machine? In: Yeung K, Lodge M (eds.) Algorithmic Regulation. Oxford University Press; 2019.

95. Goleman, D. Emotional Intelligence: Why It Can Matter More Than IQ. Bloomsbury Publishing; 1996.

96. Salovey P, Brackett MA, Mayer JD. Emotional intelligence: key readings on the Mayer and Salovey model. National Professional Resources; 2004

97. Serrat O. Understanding and Developing Emotional Intelligence. In: Serrat O (ed.) Knowledge Solutions. Springer; 2017.

98. Stanton E, Noble D. Emotional intelligence. BMJ. 2010; 341: 3781.

99. Goleman D. What makes a leader? Harvard Business Review. January 2004 (https://hbr.org/2004/01/whatmakes-a-leader).

100. The Health Foundation. Person-centred care made simple. The Health Foundation; 2014 (www.health.org.uk/ publications/person-centred-care-made-simple).

101. Balik B, Conway J, Zipperer L, Watson J. Achieving an Exceptional Patient and Family Experience of Inpatient Hospital Care. IHI Innovation Series white paper. Institute for Healthcare Improvement; 2011.

102. Drake R. Five dilemmas associated with e-rostering. Nursing Times. 2014; 110(20): 14-16.

103. Smith A, Anderson M. Americans' attitudes toward robot caregivers. In: Smith A, Anderson M. Automation in Everyday Life. Pew Research Center; 2017 (www.pewresearch.org/internet/2017/10/04/americans-attitudestoward-robot-caregivers/).

104. Liu X, Keane PA, Denniston AK. Time to regenerate: the doctor in the age of artificial intelligence. Journal of the Royal Society of Medicine. 2018; 111(4): 113-116.

105. Batalden P. Getting more health from healthcare: quality improvement must acknowledge patient coproduction. BMJ. 2018; 362: 3617.

106. Frey BS, Benz M, Stutzer A. Introducing Procedural Utility: Not Only What, But Also How Matters. Journal of Institutional and Theoretical Economics. 2004; 160(3): 377-401.

107. Lind E, Tyler T. The Social Psychology of Procedural Justice. Springer; 1988.

108. Mindell D. Our Robots, Ourse/ves: Robotics and the Myths of Autonomy. Viking Press; 2015.

109. European Group on Ethics in Science and New Technologies. Statement on Artificial Intelligence, Robotics and 'Autonomous' Systems. European Commission; 2018 (https://ec.europa.eu/research/ege/pdf/ege_ai_ statement_2018.pdf) .

110. Klann JG, Szolovits P. An intelligent listening framework for capturing encounter notes from a doctor-patient dialog. BMC Medical Informatics and Decision Making. November 2009; 9(1): S3.

111. Lin SY, Shanafelt TD, Asch SM. Reimagining clinical documentation with artificial intelligence. Mayo Clin. Proc. 2018; 93: 563-565.

112. Verghese A, Shah $\mathrm{NH}$, Harrington RA. What this computer needs is a physician: humanism and artificial intelligence. JAMA. 2018; 319:19.

113. Bansler JP, Havn EC, Schmidt K, Mønsted T, Petersen HH, Svendsen JH. Cooperative epistemic work in medical practice: an analysis of physicians' clinical notes. Computer Supported Cooperative Work. 2016; 25: 503-546. doi: 10.1007/s10606-016-9261-x.

114. Willis $\mathrm{M}$, Jarrahi $\mathrm{MH}$. Automating documentation: a critical perspective into the role of artificial intelligence in clinical documentation. In: Taylor NG, Christian-Lamb C, Martin MH, Nardi B (eds). Information in Contemporary Society: 14th International Conference. Springer; 2019. 
115. Ash J, Berg M, Coiera E. Some unintended consequences of information technology in health care: the nature of patient care information system-related errors. J Am Med Inform Assoc. 2004; 11(2): 104-112.

116. Allen, D. The invisible work of nurses: hospitals, organisation and healthcare. Routledge; 2015.

117. Royal College of Nursing. The role of the health care assistant [webpage]. Royal College of Nursing (https://rcni. com/hosted-content/rcn/first-steps/role-of-health-care-assistant).

118. Fernández-Macías E, Gómez E, Hernández-Orallo J, Loe BS, Martens B, Martínez-Plumed F, Tolan S. A multidisciplinary task-based perspective for evaluating the impact of $\mathrm{Al}$ autonomy and generality on the future of work. arXiv. 2018 (https://arxiv.org/abs/1807.02416).

119. Swinglehurst D, Greenhalgh T. Caring for the patient, caring for the record: An ethnographic study of 'back office' work in upholding quality of care in general practice. BMC Health Services Research. 2015; 15: 177.

120. Kohn LT, Corrigan JM, Donaldson MS (eds). To Err is Human: Building a Safer Health System. Institute of Medicine (US) Committee on Quality of Health Care in America. National Academies Press; 2000.

121. Chisholm CD, Dornfeld AM, Nelson DR, Cordell WH. Work interrupted: A comparison of workplace interruptions in emergency departments and primary care offices. Annals of Emergency Medicine. 2001; 38(2): 146-151.

122. Rivera-Rodriguez AJ, Karsh B. Interruptions and distractions in healthcare: review and reappraisal. BMJ Quality \& Safety. 2010; 19: 304-312.

123. Sasangohar F, Donmez B, Trbovich P, Easty AC. Not all interruptions are created equal: positive interruptions in healthcare. Proceedings of the Human Factors and Ergonomics Society Annual Meeting. 2012; 56(1): 824-828.

124. Ebright P, Patterson E, Chalko B, Render M. Understanding the complexity of registered nurse work in acute care settings. J Nurs Adm. 2003; 33(12): 630-638.

125. Autor D. Why are there still so many jobs? The history and future of workplace automation and anxiety. MIT IDE Research Brief. MIT Initiative on the Digital Economy. 2016; 07 (http://ide.mit.edu/sites/default/files/publications/ IDE_Research_Brief_v07.pdf).

126. Wiener E, Curry R. Flight-deck automation: promises and problems. Ergonomics. 1980; 23: 995-1011.

127. Endsley MR, Kiris EO. The out-of-the-loop performance problem and level of control in automation. Human Factors. 1995; 37(2): 381-394.

128. Coiera E, Ash J, Berg M. The Unintended Consequences of Health Information Technology Revisited. Yearb Med Inform. 2016; 1: 163-169.

129. Coiera E. Guide to Health Informatics, third edition. CRC Press; 2015.

130. Dixon-Woods M, Martin G, Tarrant C, Bion J, Goeschel C, Pronovost P, Brewster L, Shaw L, Sutton L, Willars J, Ketley D, Woodcock T. Safer Clinical Systems: evaluation findings. The Health Foundation; 2014 (www.health. org.uk/publications/safer-clinical-systems-evaluation-findings).

131. Shorrock S. The Varieties of Human Work [webpage]. Humanistic Systems. 2016 (https://humanisticsystems. com/2016/12/05/the-varieties-of-human-work/).

132. Perry S, Wears R, Cook R. The role of automation in complex system failures. Journal of Patient Safety. 2005; 1(1): 56-61.

133. Sittig DF, Singh H. A new sociotechnical model for studying health information technology in complex adaptive healthcare systems. BMJ Quality \& Safety. 2010; 19: 68-74.

134. Novak LL, Holden RJ, Anders SH, Hong JY, Karsh BT. Using a sociotechnical framework to understand adaptations in health IT implementation. Int J Med Inform. 2013; 82(12): 331-44.

135. Heifetz R, Laurie D. The Work of Leadership. Harvard Business Review. December 2001 (https://hbr.org/2001/12/ the-work-of-leadership).

136. Shaw S, Wherton J, Vijayaraghavan S, Morris J, Bhattacharya S, Hanson P, Campbell-Richards D, Ramoutar S, Collard A, Hodkinson I, Greenhalgh T. Advantages and limitations of virtual online consultations in a NHS acute trust: the VOCAL mixed-methods study. NIHR Journals Library; 2018. doi: 10.3310/hsdr06210.

137. Braithwaite J, Wears R, Hollnagel E. Resilient health care: turning patient safety on its head. International Journal for Quality in Health Care. 2015; 27(5): 418-420.

138. Hollnagel E, Wears R, Braithwaite J. From Safety-I to Safety-II: A White Paper. University of Southern Denmark, University of Florida, USA, and Macquarie University, Australia; 2015.

139. The Health Foundation. A learning health system approach to avoiding acute occupancy crises [webpage]. The Health Foundation (www.health.org.uk/improvement-projects/a-learning-health-system-approach-to-avoidingacute-occupancy-crises).

140. Fogel AL, Kvedar JC. Artificial intelligence powers digital medicine. npj Digital Medicine. 2018; 1:5.

141. NHS and Health Education England. Digital literacy: Towards a definition. NHS and Health Education England; 2016.

142. Lloyds Bank. UK Consumer Digital Index 2020. Lloyds Bank; 2020 (www.lloydsbank.com/assets/media/pdfs/ banking_with_us/whats-happening/lb-consumer-digital-index-2020-report.pdf).

143. Davies R. The Topol Review - Preparing the healthcare workforce to deliver the digital future [webpage]. Good Things Foundation; 2019 (www.goodthingsfoundation.org/news-and-blogs/blog/topol-review-preparinghealthcare-workforce-deliver-digital-future).

144. The Health Foundation. Data-driven systems and health inequalities: COVID-19 and beyond [webpage]. The Health Foundation (www.health.org.uk/funding-and-partnerships/our-partnerships/data-driven-systems-andhealth-inequalities). 
145. Bosley S, Dale J. Healthcare assistants in general practice: practical and conceptual issues of skill-mix change. British Journal of General Practice. 2008; 58(547): 118-24.

146. The Health Foundation. Personalised medicine analytics dashboard for triaging patients in emergency departments [webpage]. The Health Foundation (www.health.org.uk/improvement-projects/personalisedmedicine-analytics-dashboard-for-triaging-patients-in-emergency-departments).

147. Presentation at X-Gov Data Science Forum, 1 May 2020.

148. Spilsbury K, Adamson J, Atkin K, Bartlett C, Bloor K, Borglin G, Carr-Hill R, McCaughan D, McKenna H, Stuttard L, Wakefield A. Evaluation of the Development and Impact of Assistant Practitioners Supporting the Work of Wardbased Registered Nurses in Acute NHS (Hospital) Trusts in England. National Institute for Health Research; 2011. Imison C, Castle-Clarke S, Watson R. Reshaping the workforce to deliver the care patients need. Nuffield Trust; 2016.

150. Ross J, Kettles A. Mental health nurse independent prescribing: what are nurse prescribers' views of the barriers to implementation? J Psychiatr Ment Health Nurs. 2012; 19(10): 916-932.

151. Cabitza F, Rasoini R, Gensini GF. Unintended consequences of machine learning in medicine. JAMA. 2017; 318(6): 517-518.

152. Hoff T. Deskilling and adaptation among primary care physicians using two work innovations. Health Care Management Review. 2011; 36(4): 338-348. doi: 10.1097/HMR.0b013e31821826a1.

153. Buston, O. On the Edge [webpage]. Future Advocacy; 2018 (http://futureadvocacy.com/on-the-edge/).

154. Wears R, Cook R and Perry S. Automation, interaction, complexity, and failure: A case study. Reliability Engineering \& System Safety. 2006; 91: 1494-1501.

155. Coiera E. How to ensure safety for medical artificial intelligence. A/ Med; 1 August 2018 (https://ai-med.io/aimed-news/safety-medical-artificial-intelligence/).

156. Tsai TL, Fridsma DB, Gatti G. Computer decision support as a source of interpretation error. J Am Med Inform Assoc. 2003; 10(5): 478-83.

157. Parasuraman, R. Manzey, DH. Complacency and Bias in Human Use of Automation: An Attentional Integration. Human Factors. 2010; 52(3): 381-410. doi: 10.1177/0018720810376055.

158. Greenhalgh T, Wherton J, Papoutsi C, Lynch J, Hughes G, A'Court C, Hinder S, Fahy N, Procter R, Shaw S. Beyond adoption: a new framework for theorizing and evaluating nonadoption, abandonment, and challenges to the scale-up, spread, and sustainability of health and care technologies. J Med Internet Res. 2017; 19(11): 367.

159. The Health Foundation, The King's Fund and the Nuffield Trust. The health care workforce in England: Make or break? The Health Foundation, The King's Fund and the Nuffield Trust; 2018 (www.health.org.uk/publications/ the-health-care-workforce-in-england).

160. Steventon A, Deeny S, Keith J, Wolters A. Artificial intelligence in the NHS: getting the priorities right. The Health Foundation; 2019 (www.health.org.uk/news-and-comment/blogs/artificial-intelligence-in-the-nhs-getting-thepriorities-right).

161. Autor, D. Will Automation Take All of Our Jobs? TEDxCambridge; September 2016 (www.ted.com/talks/david_ autor_will_automation_take_away_all_our_jobs).

162. Hammond J, Gravenhorst K, Funnell E, Beatty S, Hibbert D, Lamb J, Burroughs H, Kovandži M, Gabbay M, Dowrick C, Gask L, Waheed W, Chew-Graham CA. Slaying the dragon myth: an ethnographic study of receptionists in UK general practice. British Journal of General Practice. 2013; 63(608): 177-184.

163. Scottish Government. The Scottish Approach to Service Design: How to design services for and with users. Scottish Government; 2019 (www.gov.scot/publications/the-scottish-approach-to-service-design/).

164. Wears, R. Health Information Technology and Victory. Annals of Emergency Medicine. 2014; 65(2).

165. Landman AB, Redden L, Neri P, Poole S, Horsky J, Raja AS, Pozner CN, Schiff G, Poon EG. Using a medical simulation center as an electronic health record usability laboratory. J Am Med Inform Assoc. 2014; 21: 558-563.

166. Department of Health and Social Care. Guide to good practice for digital and data-driven health technologies. Department of Health and Social Care; January 2021 (www.gov.uk/government/publications/code-of-conductfor-data-driven-health-and-care-technology/initial-code-of-conduct-for-data-driven-health-and-care-technology).

167. National Institute for Care Excellence. Evidence Standards Framework for Digital Health Technologies. National Institute for Care Excellence; March 2019 (www.nice.org.uk/Media/Default/About/what-we-do/our-programmes/ evidence-standards-framework/digital-evidence-standards-framework.pdf).

168. The Health Foundation. Quality improvement made simple. The Health Foundation; 2013 (www.health.org.uk/ publications/quality-improvement-made-simple).

169. The Health Foundation. Using communications approaches to spread improvement. The Health Foundation; 2013 (www.health.org.uk/publications/using-communications-approaches-to-spread-improvement).

170. Bardsley M, Steventon A, Fothergill G. Untapped potential: Investing in health and care data analytics. The Health Foundation; 2019 (www.health.org.uk/publications/reports/untapped-potential-investing-in-health-and-caredata-analytics).

171. SPIRIT-AI \& CONSORT-Al: Improving The Quality Of Evidence For Al Health Interventions. [webpage]. 2020. (https://www.clinical-trials.ai/).

172. Susskind D, Susskind R. The Future of the Professions: How Technology Will Transform the Work of Human Experts. Oxford University Press; 2015.

173. Clarke G, Keith J, Steventon A. GP at Hand model will not work for everyone. HSJ; 5 June 2019 (www.hsj.co.uk/ technology-and-innovation/gp-at-hand-model-will-not-work-for-everyone/7025226.article). 
The Health Foundation is an independent charity committed to bringing about better health and health care for people in the UK.

Our aim is a healthier population, supported by high quality health care that can be equitably accessed. We learn what works to make people's lives healthier and improve the health care system. From giving grants to those working at the front line to carrying out research and policy analysis, we shine a light on how to make successful change happen.

We make links between the knowledge we gain from working with those delivering health and health care and our research and analysis. Our aspiration is to create a virtuous circle, using what we know works on the ground to inform effective policymaking and vice versa.

We believe good health and health care are key to a flourishing society. Through sharing what we learn, collaborating with others and building people's skills and knowledge, we aim to make a difference and contribute to a healthier population.

The Health Foundation

8 Salisbury Square, London EC4Y 8AP

$\mathrm{T}+44$ (o) 2072578000

E info@health.org.uk

@ @ HealthFdn

www.health.org.uk 